Discussion Paper No. 1000

\title{
RAILROADS, TECHNOLOGY ADOPTION, AND MODERN ECONOMIC DEVELOPMENT: EVIDENCE FROM JAPAN
}

\author{
Junichi Yamasaki \\ The 19th ISER-Moriguchi Prize (2016) \\ Awarded Paper
}

April 2017

The Institute of Social and Economic Research Osaka University

6-1 Mihogaoka, Ibaraki, Osaka 567-0047, Japan 


\title{
Railroads, Technology Adoption, and Modern Economic Development: Evidence from Japan
}

\author{
Junichi Yamasaki* \\ Department of Economics, London School of Economics and Political Science
}

April 27, 2017

\begin{abstract}
Railroad access can accelerate the technological progress in the industrial sector and therefore induce structural change and urbanization, the two common features of modern economic growth. I examine this particular mechanism in the context of Japanese railroad network expansion and modern economic growth in the late 19th century and early 20th centuries. By digitizing a novel data set that measures the use of steam engines at the factory level, allowing me to directly observe the diffusion of steam power, I analyze the effect of railroad access on the adoption of steam power. To overcome the endogeneity problem, I determine the cost-minimizing path between destinations, and use this to construct an instrument for railroad access. I find that railroad access led to an increased adoption of steam power by factories, which in turn reallocated labor from the agricultural to the industrial sector, thereby inducing structural change. Railroad network also broke mean reversion in population growth, eventually leading to urbanization. My results support the view that railroad network construction was key to the modern economic growth in pre-First World War Japan.
\end{abstract}

Keywords: Railroads, Transportation Infrastructure, Technology Adoption, General Purpose Technology, Structural Change, Urbanization JEL Codes: N65, N75, O14, O18, O33

\footnotetext{
*j.yamasaki@lse.ac.uk. I am grateful to my supervisors, Robin Burgess and Greg Fischer for their constant support. I also thank Gianmarco Ottaviano, Vernon Henderson, David Atkin, Jeremiah Dittmar, Janet Hunter, Tetsuya Okazaki, Takashi Kurosaki, Yukinobu Kitamura, Kazuki Yokoyama, Hiu (Eddy) Tam, Yatang Li, Hanwei Huang, Thomas Carr and also seminar and conference participants at LSE, Kyoto, Kindai, Osaka, Tsukuba, EUDN, and NEUDC for comments and suggestions. I also thank Takubo Junpei, Tomohito Honda, Shouta Tojima, and Yoshimasa Katayama for their research assistance. This research was supported by the Joint Research Center, Institute of Economic Research, Hitotsubashi University. Also, I greatly appreciate Yutaka Arimoto, Kaori Ito, Asuka Imaizumi, Tetsuji Okazaki, Kentaro Nakajima, and Tomohiro Machikita, who digitized a part of data I am using in this paper with support from the JSPS KAKENHI Grant-in-Aid for Scientific Research (B) 21330064, for providing me permission to use the data. This paper is the 19th ISER-Moriguchi Prize awarded paper. All errors are my own.
} 


\section{Introduction}

Transportation infrastructure is considered one of the most important public goods in developing countries. In 2015, the World Bank was financing 197 transportation projects, accounting for 21 percent of its total lending. The bank's annual report for 2015 shows that the transportation sector was consistently one of the three largest recipients of lending from 2011 to 2015. In the United States (U.S.) and Western Europe, railroad network construction was associated with an increase in economic growth. Rostow (11960) argues that through increased market integration and higher demand for industrial goods, the railroad was key to the take-off from pre-industrialized economies.

This paper investigates the effect of railroads on technology adoption in the industrial sector, ${ }^{[]}$structural change, and urbanization. The result of Bustos (2011) suggests that railroad network construction should increase the adoption of new technology due to increased economies of scale. Alvarez-Cuadrado and Poschke (2011) presents evidence that the productivity growth in the manufacturing sector relative to the agricultural sector is responsible for structural change in the countries that transitioned between 1840 and 1920. However, the cause of this productivity growth, its effect on structural change, and even its consequences for the overall economy are not well understood. Apart from structural change, the other common feature of modern economic development is urbanization, which is only possible if population dynamics diverge from the pattern of mean reversion seen in agricultural economies. Desmet and Rossi-Hansberg (2009) and Michaels et al. (2012) show that the adoption of new technologies and structural change broke the mean reversion in the U.S.

I now consider the case of Japan in the late 19th and early 20th centuries. During this time, Japan expanded its railroad network, adopted many Western technologies, and experienced modern economic development. The Japanese Government, following its modernization and centralization through the Meiji Restoration in 1868, commenced constructing a railroad network in the 1870s. By 1900, this network reached around 60 percent of the counties, as shown in Figure 1. Figure 2 shows that during this time, the adoption of steam power proceeded at a faster pace than the growth in the use of fertilizers, which was

\footnotetext{
${ }^{1}$ http://wWW. Worldbank.org/en/topic/transport/overview

${ }^{2}$ This claim is tested by Fogel (1964). He uses sub-national price and trade flow data for the U.S., and concludes that the impact of railroads was not as large as expected. Donaldson (2017) tested whether the price of agricultural land increased around the construction of railroads, as the trade theory predicts. They conclude that structural market access, as derived from a model a la Eaton and Kortum (2012) , increased the land price, and that without railroad access the price would be 64 percent lower. If this effect could be mitigated by the feasible extension of waterways and road improvement, then the loss would be in the range of 13 to 20 percent.

${ }^{3}$ In this paper, I abstract from the service industry and use "industrial sector" and "non-agricultural sector" interchangeably.
} 
the primary new technology in the agricultural sector. Similarly, Figure 3 illustrates that the price of industrial goods decreased relative to that of agricultural goods. Figure 4 shows that during this time Japan also experienced structural change and Figure 5 urbanization. These changes resulted in the rapid growth of GDP. Figure 6 illustrates that in 1868, Japanese GDP was far lower than that of the U.S. or the United Kingdom (U.K.), but began to increase thereafter.

To facilitate my analysis, I digitize several novel data sets. I construct geographical data showing the railroad network expansion from the 1870s to 1910 s based on current network data and documents to identify the opening year of each section. To measure technology adoption, I digitize repeated cross-sectional factory data, which contain addresses, types of products manufactured, and information on the number of engines and total horsepower for each power source, steam and water. This allows me to construct a county-level panel data set with very concrete measures of technology adoption and productivity. In addition, I digitize county-level population and sector-wise worker data for my sample period to analyze population dynamics and structural change.

Railroad construction is an endogenous choice by the government, and this endogeneity could bias the Ordinary Least Squares (OLS) estimates. Moreover, the direction of the bias is unclear ex ante. The government may choose to favor areas where the economic benefits would be the greatest. Alternatively, the government may choose to build railroads in areas with low economic potential as a form of redistribution. I use an instrumental variable to overcome this endogeneity problem. I construct the cost-minimizing route between destinations, using slope information to determine the construction costs incurred by the government. This is a standard type of identification strategy in this literature as used in Atack et al. (2008b), Banerjee et al (2012), Hornung (2012), and Faber (2014). It exploits that the government's motivation to connect the destinations and make the network is exogenous to local economy. I then use the distance from the costminimizing path as my instrument for growth in railroad access, while conditioning on local geography and other variables in order to satisfy the assumption of quasi-random assignment. My Difference-in-Difference with IV estimates implies that having railroad access by 1892 led to an increase in steam power of about 300 horsepower at the county level between 1888 and 1902. This means that railroad access growth between 1888 and 1892 accounted for 67 percent of steam power growth between 1888 and 1902.

I also analyze the impact of gaining access to the railroad network earlier on structural change and

\footnotetext{
${ }^{4}$ In 1902, the average steam power in factories was about 32 horsepower. According to the instruction manual of the Toyoda power loom, which was invented in 1898 as the first Japanese power loom ever, the factories could handle 20 power looms by one horsepower (https://WwW.toyota.co.jp/jpn/company/history/75years/text/taking_on_the_automotive_ business/chapterl/sectionl/1tem6.htm1.
} 
urbanization. Using census data from 1920 and the agricultural worker data from 1885, I estimate the longterm impact of having railroad access by 1892 on the share of workers in the primary sector. Conditional on the share of population working in the agricultural sector in 1885, I find that early adopters have a 6.7 percent lower share of workers in the primary sector. To analyze the link between railroad access and population dynamics, I estimate the impact of railroad access on population growth, allowing for dependence on initial density. I find that without railroad access by 1892 , counties with log initial population one standard deviation above the average, have a 7.2 percent lower growth between 1885 and 1902 than that of counties at the mean. This pattern of mean reversion is broken by railroad access. If a county gained railroad access by 1892 , this 7.2 percent decline becomes a 1.9 percent decline. When I analyze population growth between 1885 and 1920, the estimates for early adopters even becomes positive. The estimated effect is 11.3 percent, compared to minus 16.9 percent for counties with no railroad access by 1892 . This is consistent with a positive feedback mechanism generating urbanization.

When combined, these results imply that railroad construction was key to both structural change and urbanization. My results provide further implications for the more general question on why the industry sector in Japan adopted Western technology so quickly and developed so rapidly after the Meiji Restoration. This paper suggests one explanation; a centralized government receptive to Western technology, which enabled these changes by rapidly constructing a railroad network.

This paper contributes to the literature on infrastructure, technology adoption, structural change, population dynamics and urbanization, as well as the economic history of Japan and the industrial revolution. In terms of the effects of railroads, ${ }^{\text {, }}$ recent studies such as Atack et al. (2008b), Atack et al. (2010), Burgess and Donaldson (2010), Herrendorf et al. (2012), Duranton and Turner (2012), Jedwab and Moradil (2013), and Fajgelbaum and Redding (2014), Donaldson and Hornbeck (2016), Donaldson (2017) investigate the effect of railroads on the number of factories, ${ }^{\text {, }}$ price equalization, famine, the price of agriculture land, specialization, structural change, and the urban population. ${ }^{\square}$ Authors such as Baum-Snow (2007), Duflo and Pande (2007), Jensen (2007), Michaels (2008), Goyal (2010), Dinkelman (2011), Rud (2012), Duranton et

PAtkin and Donaldson (2015) finds that in Ethiopia and Nigeria, trade costs are four to five times larger per unit of distance than those in developed countries.

${ }^{6}$ Factory production may include technology adoption as well, although the former is defined as an establishment with more than 15 workers, and therefore does not measure the change in management methods. In addition, even among factories, the steampowered ones had higher labor productivity than that of the non-steam-powered ones, as also shown by Atack et al. (2008a). Thus, it is worth considering this margin of steam power adoption.

${ }^{7} \mathrm{Kim}(20(15)$ and Herrendorf et al, (2012) use a rural/urban classification in their analysis of urbanization, without discussing Gibrat's Law. However, such a classification depends on the country or context, so a discussion based on population dynamics will be more general. 
al. (2014)f, Lipscomb et al. (2013), Kline and Moretti (2014), Faber (2014), and Agrawal et al. (2016) study other types of infrastructure, such as highways, dams, electricity, regional development plans and mobile phones. ${ }^{\mathbb{8}}$ On the other hand, my paper focuses on a particular mechanism why railroad construction can induce modern economic development by looking at the effect on technology adoption.

A research study on international economics also examines technology adoption, and since railroads reduce transportation costs, gaining access to a railroad network will be conceptually similar to the reduction of tariffs or trade liberalization. The paper most similar to mine is Bustos (20II), which studies the impact of MERCOSUR on the investment in technology by Argentinian firms. ${ }^{\mathbb{9}}$ Authors such as Pavcnik (20)2) and Fernandes (2007) study the relationship between trade and productivity growth at the plant level. These papers typically estimate plant-level productivity using structural methods such as Olley and Pakes (1996) or Levinsohn and Petrin (2003), whereas I directly observe each factory's use of steam engines.

Turning to the structural change literature in macroeconomics, as noted above, Alvarez-Cuadrado and Poschke (2011) shows empirically that the nature of structural change modified between 1920 and 1960. Before 1920, structural change was driven by increase in the relative productivity of non-agricultural industries, which led to a labor pull effect. Since 1960, structural change has been driven by productivity improvements in agriculture, which led to a labor push effect. This can be formulated as operating through an income effect, as in Gollin et al. (2002) and Kongsamut et al. (2001), or through a relative price effect as in Ngal and Pissarides (2007). On the other hand, recent empirical studies that use within-country exogenous variation find that growth in agricultural productivity is the cause of structural change. Foster and Rosenzweig (2008), Marden (2015), Bustos et al. (2016) and Kitamura (2016) find this to be the case for post-Second World War India, China, Brazil, and Japan, respectively. All these papers study eras and countries where Alvarez-Cuadrado and Poschke (2011) find that technological progress in agriculture is driving structural

${ }^{8}$ Faber (2014) uses an identification strategy similar to this paper in the context of highway construction in China. The Chinese Government aimed to connect all local capitals and cities with a single highway network. As an instrument, he uses geographical information to find the cost-minimizing path between each possible combination of cities, and then chooses routes to connect all cities at the lowest cost. In my case, the Japanese Government merely wanted to connect specific destinations. In particular, they aimed to connect Tokyo with the northern and western ends of Honshu, Aomori, and Niigata. I find no anecdotal evidence of their intention to directly connect every destination to every other destination.

${ }^{9}$ To be precise, her measure of investment in technology is R\&D spending, whereas mine is total horsepower, which is an outcome of investment in new technology.

${ }^{10}$ There also exist relevant literature regarding technology adoption in development economics. Munshil (20)(1) , Foster and Rosenzweig (2008), Bandiera and Rasul (2006), and Conley and Udry (2010) find evidence of network effects and learning. Suri (20II) shows evidence of heterogeneity in the effects of new technology. (Duflo et al, 20II) finds that behavioral biases exist. Gine and Yang (2009) and Dercon and Christiaensen (20II) show that the risk of return and its consequences for consumption due to credit market imperfections, are key barriers to technology adoption. This study is different because it focuses on macroeconomic barriers to technology adoption, rather than individual-level barriers, and it studies the industrial sector, rather than the agricultural sector. 
change, or are out of the sample of Alvarez-Cuadrado and Poschke (2011) entirely. This paper examines why the relative productivity of non-agricultural industries was rising before 1920, and whether this induced any structural change.

The fourth type of literature this paper is linked with are studies on population dynamics and urbanization. In these studies, Gibrat's Law, which asserts that population growth rates are constant irrespective of differences in initial population density, is one of the stylized facts ${ }^{\square}$. However, Glaeser et al. (2014) finds that it does not hold in the U.S. in some sample periods, and Dittmar (20II) finds the same result for Europe. Studies such as Giesen and Südekum (2014) and Desmet and Rappaport (2015) investigate which factors, such as city age, explain these differences in population growth rate. Desmet and Rossi-Hansberg (2009) and Michaels et al. (2012) argue that industry-specific technological progress is the key; sufficiently fast technological progress will break the pattern of mean reversion in population as better technology attracts migration. My paper tests this idea by investigating whether gaining access to a railroad network, and the subsequent adoption of new technology breaks mean reversion in population dynamics.

Finally, this paper is linked to the literature on the economic history surrounding steam power and the industrial revolution. The diffusion pattern of steam power, and its effect on factory-level productivity and urbanization in the U.S. are studied by Atack et al. (1980), Kim (2005), and Atack et al. (2008a). Other related papers consider the industrial revolution in Japan. The paper most similar to mine is Tang (2014), which analyzes the impact of railroad access on the number of firms and their capital stocks. This paper differs from Tang (2014) in that I use the various county-level outcomes, and employs instrumental variables. Tang (2014) uses prefecture-level data and Difference-in-Difference analysis. Minami (1977) and Minami (1979) describe the diffusion of new power sources using prefecture-level data, and estimate the impact on productivity through growth accounting. However, the link between the diffusion of steam power and railroad access is not studied. Kiyokawa (1995) provides an overview of technology adoption in pre-Second World War Japan, covering both agricultural and non-agricultural sectors.

The remainder of the paper proceeds as follows. Section $₫$ discusses why the construction of a railroad network could accelerate technology adoption, structural change, and urbanization. Section 3 provides an overview of the history of railroads and steam technology in Japan, describes the data sources used in the study, and explains the construction of the instrument. Sections 1 and 5 present my estimation results, and Section 6 concludes.

\footnotetext{
${ }^{11}$ Gibrat's Law is linked theoretically to Zipf's Law, another stylized fact concerning the size distribution of cities. Gabaix and loannides (2004) describes the related theory, and Giesen and Südekum (20II) provides the empirical evidence.
} 


\section{Conceptual Framework}

In this section, I first explain the market access channel, which is the main channel through which railroad access could have increased technology adoption in the industrial sector. I then describe how this could facilitate structural change and urbanization. I also discuss two other potential channels, the migration and adoption cost channels, and explain how it is possible to distinguish them from the main channel in my data. In addition, I describe how financial frictions, and whether domestic or foreign market integration is driving technology adoption, could lead to heterogeneous outcomes. I use the intuition developed in this section as the basis for formal statistical tests in Section 4 . The discussion in this section is informal, but I include a formal model for the main channel in the Appendix.

To understand the market access channel, consider a firm in a monopolistically competitive industry, which exports goods to many regions. To export its goods, the firm has to incur a trade cost of the iceberg cost. When railroads are constructed, these trade costs would decrease. The firm would then reduce its price, ${ }^{\square]}$ and facing constant elasticity of substitution (CES) consumer demand, it increases its sales. Suppose the firm can pay a fixed cost to adopt a new technology that lowers its marginal cost. As in Bustos (201I), firms that have access to a railroad network and produce more output will be more likely to adopt this new technology. [3]

Alvarez-Cuadrado and Poschke (20II) show that in the presence of an income effect in the industrial sector, the adoption of new technology by industrial firms will increase the share of total workers employed in the industrial sector, thereby implying structural change. This effect is known as labor pull. Most current empirical literature examine labor push, where productivity growth in the agricultural sector leads to industrialization. Alvarez-Cuadrado and Poschke (201I) show that the labor pull effect was dominant in developed countries before 1920. As seen above, this is also true in the case of Japan. ${ }^{\text {.4 }}$

Technology adoption would also change the population dynamics. In an agricultural economy where technology progress is stagnant, the more populated areas have lower population growth due to mean reversion of agricultural productivity. In an industrial economy, the population dynamics of the more populated areas are determined by the productivity of the industrial sector, which is more persistent due to technolog-

\footnotetext{
${ }^{12}$ We have the same implication when firms can use input with lower price. I include this as a part of this market access channel.

${ }^{13}$ David (1975) discusses similar mechanism to explain why railroad will lead to the gain in productivity at factory level, though he explain it by learning by doing rather than technology adoption. Also, he points out that this gain is not accounted in social saving estimated in Fogel (1964).

${ }^{14}$ In the Appendix, I formally modeled both labor push and pull by combining Bustos (20II) and Alvarez-Cuadrado and Poschke (2011).
} 
ical progress. More populated areas may also have additional advantages in technology adoption, such as easier access to credit, which could lead to rapid population growth.

There can be three other channels by which access to a railroad network could affect technology adoption. The migration channel may exist because railroad construction could affect migration costs. If railroads reduce the migration costs, labor mobility may consequently increase. If areas with railroad access are more attractive to workers than those without, this could increase the aggregated demand in the former areas. Sales of firms in these areas could increase as their home market will be larger. In addition, a higher labor supply would lead to lower wages, which will be passed through to lower prices, further increasing sales. As mentioned above, higher sales for firms with access to the railroad network would mean that they are more likely to adopt new technologies. Note that the market access channel will also lead to an increase in migration through the labor pull effect, therefore the market access and migration channels have broadly similar implications. However, the two differ in the timing of events. The market access channel implies that firms first adopt new technology, which is followed by an increase in population. Under the migration channel, the order is reversed. It is thus possible to distinguish between the two channels by examining the timing of technology adoption relative to population growth. ${ }^{\square}$ The information channel may also exist because railroad construction will lower the communication cost and it may induce technology adoption by sharing information such as the existence of steam power or its expected return. I will test this channel by looking at the number of expositions, an important place to share information.

The final channel is the adoption cost channel. To adopt steam power, firms had to buy machines from trading companies, which were mainly based in Tokyo or Osaka. Asajima (2001) documents that the Mitsui Trading Company, the dominant trading company in the late 19th centuries, imported and sold machines through their headquarters in Tokyo and a branch in Osaka. The introduction of a railroad network may allow firms based outside Tokyo and Osaka to access these trading companies more easily. In addition, Pomeranz (200) shows that the gain in productivity by adopting new technology depends on the price of coal. By reducing transportation costs for coal, railroad network construction could increase the productivity gain from new technology for firms in areas far from coal producers. ${ }^{\text {[6 }}$

Other than these channels, Rostow (1960) suggests that railroad construction could affect the economy

\footnotetext{
${ }^{15}$ It is possible that firms adopt new technology in anticipation of future migration, which would render timing under the migration effect ambiguous. However, the outcome variable that I examine is horsepower, a result of investment, and firms will have no incentive to increase horsepower before migration occurs.

${ }^{16}$ Coal was an export industry at that time, so the distance from the areas of coal production, and not ports, will be more appropriate.
} 
by increasing demand. The construction requires industrial goods such as rails and locomotives. However, in this case most goods were imported from abroad, so the effect on domestic demand should be minimal.

In the presence of credit market frictions, the effect of access to a railroad network on technology adoption may be heterogeneous over areas. Suppose only urban areas have credit markets, then firms in only these areas could invest in new technology ${ }^{\square}$ Gaining access to a railroad network will then have a greater impact for more populated areas. ${ }^{18}$

Heterogeneity of effects over industries are also important to distinguish which of domestic integration and external integration is the key mechanism behind. Although the conceptual framework abstracts from this, it would still affect the external validity of the results. For example, if the effect is found only in the exporting sector, then this suggests that country-level comparative advantage will fully determine the sector affected by railroad access.

\section{Background and Data}

In this section, I first provide an overview of the history of railroad network expansion, and explain how I exploit these historical facts in constructing my instrument. I then describe modern economic development in Japan. I also briefly discuss my data sources, and explain the construction of my control and outcome variables. The Appendix contains a more detailed description of each of the original data sources. Note that most of the data set comes from hundreds of newly digitized documents through archival work. A unique feature of this data set is that I observe variables at a more disaggregated level (county level) than in other existing data set (prefecture level). This enables me to analyze important economic issues such as heterogeneous impacts, externalities, and urbanization. Prefecture-level data will mask county-level variation for analysis on heterogeneous impacts and externalities. Also, it will not be appropriate to analyze urbanization if we consider within prefecture migration. Finally, I will show the descriptive statistics of my data set.

\footnotetext{
${ }^{17}$ Nakamura (2010) shows that in Japan, the credit market for firms was based on face-to-face communication and networks among elites established during the Edo period. Ohnuk1 (2007) finds that the interest rates were higher in rural than urban areas in the early 1880s and the 1890s, although the gap narrowed after the establishment of the Bank of Japan.

${ }^{18}$ When exporting has a fixed cost, only larger firms will choose to export. Bustos (20II) labels this as the firm selection effect. If larger firms tend to be located in areas with large populations, then this mechanism implies that the effect of railroad access on technology adoption will be stronger in urban areas. However, in the data I use, there is no significant relationship between population density and the average number of workers per factory. Therefore, this effect should be absent.
} 


\subsection{Development of the Japanese Rail Network}

\subsubsection{Background}

Both railroads and steam power originated in the U.K. The diffusion of these technologies to Japan was slow due to political circumstances. Consequently, the adoption started in the late 19th century. From 1612 to 1853, the Tokugawa Shogunate severely restricted interactions with foreign countries in order to preserve political stability. In 1612, Christianity was outlawed, and in 1635 Nagasaki was designated as the only port open to Western ships ${ }^{\mathbb{W T}}$. In 1639 , the Netherlands became the only Western country permitted to trade with Japan. Western knowledge could then diffuse to Japan only through the Netherlands. Throughout this period, Japan gradually adopted Western technology.

In the 1850 s, the U.S. used military force to pressurize Japan to open its ports to trade. Japan subsequently signed treaties with the U.S., the U.K., France, the Netherlands, and Russia. Political conflict over how to handle this foreign pressure resulted in a civil war, the collapse of the Tokugawa Shogunate, and eventually, the establishment of the new Meiji Government in 1861. The civil war and the threat of colonization by foreign powers led many political groups to attempt to adopt Western technology in the 1850s.

Railroad was one such technology. Japanese people first saw steam locomotives in the $1850 \mathrm{~s}^{\mathbb{2 0}}$. In 1869 , the Meiji Government created a railroad construction plan in order to link Tokyo and Kyoto. The first railway line opened in 1873 . It was approximately $30 \mathrm{~km}$ in length, and linked the capital, Tokyo, with the largest port open to foreign trade, Yokohama. In 1874, a line linking Osaka, the second-largest city, and Kobe, another port open to foreign trade, was completed. Military expenditures related to civil war in 1873 (the Seinan Senso) led to budget problems, and there was no further expansion of the railroad network in the 1870s.

In the 1880 s, the railroad network began to expand. Following these fiscal problems, the Meiji Government allowed the establishment of a private railroad company, Nihon Tetsudo in 1881. This company was issued a license to build a line from Tokyo to the northern end of Honshu, the largest island in the Japanese archipelago. Despite being a private company, Nihon Tetsudo has close connections with the government, ${ }^{2]}$ and received financial support from it. In 1887, to further increase private investment in railroads, the government enacted a law allowing the private sector to establish railroad businesses. Under this law, private

\footnotetext{
${ }^{19}$ There were three other ports open to other Asian regions: Tsushima for Korea, Satsuma for Ryukyu, and Ezo for the Ainu people

${ }^{20}$ In contrast, in the U.K., the first commercial railroad with steam locomotives had opened in 1825.

${ }^{21}$ Iwakura Toshimi, who was appointed as Udaijin (literally "Minister of the Right") for the Council of State of the Meiji Government in 1871, served on the board of Nihon Tetsudo.
} 
firms had to submit a proposal for a rail line to the government, and obtain a license. These policies enabled the railroad network to expand. The top-right panel in Figure $\mathbb{W}$ shows the railroad network in 1892. Accordingly, railway lines covered about 34 percent of the counties included in my sample.

The expansion continued even after the 1880s. In 1892, the central government enacted the Railway Construction Act (Tetsudo Husetsuho) to plan the construction of additional railroad lines. The law specified 33 lines, ${ }^{22}$ and stated that a public railroad fund would finance their construction projects. Private sector firms were also allowed to build these lines on behalf of the government, conditional on obtaining a license. The routes were chosen based on predicted local economic benefits. A map of factors, which would predict railroad revenues such as villages, industries, and other transportation, was constructed. ${ }^{[3]}$ The railroad network then expanded to cover the entire nation. In 1895, 2,126 thousand Yen was spent on railways through the public fund, constituting 2.49 percent of the total government expenditure. In comparison, the total expenditure of the Ministry of Education was 1,153 thousand Yen, and that of the Ministry of Agriculture and Commerce was 1,236 thousand Yen. The amount of freight traffic and the number of cars used for freight services increased during 1890. Figure 7 shows that the growth rate of freight services was higher than that of passenger services. ${ }^{[4]}$ The bottom-right panel of Figure $\mathbb{U}$ shows that by 1920, the rail network covered almost the entire country. Accordingly, the rail network decrease domestic trade cost. Tetsudo-In (1916) documents that railroads access decreased the trade cost by half between Tokyo and Fukui, which is about $500 \mathrm{~km}$ distance in today's highway network. Before railroad network construction, it cost 132 yen and 10 days per $10 \mathrm{kan}(37.5 \mathrm{~kg})$. After railroad network construction, it became 62 yen and 4 days. $^{\text {[5] }}$ Tetsudo-In (1916) also states that by railroad access, people increased consumption by importing from other regions, and domestic traders increased long-distance trade accordingly, which is consistent with the market access channel.

To construct my instrument, I exploit the government's policy objectives in the 1880s. Masaru Inoue, the director of the Ministry of Railways, was the driving force behind the government's railroad policy. When designing the line from Tokyo to Aomori, the northern end of Honshu, he stated that "We should not make side trips to consider local benefits." This statement implies that the government prioritized the connection from Tokyo to the end points of Honshu over the benefits to the local economy, suggesting exogeneity with respect to the economic conditions of the local areas along the route. In addition, technological con-

\footnotetext{
${ }^{22}$ This includes some lines that were already completed.

${ }^{23}$ p. 123 in Vol. 3 of Nihon Kokuyu Tetsudo (1997)

${ }^{24}$ At that time, most railroads carried both freight and passengers, whereas modern high-speed trains carry only passengers.

${ }^{25}$ Unfortunately, there is no comprehensive trade cost data before railroad network construction.
} 
straints meant that the slope was an important consideration when planning routes. As pictured in Figure 8, construction was more difficult and costly in steeper areas. For example, the line connecting Tokyo with Western Honshu was initially planned to pass through steep terrain, but after re-evaluation in 1885 , the route was changed to pass through flatter areas as shown in Figure 9. A report comparing the two routes was prepared after this re-evaluation. This report estimated that the construction cost per mile of the original route was roughly double that of the final route. The slope was also significant for the operation of rail lines. Locomotives would run more slowly on slopes, and were not powerful enough to climb some steep slopes. The report estimated that a train on the original line would take one and half times as long as the revised route would, despite the length of the two routes being roughly the same.

Given this historical context, I construct cost-minimizing paths from Tokyo to the prioritized destinations to use as an instrument for railroad network expansion from the 1880 s to 1892 . In 1881, Nihon Tetsudo prioritized a few destinations in their statement. The first objective of Nihon Tetsudo was to connect Tokyo and Aomori, the latter being historically regarded as both the northern end of Honshu and the gateway to Hokkaido. The other two prioritized lines connected Tokyo and Niigata, and Moji and Nagasaki. Niigata and Nagasaki were both ports open to Western trade, and Moji was the gate port of Kyushu facing Shimonoseki. ${ }^{[6]}$ To the West, Shimonoseki was prioritized by the government as the gate port for the island of Kyushu. ${ }^{\text {[D] }}$ In constructing the cost-minimizing path, I use information on slopes together with an algorithm by Dijkstra (1959), which I explain below.

To be a valid instrument, the cost-minimizing path must satisfy the relevance, quasi-random assignment, and exclusion restrictions. Since cost was considered when the route was planned, the cost-minimizing path will predict the actual expansion of the network. Furthermore, we can easily test this using the results of the first-stage regression. On the other hand, by construction, the cost-minimizing path will be correlated with local geography, which affects its own outcomes, and this violates the assumption of quasi-random assignment. Therefore, I use the distance from these paths conditional on local geography including slope

\footnotetext{
${ }^{26}$ The original statement by Nihon Tetsudo states that the line to Niigata will continue to Ushu, a historical province to the north of Niigata, comprising the modern Yamagata and Akita prefectures. However, the statement does not specify a city in this province as the intended destination. Therefore, I set Niigata as the destination as their priority. Niigata was the only foreign port open to Western trade on the Sea of Japan, rendering it a natural choice as the final destination. In addition, the fact that no exact destination in Ushu was specified indicates its subsidiary importance relative to Niigata. Similarly, the line between Moji and Nagasaki was originally intended to continue to Higo province, a historical province corresponding to today's Kumamoto prefecture. Assuming that the final destination is Kumamoto city, the line to Higo would be only $70 \mathrm{~km}$ in length and pass through five or six counties along the cost-minimizing path, so excluding this branch will not affect the final results.

${ }^{27}$ In the statement by Nihon Tetsudo, Kyoto was specified as the destination of the line to the West from Tokyo. However, the government recognized that Shimonoseki as the important destination to the West. In 1887, to consider the proposal from the private sector to a line to Shimonoseki, Masaru Inoue stated in a document to the cabinet that the line to Shimonoseki is a part of prioritized network. In Table A.Ju, I do robustness checks by excluding counties which are located between Kyoto and Shimonoseki.
} 
information. Figure [0] illustrates this idea. As an example, I consider two potential paths from Tokyo to the destination in question, although there is an infinite set of potential. In this case, path B will be chosen as it passes through flatter terrain than path A does. If paths A and B are compared unconditionally, the assumption of quasi-random assignment will be violated as the flatter area may have better economic potential. By conditioning on local geography, the comparison is between counties with similar slopes, but one lies on path A and the other on path B. The variation of the instrument is now from the goverment's networking motivation and other counties' geography, which will be exogenous to local economy. Moreover, before the railroad era, there were no attempts to connect Tokyo with other destinations by public expenditure on land transportation due to the absence of a powerful centralized government and the low level of technology in land transportation. ${ }^{[8}$ Therefore, conditional on local geography, the cost-minimizing path will not be associated with economic variables before railroad construction started.

To further ensure quasi-random assignment, I estimate specifications including the initial population density and the existence of traditional roads as additional controls. I show that these controls do not affect the results, suggesting that conditional on local geography, the instrument is plausibly exogenous. There may also be concerns related to the exclusion restriction. For example, the central government may allocate other kinds of public goods together with railroad construction. This would cause the effects of railroad access to be overestimated, although the reduced form will not be biased. To eliminate this possibility, I check for a relationship between the instrument and other kinds of public spending, such as investment in roads or irrigation. I will also discuss other important policies and technological progresses during this time and argue that these polices and progresses will not affect the main result.

\subsubsection{Data}

Using the current railroad network data, I construct historical data for the rail network. The National Land Numerical Information (NLNI) download service ${ }^{29}$ offers geographical data that includes all railroad network and station data from 1950 onwards. However, it does not include the opening years for all railroads that opened before 1950, and therefore cannot be used to generate geographical data for the railroad network for each year of the sample period. Consequently, I use two additional official documentary sources, the Nihon Kokuyu Tetsudoshi (The History of Japan's National Railroad) and the Nihon Tetsudoshi (The History of Japanese Railroads) to retrieve the railroad opening years. After constructing the historical network data,

\footnotetext{
${ }^{28}$ Before railroads were constructed, marine transportation was the major transportation mode for long-distance freight.

${ }^{29}$ http://nlttp.mlit.go.jp/ksj]
} 
I identify the year in which each country gained access to the railroad network. ${ }^{[0}$

To calculate the cost-minimizing paths, I download 250 meter mesh data for average slopes from the National Land Numerical Information Download Service, ${ }^{1]}$ and calculate the cost-minimizing path using the algorithm in Dijkstra (1959). ${ }^{132}$ My basic specification assumes that construction costs are a linear function of average slope. Since the true cost function is unknown, I also try a specification, which includes a constant term, and a specification, which does not penalize a slope of less than 25 per mill. The results under these specifications are discussed in detail in the Appendix, but the form of the cost function did not affect the main results. After constructing the paths, I simply calculate the distance to each path from each county, which I then use as the cross-sectional variation of the instrument to predict growth in railroad access by 1892 .

To control for the time-variant effect of traditional roads, I constructed network data for traditional roads by connecting the towns that each route passed through with straight lines, referring to the Nihon no Kaido Handbook (Handbook of Japanese Traditional Roads). Although this is an approximation, but since the towns are fairly close to one another, the measurement bias will be minimal at the county level. I also included a different dummy for the Gokaido, which are five major routes specified and controlled by the Shogunate. The Shogunate directly specified checkpoints, pre-modern post stations, and lodging on the routes, and therefore these areas might have higher economic potential.

\subsection{Steam Power and Japanese Economy}

\subsubsection{Background}

The diffusion of steam power to Japan was also gradual. In 1712, the British inventor Thomas Newcomen was the first to develop a practical steam engine. ${ }^{[3]}$ James Watt, among others, subsequently attempted to improve the engine's thermal efficiency. In 1785, Edmund Cartwright used steam power as the basis for his power loom. Robert Stephenson later used steam to power locomotives on the Stockton and Darlington railway lines. Many industries thus began to use this new source of power.

In Japan, the Tokugawa Shogunate was the first to experiment with Western steam technology. In 1861, the Shogunate established a steam-powered metal producing factory in Nagasaki. Throughout the 1860s, the

\footnotetext{
${ }^{30}$ Throughout this paper, the variable railroad access is a dummy, which takes a value of one for a county-year when that county has any intersection with a $1 \mathrm{~km}$ buffer of railroad lines by the beginning of that year. I include the buffer since minor data issues lead some lines to pass outside the coast.

${ }^{31}$ For computational reasons, when rasterizing the mesh data, I set 0.002 , which is around $1.7 \mathrm{~km}$, as the mesh size.

${ }^{32}$ The Arcgis "cost" commands use this algorithm.

${ }^{33}$ The idea of steam power is not new. In the first century AD, Hero of Alexandria described a simple steam turbine known as the Aeolipile (Hero's engine).
} 
Shogunate, local domains, and the Meiji Government established similar factories in other industries such as textiles and mining (Minami, 1977), but it was not until the 1880s that the private sector began to utilize steam engines. 134

Adoption of steam power led to a significant increase in the aggregate horsepower, as can be seen in Figure 2. In 1884, the total horsepower was 1,051 , which increased to 21,825 by 1890 . In addition, as Figure 11] shows, there is regional variation in steam power adoption. On the other hand, Figure $\square$ also shows that technological progress in the agricultural sector, often considered the key to structural change, did not occur during this period. Fertilizer consumption did not increase as rapidly as horsepower did, and the next major technological breakthrough, a new high-yield variety of rice ${ }^{[3]}$ did not occur until $1910 .{ }^{[6]}$ Consistent with these developments, Figure 3 shows that the relative price of industrial goods declined before 1940, particularly before 1900. Alvarez-Cuadrado and Poschke (2011) notes that this pattern can be observed for 11 countries that experienced structural change between 1840 and 1920. This implies that productivity growth is faster in the manufacturing sector than in the agricultural sector, consistent with the labor pull effect emphasized in Lewis (1954), and not labor push.

A stylized pattern of structural change and economic growth can also be seen. Agriculture's share of labor and value added decreased, while GDP per capita increased. Figure $\$$ shows the declining importance of the primary sector (agriculture and fishery) after the 1880s. Figure 6 shows growth in GDP per capita for Japan, and three other countries included for comparison. Before 1868, both Japan and China lagged far behind the U.S. and the U.K., Western countries that had already experienced industrial revolutions. After 1868, Japan began to grow while China's growth was stagnant. Japan's catch-up period ended during World War II, but began to grow again afterward and surpassed the U.K. in $1980 .[7$

Cross-sectional data also illustrates a regional pattern of technology adoption, structural change, and urbanization. Figure $12 \mathrm{2}$ plots the share of primary workers in a county against the log of total horsepower

\footnotetext{
${ }^{34}$ The fixed cost of adopting steam technology was significant, as I assumed in the conceptual framework. In the pulp and paper industry, in 1890 Fuji Seishi, the second-largest company at that time, estimated the cost of establishing a steam-powered factory as 32,919 Japanese Yen. Unfortunately, they did not report any revenue, but using the revenue of Ouij Seishi and the relative production of the two companies, estimated that of Fuji Seishi to be around 230,000 Japanese Yen. The cost of this new factory would thus be around 14.3 percent of the annual revenue.

${ }^{35}$ The key scientific knowledge underlying this breakthrough, Mendelian inheritance, was re-discovered in 1900.

${ }^{36}$ Kiyokawa (1995) states that there were two other adoptions of major technology in agriculture. The first was a new type of cocoon that could grow after July. Its adoption rate was stagnant during the 1890s, although there is no data available before this decade. Additionally, this cocoon does not belong to the agricultural sector as defined in most growth models, because there will be no subsistence level of consumption for this crop. Therefore, I interpret technology adoption in this industry similar to steam power adoption in the industrial sector, although most data do not treat it separately from non-cash crops, such as rice. The second new technology was the non-human-powered agricultural machinery, although adoption of this technology started in the 1900s.

${ }^{37}$ Hayashi and Prescott (2008) argues that pre-Second World War cultural factors explain this progress, while the war and the resulting destruction of the country acted as constraints on migration and hindered structural change.
} 
per factory worker and rice productivity per land. Both are negatively correlated with the primary industry's share of employment with the primary industry's share of employment, with the slope being much steeper for $\log$ horsepower (on a standardized $\mathrm{X}$-axis). This is consistent with labor pull rather than labor push. Figure [13] shows that a negative correlation exists between the share of primary workers and the log of population density.

To summarize, there is a positive relationship between technology adoption in the industry sector, structural change, urbanization, and economic growth from the 1880s onwards. This is true both in time series and cross-sectional data. It is therefore important to examine the factors that induced technology adoption in the industrial sector.

\subsubsection{Data}

To capture technology adoption and economic development, I newly digitize three different publication series, and supplement this data with two other previously digitized series. I use two types of data: factory data, which allows me to observe technology adoption, and population data, which allows me to observe structural changes and urbanization.

To obtain factory data, I digitize two statistical series published by the central government, Noshomu Tokeihyo (Agriculture, Commerce and Manufacturing Statistics) and Kojo Tsuran (the Factory Catalog). These contain the total horsepower generated through steam power, the number of steam-powered factories, and the number of workers in steam-powered factories from 1888 to 1891, 1902, and 1919. These series also contain product information, which allows data to be classified by industry. However, there is no reliable common identifier for individual factories, so I aggregate all variables to the county level.

I digitize a similar local government publication, the Huken Tokeisho (Prefectural Statistics) from 1884 to 1902 to obtain the revenue, share capital, number of workers, product type, and location of each factory. This publication has many missing volumes, so I do not use it in my main analysis. However, I use the profit data to check if the use of steam power is associated with improvements in revenue productivity.

For the population variables, I digitize several central government population publications, the Nihon Teikoku Minseki Koguchi Hyo (Table of Registered Population), the Nihon Teikoku Seitai Jinko Tokei (Table of Population Statistics), and the Population Census, and obtain population data for 1885,1888 to 1898 , 1903, 1908, and 1920. Data is also available for 1879, 1880 and 1882, which is before IV affected railroad construction. However, this data uses a slightly different definition for population, so I use it only in checking 
the exclusion restriction. The data for 1920 was collected by census, and contains the number of workers in each sector. I use this data to test for the effect of technology adoption on structural change. Before 1920, no central government publication records the number of workers in the agricultural sector. I obtain this data from a local government publication, the Huken Tokeisho, which records the number of workers in the agricultural sector around 1885. This is used as a control when testing for effects on structural change.

\subsection{Descriptive Statistics}

Before moving to regression analyses, I show the descriptive statistics. Table $\square$ presents the descriptive statistics for three data points: an initial stage at 1888, a middle stage at either 1902 or 1903, and an end stage at either 1919 or 1920. Panel A shows that steam power was in limited use in 1888. The average total horsepower per county was 12.4 , and the average number of steam-powered factories per county was only 0.58 . There were two-thirds as many water-powered factories as there were steam-powered ones, but the former's total horsepower was 15 percent of that of the latter. Only 5.8 per cent of the counties had railroad access. The average county population was 69,087 and the average population density was 245.84 . This level of population density is similar to that of Pakistan in 2014, which had a density of 240, and lower than that of Vietnam in 2014, where the density was $293 . \sqrt{58}$ Most counties had traditional roads, as is also shown in Figure 14, while the Gokaido did not reach the end points as the railroad network did after 1868.

By the middle stage, the average number of steam-powered factories had increased to 3.51 , and the horsepower to 112.79 , roughly 10 times that of the initial period. The number of water-powered factories had also increased, but their contribution to the total horsepower was 22.62, much lesser than that of steampowered factories. ${ }^{399}$ Population and railroad access both have increased. About 64 percent of the counties now have railroad access.

Toward the end stage, electricity and gas emerged as the new types of power source. These new power sources are more important than steam power, both in terms of horsepower (621.57 vs. 1207.96) and the number of factories (8.17 vs. 20.1). I aggregate these two power sources when analyzing the long-term impacts later. Population has also increased, and 79 percent of the counties now have railroad access. ${ }^{40}$

\footnotetext{
${ }^{38}$ http://data.worldbank.org/indicator/EN.POP.DNST

${ }^{39}$ The original data records the horsepower for "steam" and "other," not specifically water. However, given the context, it is appropriate to read this as water power. I therefore assume this variable is consistent between the data in 1902 and before.

${ }^{40}$ To show the extent to which steam power had diffused in more detail, I present the descriptive statistics at the industry and factory levels in 1902, as in Table A.2.
} 


\section{Main Results}

In this section, I first confirm that the introduction of steam power increases the factory size and labor productivity by using the Huken Tokeisho. Then, I estimate the causal effect of railroad access on steam power adoption. I then perform robustness checks and heterogeneous impact analysis.

\subsection{Preliminaries: Factory-level Analysis}

To analyze the relationship between the introduction of steam power, and factory size and labor productivity, I use the following specification

$$
\text { Outcome }_{i t}=\alpha_{1} \text { Steam Power Fty }_{\cdot i t}+\text { County }^{*} \text { Year FE }+ \text { County } * \text { Industry FE }+u_{i t} \quad,
$$

where Steam Power Fty. . $_{\text {it }}$ is a binary variable, which takes a value of one if firm $i$ is using steam power at time $t$. Note that because the source data lacks a common identifier for individual factories, I cannot include factory fixed effects. As an alternative, I include interaction terms with country and industry dummies. ${ }^{-11}$

Table $\square$ presents the results for factory size and share capital. Columns (1) to (3) show the relationship between the adoption of steam power and the number of workers. The estimates in column (1) indicate that factories that use steam power are roughly 58 percent larger than those that do not. ${ }^{42}$ I find similar results for share capital, which is consistent with factories' issuing stock to fund the adoption of new technology. Columns (4) shows that steam-powered factories have 78 percent more share capital than those without steam power, and we have similar the point estimates in column (5) and (6).

Table B shows the impact on labor productivity, measured by the log revenue per worker. Columns (1) to (3) use different combinations of fixed effects, and columns (4) to (6) add share capital as additional control. Panel A uses all available data. However, revenue is only observed for one year in some prefectures. In Panel B, I estimate the model using the subset of prefectures where revenue data is available for multiple years. Both panels show a positive relationship between labor productivity and the use of steam power, even after controlling for share capital. In column (6), for example, steam-powered factories have 49.7 percent higher productivity than non-steam-powered ones have.

Overall, although these results are not free from selection bias, the introduction of steam power is asso-

\footnotetext{
${ }^{41}$ Only Factory Catalog has industry classification, so for other data sources I use the product type to classify factories.

${ }^{42}$ Atack et al (2008a) estimates a similar equation using US data from 1880, and finds a coefficient of 1.281 for steam power and 0.760 for water power. When I include a water power dummy, both estimated coefficients are smaller, but the difference between the two is similar.
} 
ciated with a larger number of workers, higher share capital, and higher labor productivity. All these results are consistent with the assumptions of this paper.

\subsection{Main Result: Effect of Railroad on Technology Adoption in 1888-1902}

Now, I will analyze the impact of railroad access on technology adoption using data from 1888 and 1902 or 1903. ${ }^{13}$ Since the government will construct railroads endogenously, I will rely on the instrumental variable explained in the previous section to estimate the causal impact of railroad access.

First, I examine the relationship between the actual railroad network and my instrument. Figure 155 plots both the railroad network and the cost-minimizing path, showing the relevance of the instrument graphically. To see how the relationship between the cost-minimizing and actual paths evolves over time, I nonparametrically estimate the relationship between distance from the cost-minimizing path and railroad access in selected years. Figure 16 plots the resulting functions. In 1880, when only a small part of the railroad network had been constructed, there was no relationship. In 1888 and 1892, counties closer to the costminimizing path were more likely to have railroad access. Subsequently, government support of railway construction led to an increase in the access for counties far from the cost-minimizing path. The line for 1902 shows that between 1892 and 1902, the same amount of railroad was constructed across all counties. By 1919, due to catch-up in previously non-prioritized counties, the gap in railroad access has disappeared, and the function is flat. In Table A.3, I show that this relationship is true even after including the controls.

I next estimate the impact of railroad access on various outcomes, using the cost-minimizing path as an instrument, as seen in Figure 16. The main specification is

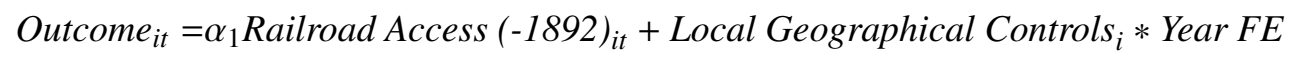

$$
\begin{aligned}
& +\left(\text { Local Other Controls }_{i} * \text { Year FE) }+ \text { Year FE }+ \text { County FE }+e_{i t}\right. \\
& \text { Railroad Access }(-1892)_{i t}=\text { Distance to the Path }{ }_{i} * \text { Year FE }+ \text { Local Geographical Controls }_{i} * \text { Year FE } \\
& +\left(\text { Local Other Controls }_{i} * \text { Year FE }\right)+\text { Year FE }+ \text { County FE }+e_{i t}
\end{aligned}
$$

where Railroad Access $(-1892)_{i t}$ is a binary variable. When $t \leq 1892$, it takes a value of one if county $i$ has railroad access in year $t$. When $t>1892$, it takes the value it had at $t=1892$. The treatment variable is

\footnotetext{
${ }^{43}$ I focus on the medium-term effect here, as I expect the effect of railroads to permeate gradually. This is because our outcome variable is the result of investment, unlike $R \& D$ expenditure.
} 
defined differently from the previous analysis. I construct it in this way since my instrument is related to railroad construction before 1892. This means that the treatment effect should be interpreted as the effect of having access to the railroad network before 1892, which will be less than the simple unconditional effect of railroad access.

Table 4 presents the estimates of the effect of railroad access before 1892 on the adoption of steam power in a county. Panel A contains the estimated effect on steam power measured by its horsepower, with column (2) adding the initial population density and the presence of traditional or main traditional roads, both of which are correlated with the instrument in the cross section as additional controls. In columns (3) and (4), I added the distance to the destinations as an additional control to columns (1) and (2). The point estimate is around 300 in column (1), and the result is robust by including an additional control in columns (2) to (4). To understand the magnitude of the effect, I multiply the effect with the number of counties that obtained rail access between 1888 and 1892, and find that the growth in rail access between 1888 and 1892 accounts for 67 percent of the growth in steam power between 1888 and 1902. In Panel B, I use a slightly different measure of technology adoption, the number of steam power engines. In all specifications, the coefficients are significantly positive, and the point estimates do not change substantially over different sets of controls. The point estimates are around 21 and by similar calculation, the growth in rail access between 1888 and 1892 accounts for 97 percent of the growth in the number of steam engines between 1888 and 1902. Although this calculation assumes that LATE is equal to ATT, but overall, a large amount of technology adoption is explained by more widespread railroad access.

\subsection{Robustness Checks}

First, I analyze the direction of the bias of OLS. Table A.4 in the Appendix, I perform the same regression analysis with Table 4 without the use of instrumental variables. I find that the OLS estimate is biased downwards, possibly due to the government favoring less developed areas. Agrawal et al. (2016) notes that this is a typical result in transportation literature. Alternatively, the result may be due to the difference between ATT and LATE. The instrument captures the main lines for long-distance transportation, not branches, and these main lines may be better connected and offer better service than branches do.

\footnotetext{
${ }^{44}$ I choose distance from the cost-minimizing path as my instrument, rather than a binary variable taking a value of one for counties on the path, as the fit of the first stage is better. Figure 16 shows that the relationship is close to linear in 1892.

${ }^{45}$ This "hypothetical" path is a better instrument than government plans commonly used in the literature, because it is constructed using only geographical information, whereas government plans may depend on other economic or political factors. After controlling for local geography, the only variation in my instrument is whether the county lies on the cost-minimizing path, so the quasi-random assignment and exclusion restrictions are likely to be satisfied.
} 
In Table A.5, I investigate the effect of railroad access on other outcomes, the number of (steam-powered) factories, the proportion of the population working in (steam-powered) factories, and the population with the same sets of specifications with Table 4. The results indicate that railroad access increased the total number of steam factories, population, and the proportion of workers employed by steam-powered factories, but not the total number of factories or the proportion of workers employed in any factory, although some results are not significant in some specifications. This is consistent with railroad access accelerating technology adoption, but not the entry into factory-based production. 10 国

We can use the result of the number of steam-powered factories to study the effect of railroads on the productivity of factories. The results in column (6) of Table [3 imply that steam power raises productivity by 49.7 percent. ${ }^{48}$ The estimates in column (1) of Panels A and B in Table 1.5 depict that growth in railroad access between 1888 and 1892 accounted for 29.5 percent point of the proportion of steam-powered factories in 1902. Together, these estimates imply that access to a railroad network increases factory productivity by 16.2 percent. This figure does not correct for selection effects, and therefore should be treated as an upper bound. However, it provides a rough estimate of the effect of railroads on productivity.

I next perform a falsification test of the assumption of quasi-random assignment by examining population growth. Between 1879 and 1880, no county gained access to the railroad network, 11 and between 1879 and 1882, only six counties gained access. If the instrument is quasi-randomly assigned, it should have no impact on the population in this period. As my headline specification includes county fixed effects, the test

\footnotetext{
${ }^{46}$ Although the proportion of people working in factories did not increase, this is not a measure of structural change. Matsumoto and Okuda (11997) and Nakamura (11971) note that there is a non-factory-based sector connected with the factory-based sector.

${ }^{47}$ As a robustness check, I include prefecture-level geographical controls and cluster standard errors at the prefecture level, as county-level geographical controls may be too restrictive. एable A.6 shows the results. The general pattern is similar to the results without prefecture-level controls.

${ }^{48}$ This is a comparison between steam power and non-steam power. When I include a water power factory dummy in the analysis, the difference between water power and steam power is 30 percent, and that between human power and steam power remains 50 percent, and both effects are significant. I use a simple steam versus non-steam comparison because water power is only feasible near steep rivers, and is not suitable for industries that require a constant amount of energy input. Atack et al. (20)(08a) finds that the difference between steam power and water power, in terms of log revenue, for establishments with more than 16 employees is 0.181 without controlling capital per worker, and 0.201 when controlling for capital per worker. The estimate with capital per worker is similar to my result. However, capital in Atack et al. (2008a) is defined as the actual capital invested, whereas capital in this paper refers to the share capital, so the two specifications are not identical.

${ }^{49}$ Bias may also arise due to the use of revenue productivity rather than physical productivity. Productivity will increase following the adoption of new technology, but a monopolistically competitive firm will reduce prices in response to the decrease in marginal cost, and this will have a negative effect on revenue productivity. However, separating these effects is impossible in my data.

${ }^{50}$ Minami (1979) examines the adoption of the power loom by the Japanese textile industry, and its effect on industry productivity. Using cross-sectional differences in the adoption rate in 1924, he finds that in the cotton industry, a one percentage point increase in the adoption of the power loom leads to an increase in labor productivity of 0.91 percent $(0.59$ percent conditional on capital per worker), in the silk industry the estimated effect is 0.57 percent ( 0.12 percent conditional on capital per worker). However, by 1920 the dominant source of power was electricity, so the effect of the power loom will not be the same with the effect of steam power.

${ }^{51}$ At this point, there were already short lines in the Tokyo and Osaka areas.
} 
is to determine whether railroad access affects the trend.

Results are contained in Table 5. It estimates where the dependent variable is population growth in 18791880 in columns (1) and (2), and 1879-1882 in columns (3) and (4). Similar to the main results, I estimate all models with and without additional non-geographical controls. ${ }^{52}$ I find no significant correlation in any columns. IV is not correlated with economic growth proxied by population growth before it could start to affect thorough railroad construction, and there is no evidence of the violation of quasi-random assignment.

I now test for the exclusion restriction. This restriction would be violated if being on the cost-minimizing path affects the outcomes through some channel other than railroad access. I test it informally by checking whether there is any effect of the IV on a potential channel, which might affect the outcomes. Specifically, I use prefecture-level data on government infrastructure spending, as the government may increase spending on other forms of public infrastructure such as roads or irrigation at the same time as constructing the railroad. I digitize its data from the Home Ministry's Statistical Yearbook and estimate the following specification.

\section{Outcome $_{i t}$}

$=\alpha_{1}$ Prop of Railroad Access County (-1892) $)_{i t}+$ Prefecture Geographical Controls ${ }_{i} *$ Year FE

+ Year FE + County $F E+e_{i t}$

Prop of Railroad Access County (-1892) it

$=$ Ave. Distance from the Path f Year Trend (-1892) + Prefecture Geographical Controls $_{i} *$ Year FE

+ Year FE + County FE $+e_{i t}$

Outcome $_{i t}$ is public infrastructure spending in prefecture $i$ for year $t$. For $t \leq 1892$, Prop of Railroad Access County $(-1892)_{i t}$ is the proportion of counties with railroad access in prefecture $i$ for year $t, t>1892$ it takes its value at $t=1892$. Prefecture Geographical Controls ${ }_{i}$ and Prefecture Geographical Controls are the same controls used in county-level analysis, recalculated at the prefecture level. Ave. Distance from the Path ${ }_{i}$ is the average of the distance from the cost-minimizing path, taken across counties in prefecture $i$. Instead of using year fixed effects, I use Year Trend (-1892), which is linear trend for $t \leq 1892$ and 1892 afterwards to be interacted with Ave. Distance from the Path $h_{i}$ to increase the F-value in the first stage.

Table 6 shows the results. Columns (1) and (3) do not use any instrument for the railroad variable, while

\footnotetext{
${ }^{52}$ Since I control for log area, the level of $\log$ population is the same as log population density.
} 
columns (2) and (4) do. Columns (1) and (2) use levels, while (3) and (4) use a log specification. The point estimates are negative, and insignificant at the 10 percent level. Furthermore, the mean of Public Expenditure ${ }_{i t}$ is 514,013 , so the point estimates in columns (1) and (2) are not economically significant. It does not appear that the exclusion restriction is violated by public spending.

Further robustness checks are presented in the Appendix. In Table A.7 and Table A.8, I check for robustness to the choice of cost function used in calculating the cost-minimizing path. In Table A.9, I control the distance to the destinations and exclude the counties adjacent to the destinations to exclude potential spillover effect from the destinations. In Table A.10, I see if dropping subsamples affects the main results. The main results are robust to these modifications. In addition, Redding and Turner (2015) points out that the estimated treatment effect may just be a displacement effect. In other words, the estimated effect in the main result is overestimating the effect due to negative externalities. To test this possibility, I first use a different treatment variable, Railroad (-1892) within $50 \mathrm{~km}_{\text {it }}$ which takes one if Railroad (-1892) it takes one or Railroad (-1892) jt of any of neighbor counties within $50 \mathrm{~km}$ takes one. Because out of counties which switch on the new treatment variable between 1888 and 1902, 29 per cent counties switch on due to their neighbor's access, we will see a huge drop in the coefficient when displacement effect is large. However, when comparing column (1) and (2) in Table A.Tl, we do not see a huge difference in the effect on steam power. The result is similar in column (4) and (5), using the number of steam engines, suggesting no displacement effect. I also see the effect of having railroad access only in their neighbor counties to capture local externalities directly. In column (3) and (6) I use Neighbor's Railroad within $50 \mathrm{~km}_{i t}$ which takes one if Railroad (-1892) within $50 \mathrm{~km}_{\text {it }}$ takes one and Railroad (-1892) it take zero. I instrumented this by Adjacent to the Path ${ }_{i}$ Y Year FE $E_{t}$ where Adjacent to the Path ${ }_{i}$ takes one if Distance to the Path ${ }_{i}$ takes from $20 \mathrm{~km}$ to $50 \mathrm{~km} .{ }^{[3]}$ If there is displacement effect, its coefficient should show negative sign, but column (3) and (6) shows no significant effects. Another way to see displacement effect will be to compare counties in Shikoku island, the island in the south without any destination shown in Figure 15 with counties in the other three islands far from the path. If displacement effect existed and only occurred within islands, counties in Shikoku island should have higher growth than counties far from the path in the other islands. I analyze this point in Table A.12, but I do not see significant difference between them. Of course, displacement may occur across islands, but this is difficult to characterize without knowing the form of the entrepreneur's entry decision problem, and difficult to observe in a small area like Japan. In Table A.13, I conduct analysis regarding

\footnotetext{
${ }^{53}$ During 1888 and 1892, counties in this region are railroad access three percent (insignificant) more likely to get railroad access than counties which is more than $50 \mathrm{~km}$ from the path are, so there is minimal bias from the direct impact of railroad access.
} 
which variables are affected in the short term. I find the effect on steam power although the its magnitude is much smaller than in the main result as expected.

I now investigate whether channels other than market access are responsible for the main results ${ }^{64}$. The difference between migration and market access channels is in the timing of the effects. Table $A .13$ shows the short-term reduced form effect of railroad access on technology adoption and population. In the short term, the only significant effect is on technology adoption in Panel A, and not population in Panel B. Table 1.14 investigates whether the short-term impact is heterogeneous. The results imply that there was no urban-rural migration by railroad. Overall, these results indicate that migration due to railroad access does not occur before or at the same time as technology adoption, which is inconsistent with the migration channel being the main channel. To examine whether the cost channel is driving my results, and also to examine heterogeneity of the effect of railroad access between rural and urban areas, I estimate a model allowing for heterogeneous impacts. Table $\square$ shows the results. Columns (1) to (3) present the estimates of short-term effects using annual data from 1888 to 1891, and columns (4) to (6) present estimates of mediumterm effects using data from 1888 and 1902, as shown in the main results. In both cases, the estimates indicate that the effect was stronger in countries with a higher population density. This is consistent with the presence of credit constraints in rural areas, and implies that the distance from Tokyo and Osaka is not important, which is not what we would observe if the cost channel was important. In Table A.15 of the Appendix, I show that the distance from areas where coal is produced is not significant, so the coal price

\footnotetext{
${ }^{54}$ If the effect of railroad access on trade costs can be observed, then this data can be used to test whether trade is a key mechanism. However, there is no data on trade costs before the railroad era, and even if there were, it is not clear how these trade costs could be summarized into a single variable, as my framework does not allow for multiple or asymmetric regions. The impact could possibly be greater for inland areas as they do not have access to marine transportation. I tested for heterogeneity in the impact of railroad access using distance from the coast, but did not find any robust pattern. There are two potential reasons for this. First, the costminimizing path mostly follows the coast, so there is not enough variation to detect heterogeneity. This problem of insufficient variation also applies to the distance from ports open for foreign trade. Second, marine transportation may also be conducted using rivers, so the distance from the coastline may not be an appropriate proxy for trade costs before railroad construction. Another possibility is to construct market size explicitly as in Donaldson and Hornbeck (2016). This does not work in my context because undulate geography and the lack of trade cost data before railroads came prevent us to make a meaningful measure of market size. However, Figure $\square$ shows that the amount of freight traffic on the railways increased as the network expanded, and the growth of freight was higher than that of passenger traffic. Hence, I believe that trade is the driving force, as explained in the conceptual framework.

${ }^{55}$ Hornung (2012) estimates the effect of railroads on population growth for cities in Prussia from 1840 to 1864 by using a straight line between the cities as an instrument for the railroad. His estimates are similar to the ones presented here.

${ }^{56} \mathrm{Kim}(1995)$ estimates the impact of steam power adoption on the location of firms in the U.S. between 1850 and 1880 , and finds the effect negligible. The analysis in this case is, however, limited to a simple cross-sectional regression, with no instrumental variable or natural experiment. Atack et al (2010) estimates the effect of railroads on population density and the rural population in the Midwest United States between 1850 and 1860, and finds a roughly 3 percent increase in both. In this case, the initial estimates are obtained using a Difference-in-Difference estimator, and further estimates are obtained by using a congressional survey as an instrument. The results of the IV estimation imply that Difference-in-Difference is biased downward, although the IV estimates are imprecise.
} 
channel will not be the main force.

Another possible channel is the information channel. The results in Conley and Udry (2010), Agrawal et al. (2016), and Catalini et al. (2016) suggest that introducing railroads to an area may transmit information such as the existence of steam engines and the profitability of the firms using them. I test this channel by looking at the impact of railroad on the number and total days of expositions held at prefecture. Expositions played a major role to share in the industrial sector (Kiyokawa, 1995), railroad may increase expositions by reducing transportation cost to invite speakers. Using the same specification with Table 6 , Table A.16 shows no effect of railroad on expositions. Also, there are many cases where factories adopted steam power even without access to a railroad, which suggests that the effect through this channel is minor. In 1888, 101 counties contained at least one steam-powered factory, and 82 of them did not have railroad access. Therefore I do not think that the information channel is working in my context. Another potential channel is within-city commuting, as suggested by Duranton and Turner (2012). However, commuting by train would not have been affordable for most workers. The average daily wage in 1902 was between 0.3 and 0.7 Yen,, 57 while the cheapest ticket from Tokyo (Shimbashi) to Yokohama, a commute of $30 \mathrm{~km}$ and 45 minutes, was 0.3 Yen. ${ }^{\sqrt{8}}$ Therefore, the effect of within-region commuting is most likely small.

The results so far indicate that the market access channel is likely to be the main forces behind the effect of railroad access. It is also possible to discern whether the incentive to adopt new technology is driven by improved access to domestic or foreign markets. If domestic market integration is important, then railroad access should affect purely domestic industries. I focus on two domestic industries, brewing and printing, both of which have low export shares as they produce goods for the domestic market. ${ }^{\text {I }}$ I then used steam power in these industries as an additional outcome. I also showed the results from the mining and textile industries, both exporting industries, for comparison.

Table A.17 shows the estimates of industry-specific effects. The specification is the same as column (1)

\footnotetext{
${ }^{57}$ This estimate is obtained from Umemura et al. (1965).

${ }^{58}$ Nihon Kokuyu Tetsudo (11997).

${ }^{59} \mathrm{I}$ consider industries with more than 200 factories (2.6 percent of the total) in 1902, used estimates by Taguchil (1994) to calculate the export share of each, and selected the industries with an export share of less than 10 percent. I construct the brewing industry as an aggregate of miso, soy sauce, sake, and beer manufacturers. The export share of this aggregate is 2.5 percent. No exports were recorded for printing. The tobacco industry also had an export share of 2.5 percent, but was monopolized by the government in 1898, so I have excluded it. Explosion material, mining, ceramic, and textile industries had more than 200 factories, but were not categorized as domestic.

${ }^{60}$ In total, these two industries account for 50 to 60 percent of the total value of exports in the 1880 s and 1900 s. In the data from 1909 , both industries also exhibit a fairly high export rate, defined as the value of exports divided by the value of total production. The textile industry itself has a low export ratio, but this industry is difficult to distinguish from the yarn industry in my data, so I work with their aggregate, which I define as the textiles and related products industry.
} 
of Table 4. Column (1) shows the result for the domestic industry, which I consider significant. ${ }^{\text {W }}$ Other columns show the results for the mining and textile industries. The effect on the mining industry is huge and accounts for roughly two-thirds of the overall effect. The estimated effect for the textile industry, shown in column (4), is positive but insignificant. I also show the coefficient divided by the standard deviation of outcomes in the row below the standard error. These results indicate that the effect of railroad access affects both the domestic and exporting industries by a similar size. ${ }^{[2]}$ The effect on the exporting industry will have an implication on external validity. If a country has a comparative advantage in the agricultural sector, then its railroads may affect the agricultural sector, and not the industrial sector.

I consider other important policies or technological progress in my sample period to discuss whether it might affect my main result. ${ }^{[3]}$ For the policies, I consider modern post offices, telegraphs, and telephones as important upgrades in communication infrastructure after the Meiji Restoration because communication costs might affect technology adoption and the government might have similar networking motivation for communication infrastructure as for transportation infrastructure. The modern post office was introduced in 1872 and covered the entire nation in 1873 in cooperation with village leaders, so it will not affect our identification strategy. Similarly, the telegraph was introduced in 1869 between Tokyo and Yokohama, and started to expand in 1874. By 1878, almost all the capital cities of the prefectures had obtained telegraph stations, so this would also not affect the main result. ${ }^{64}$ The telephone network spread in 1898, so this might be affected by the cost-minimizing path. During that time, telephone service was restricted within the city area, so I exclude seven counties that obtained telephone service by 1902, and estimate the same model with the main result, but the result does not change (See Table A.18). As an important industrial policy, Meiji Government established state-owned factories in 1870s. These factories tried to adopt Western technologies to demonstrate them for the private sector. Though many of them are not profitable, it might affect the main result. Table A.19 shows the result without counties where state-owned factories are located, ${ }^{6]}$ the result

\footnotetext{
${ }^{61}$ Tanimoto (2006) finds that firms in the domestic industries are run by local elites.

${ }^{62}$ Even without technology adoption in the exporting industry, structural change can occur by exposure to the foreign market, and specialization in non-agricultural goods due to comparative advantage. However, this would imply that the relative price of industrial goods increases after a county gains access to the railroad network, whereas the trend in the aggregated data is the opposite. Alvarez-Cuadrado and Poschke (20II) uses similar reasoning to argue that trade does not explain the decrease in the price of industrial goods and the increase in the industrial sector's share of workers. I also show more detailed export data in Figure A1]. It shows the growth in the openness and the trade volume with developed countries and of metal and textile industries, and no trade growth in agriculture and machinery industries. Figure A2 shows industry-specific relative price data and confirms that the exporting industry also experienced a drop in the price over the sample period.

${ }^{63}$ The issue of specification error for IV is covered in Figure A3, Table A.7 and Table A.8.

${ }^{64}$ Telegraph was available even without telegraph stations through post offices covering the entire nation. In their public announcement, the Ministry of Technology instructed how to use telegraphs in the absence of telegraph stations. Source:http: //dl.ndl.go.jp/into:ndljp/pid/796222

${ }^{65}$ The list of factories are available by Kobayashi (1977)
} 
do not change substantially. Also, the new government tried to improve credit market and it might affect technology adoption through credit constraint. However, they made an act to establish national bank system in 1876 and private banks cover the nation uniformly by the end of 1870s. Accordingly, Table Table A.20 implies that the instrument is not correlated with interest rate in the initial period and railroad construction does occur in area where interest rate was getting lower, so credit market story will not explain the main result. Steamship is another concern, because it became popular during my sample period and decreased the trade cost like the railroads do. However, it will affect the coastal areas more, and the cost-minimizing path is located inland on average. In addition, since the distance to the coast is controlled in all the specifications, I do not think that the adoption of steamships drives the main result. ${ }^{66}$

\section{The Effect on Modern Economic Development}

As I discuss earlier, technological progress in the industrial sector will induce structural change by labor pull effect ${ }^{[0]}$ and urbanization by breaking the pattern of mean reversion in population. In this section, I examine the effect of earlier railroad access on structural change and urbanization, common features of modern economic development.

\subsection{Structural Change}

Here, I examine whether gaining railroad access induces structural change. I cannot analyze the short- and medium-term effects as the sectoral employment data is not available. However, by using 1880's Huken Tokeisho and the 1920 Population Census, I can analyze the long-term effects. I use the following specifica-

\footnotetext{
${ }^{66}$ As another technological change in the transportation infrastructure, Chandler (1977) documents that some firms producing perishable products such as milk or meat adopted refrigerated railroad cars in the context of U.S.. However, refrigerated railroad cars will be interpreted as the outcome of railroad access if factories invest as in the case of U.S. or a part of the treatment if railroad companies introduced. Also, it does not affect the main result because it was introduced to Japan in 1908.

${ }^{67}$ Railroads might affect industrialization through regional specialization. However, there is no strong reason to believe that railroad access will induce industrialization on average. Also, it might induce structural change through the potential effect on agricultural productivity, but this will be less important as shown in Figure 2 and Figure 3 in my context. The potential reasons why railroad access did not induce technology adoption in the agricultural sector are that farmers are credit constrained, new Western technology was not available, Western technology was not directly applicable to Japanese crops, and the technological gap between Japanese and Western technology in the agriculture was not as huge as one in the industrial sector. Hence, in this paper, I think labor pull effect as the main channel.
} 
$\operatorname{tion}^{68}$

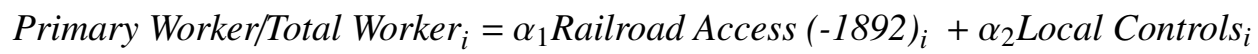

$$
\begin{aligned}
& +\alpha_{3} \text { Initial Agricultural Worker / } \text { Population }_{i}+e_{i}
\end{aligned}
$$

Primary Worker/Total Worker ${ }_{i}$ is the primary sector's share of workers in county $i$ in the 1920 census. Railroad Access (-1892) $)_{i}$ is a dummy variable, which takes the value of one if county $i$ had gained railroad access by 1892 . As before, Railroad Access $(-1892)_{i}$ is instrumented by Distance to the Path . Initial $^{-}$ Agricultural Worker/Population ${ }_{i}$ is the share of agriculture workers in the total population of county $i$, calculated from the population data of 1885 and the number of agricultural workers in either 1884, 1885, or 1886. Although this control and outcome are not identically constructed, they are conceptually similar. Since the outcome variable is only available for 1920, this is a cross-sectional analysis. However, I control for the initial level of industrialization using Initial Agricultural Worker/Population . $_{\text {. }}$

Table 8 presents the results. In column (1), I find a significant negative relation between the two, as expected. This finding is robust after controlling the time-variant effect of traditional roads in column (2). In column (3), I also include the time-variant effect of main traditional roads and lose significance, but this is because of higher standard error rather than omitted variable bias. To confirm that railroad access affects the manufacturing sector rather than the service sector, I use the share of workers in the industrial sector as the dependent variable in columns (4) to (6), and estimate the effect with the same sets of controls with columns (1) to (3). The size of the effect is similar to that in columns (1) to (3), so the negative effect on primary sector employment is due to the industrial sector, rather than the service sector. In column (4), the magnitude is 5.7 percent, and this corresponds to 0.36 of a standard deviation. This estimate may be attenuated since after 1900 steam power had diffused widely and agricultural technology was upgraded, which induced widespread structural change and narrowed the gap in structural change with the early adopters.

\footnotetext{
${ }^{68}$ See Figure A4 and Table A.2] in Section A.9 for the long-term effects on technology and population.

${ }^{69}$ Since this variable is taken from the Huken Tokeisho, data availability varies by year and prefecture. To increase the sample size, I used the earliest available data from these three years. Even so, no data was available for 87 of 487 counties used in the main estimation.
} 


\subsection{Urbanization}

To analyze the impact on urbanization, I estimate the following model for two data points, 1903 and 1920.

$$
\begin{aligned}
& \text { Log of Population } \text { Pt }- \text { Log of Population } \\
& i, 1885 \\
& =\alpha_{0}+\alpha_{1} \text { Log of Population Density }_{i, 1885}+\alpha_{2}{\text { Railroad Growth } 1885-1892_{i}} \\
& +\alpha_{3} \text { Log of Population Density }_{i, 1885} * \text { Railroad Growth } 1885-1892_{i}+\alpha_{4} \text { Local Controls }_{i}+e_{i t}
\end{aligned}
$$

where Railroad Growth 1885-1892 $i$ is Railroad Access ${ }_{i, 1892}$ - Railroad Access $s_{i, 1855}$. As in the previous analysis, this is instrumented by Distance to the Path ${ }_{i}$. This variable captures the effect of railroads constructed by priority, and will have a long-term effect after 1982, when the new railroad law was enacted and counties that were not prioritized began to catch up. Local Controls $s_{i}$ contains the set of geographical (and non-geographical) controls as in the other analysis. Due to the mean reversion effect in pre-modern agricultural economies, I expect $\alpha_{1}$ to be a negative coefficient. I expect $\alpha_{2}$ and $\alpha_{3}$ are expected to be positive coefficients because of technology adoption in the industry sector. ${ }^{\mathbb{W}}$ The parameter of interest is $\alpha_{1}+\alpha_{3} *$ Railroad Growth 1885-1892 . This determines whether bigger cities could grow more, and if we have a fatter tail on the right side in the distribution of the log of population density as we see in Figure 13, then it also determines how it differs between early and late adopters of railroads. If Gibrat's Law, the benchmark in the population dynamics of the modern economy, holds for any sample, $\alpha_{1}$ and $\alpha_{3}$ will have a coefficient of zero.

Table 9 contains the results. To simplify the interpretation of the effects, I normalize all controls. For all the years and specifications, $\alpha_{1}$ has a negative sign and the interaction terms, $\alpha_{2}$ and $\alpha_{3}$ have positive signs, as expected. Moreover, the estimated coefficient of Log of Population Density ${ }_{i, 1885}$ when Railroad Growth, $1885-1892_{i}=1$ is less negative and even becomes positive in some specifications. In columns (1) and (3), the overall effects are -0.0189 and 0.113 , suggesting that the urbanization effect is stronger in the long term. I obtain similar estimates in columns (2) and (4), when access to (main) traditional roads is added as a control. These results are consistent with the technology adoption and structural change caused by railroad access inducing urbanization by breaking the pattern of mean reversion.

\footnotetext{
${ }^{70}$ Michaels et al. (2012) shows that conditional on productivity, manufacturing areas should have higher population density because production is less land intensive.

${ }^{71}$ If railroads affect population dynamics by reducing migration costs, then the negative slope of Log of Population Density ${ }_{i, 1885}$ would become steeper when interacted with railroad access. This is because the mean reversion process will be accelerated by costless migration. My estimate is precisely the opposite.
} 


\section{Conclusion}

The central contribution of this paper is to find a causal impact of gaining access to a railroad network on technology adoption in the industry sector, which is a key mechanism that explains why railroads would be a major impetus for structural change and urbanization. To achieve this, I digitize a novel county-level data set covering Japan from the 1880s to 1920s, a period that witnessed railroad network expansion, transformation of the industrial sector by steam power, and structural change and urbanization. I start the analysis by using factory-level data and confirm that steam-powered factories are bigger and more productive, which is consistent with the key assumption that steam power has a high fixed cost but low marginal cost. Then, I perform DID-IV estimation by calculating the cost-minimizing path between destinations, and using the distance from this path to predict the growth in railroad access by 1892. I find that gaining railroad access by 1892 increased steam power in 1902. These estimates imply that railroad access growth from 1888 to 1892 accounts for 67 percent of the growth of steam power from 1888 to 1902 . The effect is smaller for less populated areas, suggesting its disadvantage for technology adoption such as credit constraints. We observe the effect for both the domestic and export industries, which highlights that railroads access integrated the regions internally and externally.

As additional results, I find that railroad access affects structural change and urbanization. As in the labor pull story, gaining railroad access by 1892 increased the share of workers employed outside the agricultural sector in 1920, and most of the effect is explained by the increase in workers in the manufacturing sector. It also breaks the pattern of mean reversion in population dynamics during 1885-1903 or 1920, which is an important change for big cities to emerge. Overall, these results are consistent with the picture that railroads induce the two features of modern economic development, structural change and urbanization, through technological progress in the industrial sector.

The findings suggest a view on the history of take-off of the Japanese economy. Before the 1850s, the diffusion of Western technology was mostly blocked by the restrictive trade policy by Tokugawa Shogunate. By the foreign pressure from Western countries, the Shogunate was forced to open several ports for foreign trade in the late 1850s, but the fear of colonization resulted in the collapse of the Shogunate in 1868. The new Meiji Government, a more centralized one than the Shogunate, tried to adopt Western technology to strengthen their state capacity to avoid colonization. Railroad network was one of them, and this adoption would not be possible without the Meiji Government because constructing a railroad network required significant government spending, coordination, and a positive attitude towards Western technology. If this is 
the case, then the findings of this paper support the view that the centralization and modernization of the government in 1868 aided Japan's economic development through public goods provision, that is, railroad construction.

\section{References}

Agrawal, Ajay, Alberto Galasso, and Alexander Oettl, "Roads and Innovation," Review of Economics and Statistics, 2016. Forthcoming.

Alvarez-Cuadrado, Francisco and Markus Poschke, "Structural Change Out of Agriculture: Labor Push versus Labor Pull,” American Economic Journal: Macroeconomics, July 2011, 3 (3), 127-158.

Asajima, Shoichi, Senzenki Mitsui Bussan no Kikai Torihiki (Transaction of Machines by Mitsui Trading Company before WWII), Tokyo, Japan: Nihon Keizai Hyoron Sha, 2001.

Atack, Jeremy, Fred Bateman, and Robert A. Margo, "Steam Power, Establishment Size, and Labor Productivity Growth in Nineteenth Century American Manufacturing," Explorations in Economic History, April 2008, 45 (2), 185-198.

— , - , and Thomas Weiss, "The Regional Diffusion and Adoption of the Steam Engine in American Manufacturing," Journal of Economic History, June 1980, 40 (02), 281-308.

_ , _ , Michael Haines, and Robert A. Margo, "Did Railroads Induce or Follow Economic Growth? Urbanization and Population Growth in the American Midwest, 1850-1860," Social Science History, 2010, $34(2), 171-197$.

—, Michael R. Haines, and Robert A. Margo, "Railroads and the Rise of the Factory: Evidence for the United States, 1850-70,” NBER Working Paper 14410 October 2008.

Atkin, David and Dave Donaldson, "Who's Getting Globalized? The Size and Implications of Intranational Trade Costs,” NBER Working Paper 214392015.

Bandiera, Oriana and Imran Rasul, "Social Networks and Technology Adoption in Northern Mozambique*," Economic Journal, 2006, 116 (514), 869-902.

Banerjee, Abhijit, Esther Duflo, and Nancy Qian, "On the Road: Access to Transportation Infrastructure and Economic Growth in China," NBER Working Paper 17897 March 2012. 
Baum-Snow, Nathaniel, “Did Highways Cause Suburbanization?," Quarterly Journal of Economics, 2007, $122(2), 775-805$.

Bleakley, Hoyt and Jeffrey Lin, "Portage and Path Dependence," Quarterly Journal of Economics, April 2012, pp. 1-58.

Burgess, Robin and Dave Donaldson, "Can Openness Mitigate the Effects of Weather Shocks? Evidence from India’s Famine Era,” American Economic Review, May 2010, 100 (2), 449-453.

Bustos, Paula, "Trade Liberalization, Exports, and Technology Upgrading: Evidence on the Impact of MERCOSUR on Argentinian Firms," American Economic Review, February 2011, 101 (1), 304-340.

- , Bruno Caprettini, and Jacopo Ponticelli, "Agricultural Productivity and Structural Transformation. Evidence from Brazil," American Economic Review, 2016, 106 (6), 1320-65.

Catalini, Christian, Christian Fons-Rosen, and Patrick Gaulé, "Did Cheaper Flights Change the Direction of Science?," MIT Sloan Research Paper No. 5172-16 2016.

Chandler, Alfred D., The Visible Hand: The Managerial Revolution in American Business, Cambridge, Massachusetts: Harvard University Press, 1977.

Conley, Timothy G and Christopher R Udry, "Learning about a New Technology: Pineapple in Ghana," American Economic Review, March 2010, 100 (1), 35-69.

David, Paul A., Technical Choice Innovation and Economic Growth: Essays on American and British Experience in the Nineteenth Century, London, UK: Cambridge University Press, February 1975.

Dercon, Stefan and Luc Christiaensen, "Consumption Risk, Technology Adoption and Poverty Traps: Evidence from Ethiopia," Journal of Development Economics, November 2011, 96 (2), 159-173.

Desmet, Klaus and Esteban Rossi-Hansberg, "Spatial Growth and Industry Age," Journal of Economic Theory, November 2009, 144 (6), 2477-2502.

- and Jordan Rappaport, "The Settlement of the United States, 1800-2000: The Long Transition towards Gibrat's Law," Journal of Urban Economics, 2015.

Dijkstra, E. W., "A Note on Two Problems in Connexion with Graphs," Numerische Mathematik, December 1959, 1 (1), 269-271. 
Dinkelman, Taryn, “The Effects of Rural Electrification on Employment: New Evidence from South Africa," American Economic Review, December 2011, 101 (7), 3078-3108.

Dittmar, Jeremiah, “Cities, Markets, and Growth: The Emergence of Zipf's Law,” Mimeo 2011.

Donaldson, Dave, "Railroads of the Raj: Estimating the Impact of Transportation Infrastructure," American Economic Review, 2017, forthcoming.

- and Richard Hornbeck, "Railroads and American Economic Growth: A 'Market Access' Approach," Quarterly Journal of Economics, 2016, 131 (2), 799-858.

Duflo, Esther and Rohini Pande, “Dams," Quarterly Journal of Economics, 2007, 122 (2), 601-646.

- , Michael Kremer, and Jonathan Robinson, "Nudging Farmers to Use Fertilizer: Theory and Experimental Evidence from Kenya," American Economic Review, October 2011, 101 (6), 2350-2390.

Duranton, Gilles and Matthew A. Turner, "Urban Growth and Transportation," Review of Economic Studies, 2012, 79 (4), 1407-1440.

- , Peter M. Morrow, and Matthew A. Turner, "Roads and Trade: Evidence from the US," Review of Economic Studies, April 2014, 81 (2), 681-724.

Eaton, Jonathan and Samuel Kortum, “Technology, Geography, and Trade,” Econometrica, 2002, 70 (5), 1741-1779.

Faber, Benjamin, “Trade Integration, Market Size, and Industrialization: Evidence from China's National Trunk Highway System,” Review of Economic Studies, July 2014, 81 (3), 1046-1070.

Fajgelbaum, Pablo and Stephen J. Redding, "External Integration, Structural Transformation and Economic Development: Evidence from Argentina 1870-1914,” NBER Working Paper 202172014.

Fernandes, Ana M., “Trade policy, Trade Volumes and Plant-level Productivity in Colombian Manufacturing Industries," Journal of International Economics, March 2007, 71 (1), 52-71.

Fogel, Robert William, Railroads and American Economic Growth: Essays in Econometric History, 1st ed., Baltimore, Maryland: The Johns Hopkins University Press, December 1964.

Foster, Andrew D. and Mark R. Rosenzweig, "Economic Development and the Decline of Agricultural Employment," in "Handbook of Development Economics," Vol. 4, Elsevier, 2008, pp. 3051-3083. 
Gabaix, Xavier and Yannis M. Ioannides, "The Evolution of City Size Distributions,” in J. Vernon Henderson and Jacques-François Thisse, ed., Handbook of Regional and Urban Economics, Vol. 4 of Cities and Geography, Elsevier, 2004, pp. 2341-2378.

Giesen, Kristian and Jens Südekum, "Zipf's Law for Cities in the Regions and the Country," Journal of Economic Geography, July 2011, 11 (4), 667-686.

- and - , "City Age and City Size," European Economic Review, October 2014, 71, 193-208.

Gine, Xavier and Dean Yang, "Insurance, Credit, and Technology Adoption: Field Experimental Evidence from Malawi," Journal of Development Economics, May 2009, 89 (1), 1-11.

Glaeser, Edward L., Giacomo A. M. Ponzetto, and Kristina Tobio, "Cities, Skills and Regional Change," Regional Studies, January 2014, 48 (1), 7-43.

Gollin, Douglas, Stephen Parente, and Richard Rogerson, "The Role of Agriculture in Development," American Economic Review, 2002, 92 (2), 160-164.

Goyal, Aparajita, "Information, Direct Access to Farmers, and Rural Market Performance in Central India," American Economic Journal: Applied Economics, July 2010, 2 (3), 22-45.

Hayashi, Fumio and Edward C. Prescott, "The Depressing Effect of Agricultural Institutions on the Prewar Japanese Economy," Journal of Political Economy, August 2008, 116 (4), 573-632.

Herrendorf, Berthold, James A. Schmitz Jr, and Arilton Teixeira, "The Role of Transportation in US Economics Development: 1840-1860," International Economic Review, 2012, 53 (3), 693-716.

Hornung, Erik, “Railroads and Micro-regional Growth in Prussia,” Ifo Working Paper 1272012.

Jedwab, Remi and Alexander Moradi, “Transportation Technology and Economic Change: The Impact of Colonial Railroads on City Growth in Africa," CSAE Working Paper Series 2013-17 2013.

Jensen, Robert, “The Digital Provide: Information (Technology), Market Performance, and Welfare in the South Indian Fisheries Sector," Quarterly Journal of Economics, August 2007, 122 (3), 879-924.

Kim, Sukkoo, "Expansion of Markets and the Geographic Distribution of Economic Activities: The Trends in U.S. Regional Manufacturing Structure, 1860-1987," Quarterly Journal of Economics, November 1995, $110(4), 881-908$. 
- , "Industrialization and Urbanization: Did the Steam Engine Contribute to the Growth of Cities in the United States?," Explorations in Economic History, October 2005, 42 (4), 586-598.

Kitamura, Shuhei, "Land Ownership, Technology Adoption, and Structural Transformation: Evidence from Postwar Japan,” Mimeo 2016.

Kiyokawa, Yukihide, Nihon no Keizai Hatten to Gijutsu Fukyu (Economic Growth and Technology Diffusion in Japan), Tokyo, Japan: Toyo Keizai Simposha, 1995.

Kline, Patrick and Enrico Moretti, "Local Economic Development, Agglomeration Economies, and the Big Push: 100 Years of Evidence from the Tennessee Valley Authority," Quarterly Journal of Economics, February 2014, 129 (1), 275-331.

Kobayashi, Masaaki, Nihon no Kogyoka to Kangyo Haraisage (Industrialization and Disposal of Stateowned Factories in Japan), Tokyo, Japan: Toyo Keizai Simposha, 1977.

Kongsamut, Piyabha, Sergio Rebelo, and Danyang Xie, "Beyond Balanced Growth," Review of Economic Studies, October 2001, 68 (4), 869-882.

Levinsohn, James and Amil Petrin, "Estimating Production Functions Using Inputs to Control for Unobservables," Review of Economic Studies, April 2003, 70 (2), 317-341.

Lewis, W. Arthur, "Economic Development with Unlimited Supplies of Labour," The Manchester School, May 1954, 22 (2), 139-191.

Lipscomb, Molly, A. Mushfiq Mobarak, and Tania Barham, "Development Effects of Electrification: Evidence from the Topographic Placement of Hydropower Plants in Brazil," American Economic Journal: Applied Economics, January 2013, 5 (2), 200-231.

Marden, Samuel, “The Agricultural Roots of Industrial Development: 'Forward Linkages' in Reform Era China," Mimeo 2015.

Matsumoto, Takanori and Miyako Okuda, "Senzenki Nihon ni Okeru Zairai Sangyo no Zenkoku Tenkai (The Distribution of Traditional Industris in Pre-War Japan)," in Takafusa Nakamura, ed., Nihon no Keizai Hatten to Zairai Sangyo (Economic Development and Traditional Industries in Japan), Yamakawa Shuppansha, 1997, chapter 1, pp. 11-68. 
Michaels, Guy, "The Effect of Trade on the Demand for Skill: Evidence from the Interstate Highway System," Review of Economics and Statistics, November 2008, 90 (4), 683-701.

— , Ferdinand Rauch, and Stephan. J. Redding, “Urbanization and Structural Transformation,” Quarterly Journal of Economics, May 2012, 127 (2), 535-586.

Minami, Ryoshin, "Mechanical Power in the Industrialization of Japan," Journal of Economic History, December 1977, 37 (04), 935-958.

- , Doryoku Kakumei to Gijutsu Simpo - Senzen Seizoki no Bunseki (Power Source Revolution and Technological Progress), Tokyo, Japan: Sanseido, 1979.

Munshi, Kaivan, "Social Learning in a Heterogeneous Population: Technology Diffusion in the Indian Green Revolution,” Journal of Development Economics, February 2004, 73 (1), 185-213.

Nakamura, Naohumi, Chihou kara no Sangyo Kakumei (Industrial Revolution from Local Economy), Nagoya, Japan: The University of Nagoya Press., 2010.

Nakamura, Takahusa, Senzenki Nihon Keizai Seicho no Bunseki (Analysis on Economic Growth in preWWII Japan), Tokyo, Japan: Iwanami Shoten, 1971.

Ngai, L. Rachel and Christopher A. Pissarides, "Structural Change in a Multisector Model of Growth," American Economic Review, 2007, 97 (1), 429-443.

Nihon Ginko Tokeikyoku, Meiji Iko Hompo Shuyo Keizai Tokei (Major Economic Statistics in Japan after Meiji), Tokyo, Japan: Namiki Shobo, 1997.

Nihon Kokuyu Tetsudo, Nihon Kokuyu Tetsudo Shi (The History of Japan National Railroad), Tokyo, Japan: Seizando-Shoten Publishing, 1997.

Ohnuki, Mari, "The Bank of Japan Network and Financial Market Integration: From the Establishment of the Bank of Japan to the Early 20th Century," Monetary and Economic Studies, 2007, 25 (1), 95-128.

Olley, G. Steven and Ariel Pakes, "The Dynamics of Productivity in the Telecommunications Equipment Industry," Econometrica, 1996, 64 (6), 1263-1297.

Pavcnik, Nina, "Trade Liberalization, Exit, and Productivity Improvements: Evidence from Chilean Plants," Review of Economic Studies, 2002, 69, 245-276. 
Pomeranz, Kenneth, The Great Divergence: China, Europe, and the Making of the Modern World Economy., revised ed., Princeton University Press, December 2001.

Redding, Stephen J. and Matthew A. Turner, "Transportation Costs and the Spatial Organization of Economic Activity," in "Handbook of Regional and Urban Economics," Vol. 5, Elsevier, 2015, pp. 1339-1398.

—, Daniel M. Sturm, and Nikolaus Wolf, "History and Industry Location: Evidence from German Airports," Review of Economics and Statistics, 2010, 93 (3), 814-831.

Rostow, Walt Whitman, The Stages of Economic Growth: A Non-Communist Manifesto, Cambridge, UK: Cambridge University Press, 1960.

Rud, Juan Pablo, "Electricity Provision and Industrial Development: Evidence from India," Journal of Development Economics, 2012, 97 (2), 352-367.

Suri, Tavneet, "Selection and Comparative Advantage in Technology Adoption," Econometrica, 2011, 79 (1), 159-209.

Taguchi, Terumi, "Meiji Koki no Seisan Yushutsu Tokei Hinmoku oyobi Seisan Suikei Hinmonku no Hikaku Shogo -Meiji 42 nen (Comparison of Production and Export/Import Data in Late Meiji Period)," Keizai Siryo Kenkyu, 1994, 25, 54-107.

Takeuchi, Makoto, Nihon no Kaido Handbook (Handbook of Japanese Traditional Road), Tokyo, Japan: Sanseido, 2006.

Tang, John P., "Railroad Expansion and Industrialization: Evidence from Meiji Japan," Journal of Economic History, September 2014, 74 (03), 863-886.

Tanimoto, Masayuki, "Capital Accumulation and the Local Economy: Brewers and Local Notables," in Masayuki Tanimoto, ed., The Role of Tradition in Japan's Industrialization, Oxford University Press, May 2006.

Tetsudo-In, Hnpou Tetsudo no Shakai oyobi Keizai ni Oyohoseru Eikyo (The Social and Economic Impact of Railroads in Japan), Tokyo, Japan: Tetsudo-In, 1916.

Umemura, Mataji, Saburo Yamada, Yujiro Hayami, Kiyonobu Takamatsu, and Minoru Kumazaki, Choki Keizai Tokei (Long-Term Economic Statistics), Tokyo, Japan: Toyo Keizai Simposha, 1965. 
Figure 1: Railroad Network

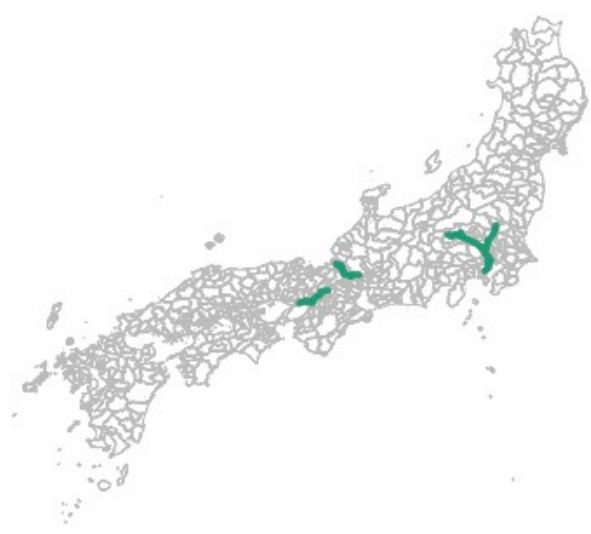

1902

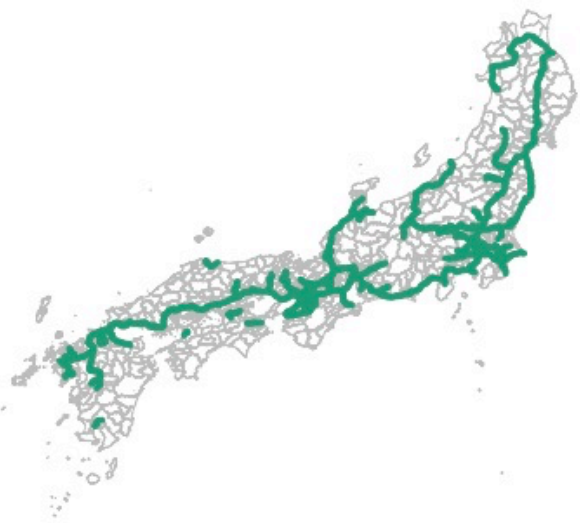

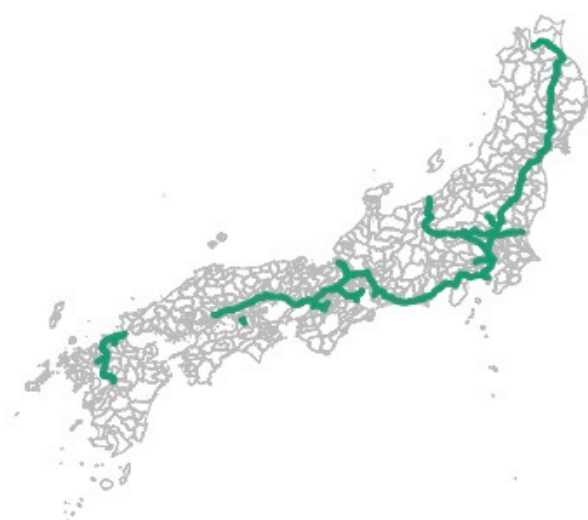

1920

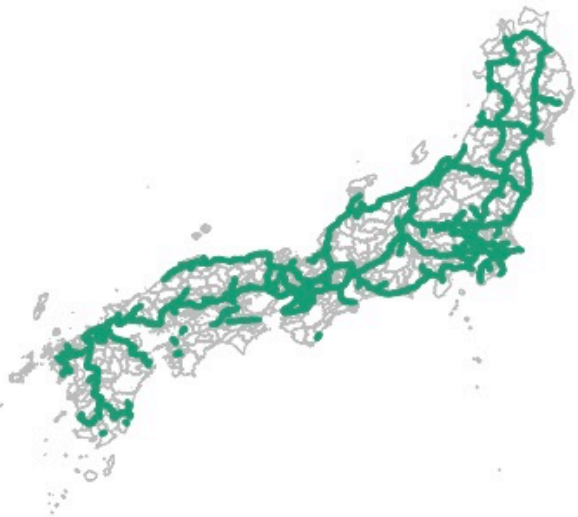

The green lines represent those that existed in each year. See subsubsection 3.12 for the source 
Figure 2: Adoption of New Technology in the Industrial and Agricultural Sectors

\section{Technology Adoption in Industrial / Agricultural Sector}

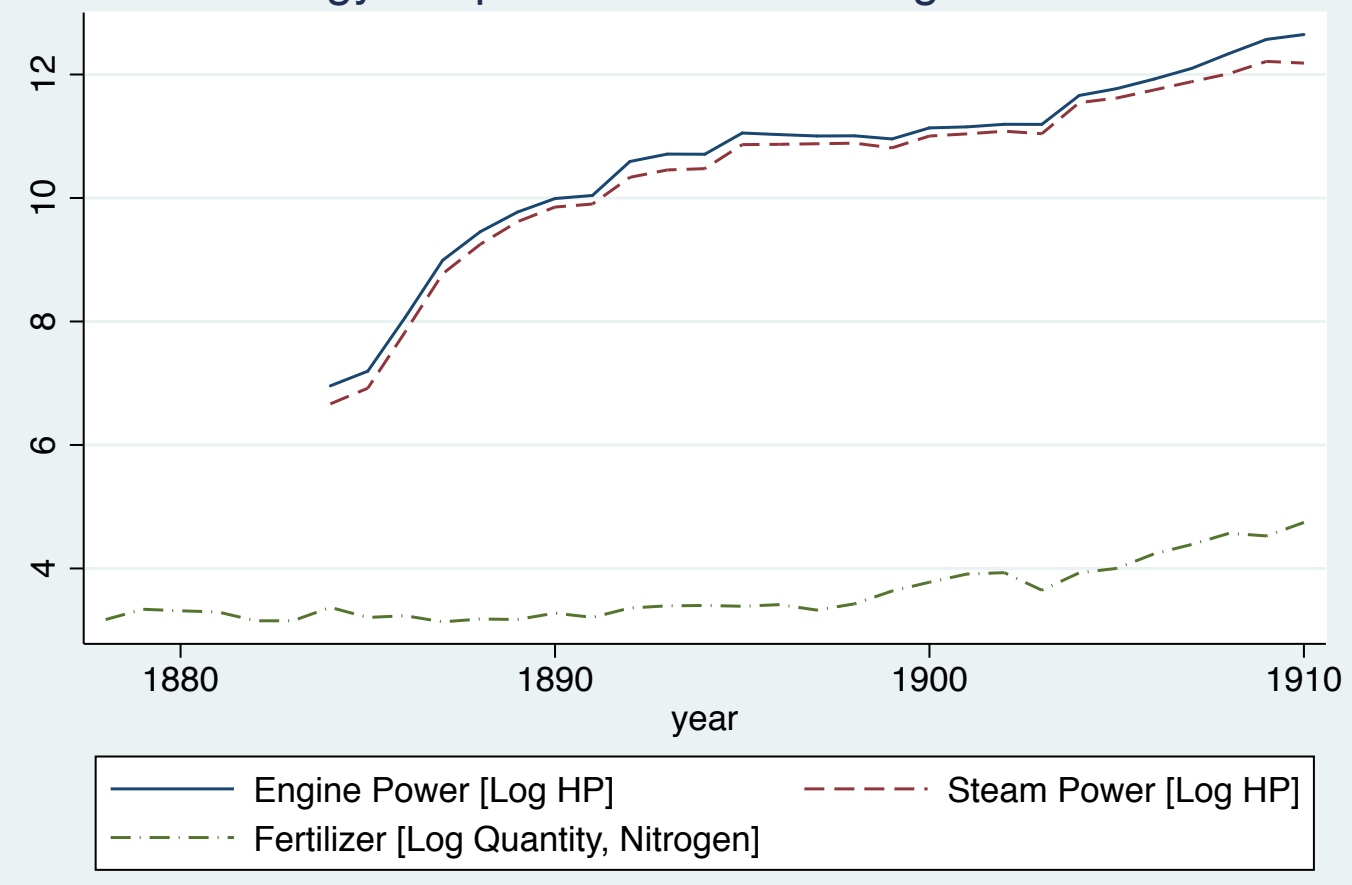

Source: Minami (1979) for steam power and Umemura et al. (1965) for fertilizers. These show aggregated level numbers. 
Figure 3: Relative Price (Industry/Agriculture)

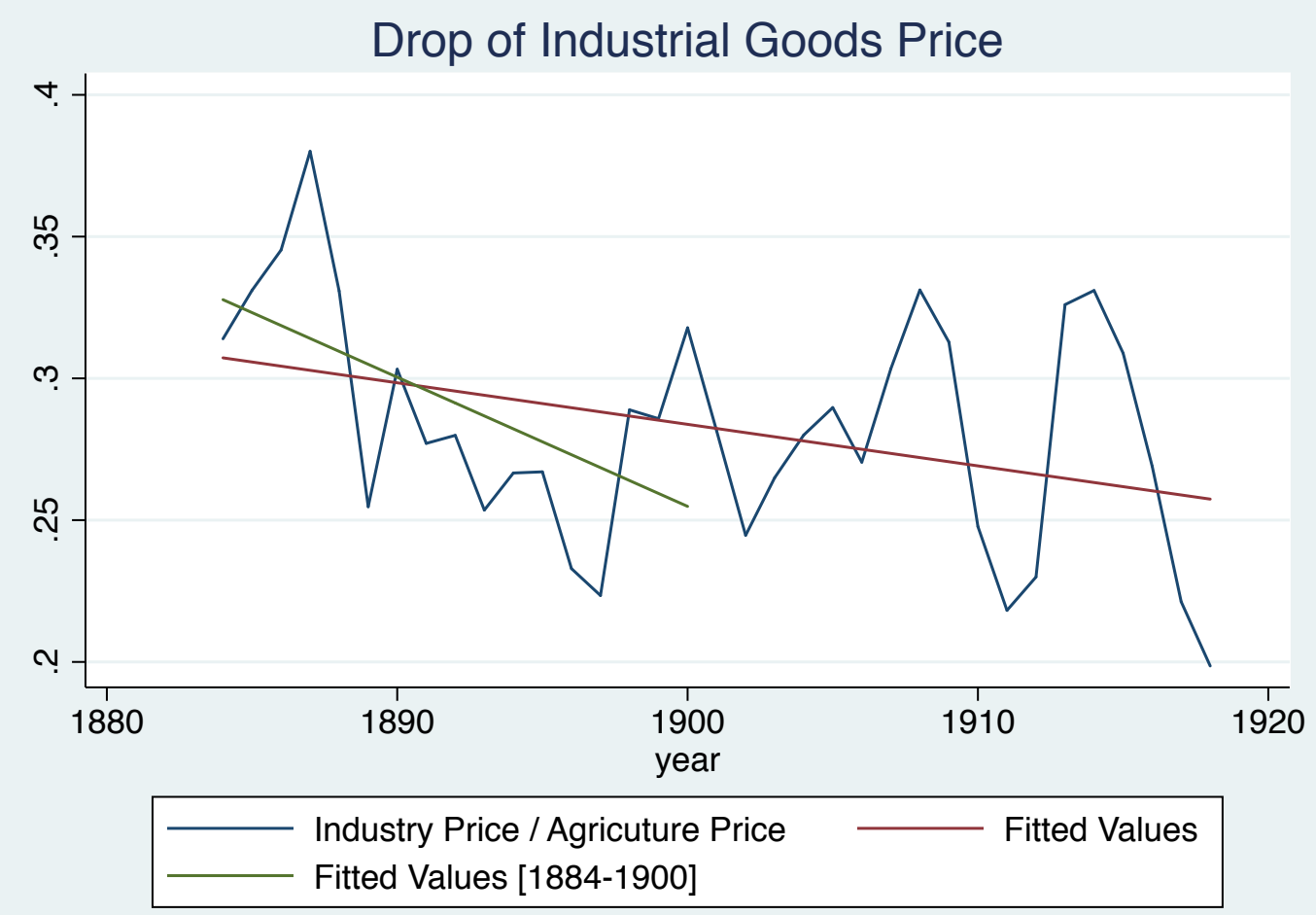

Source: Umemura et al. (1965) as used in Alvarez-Cuadrado and Poschke (2011) 
Figure 4: Decline of Primary Sector, 1885-1920

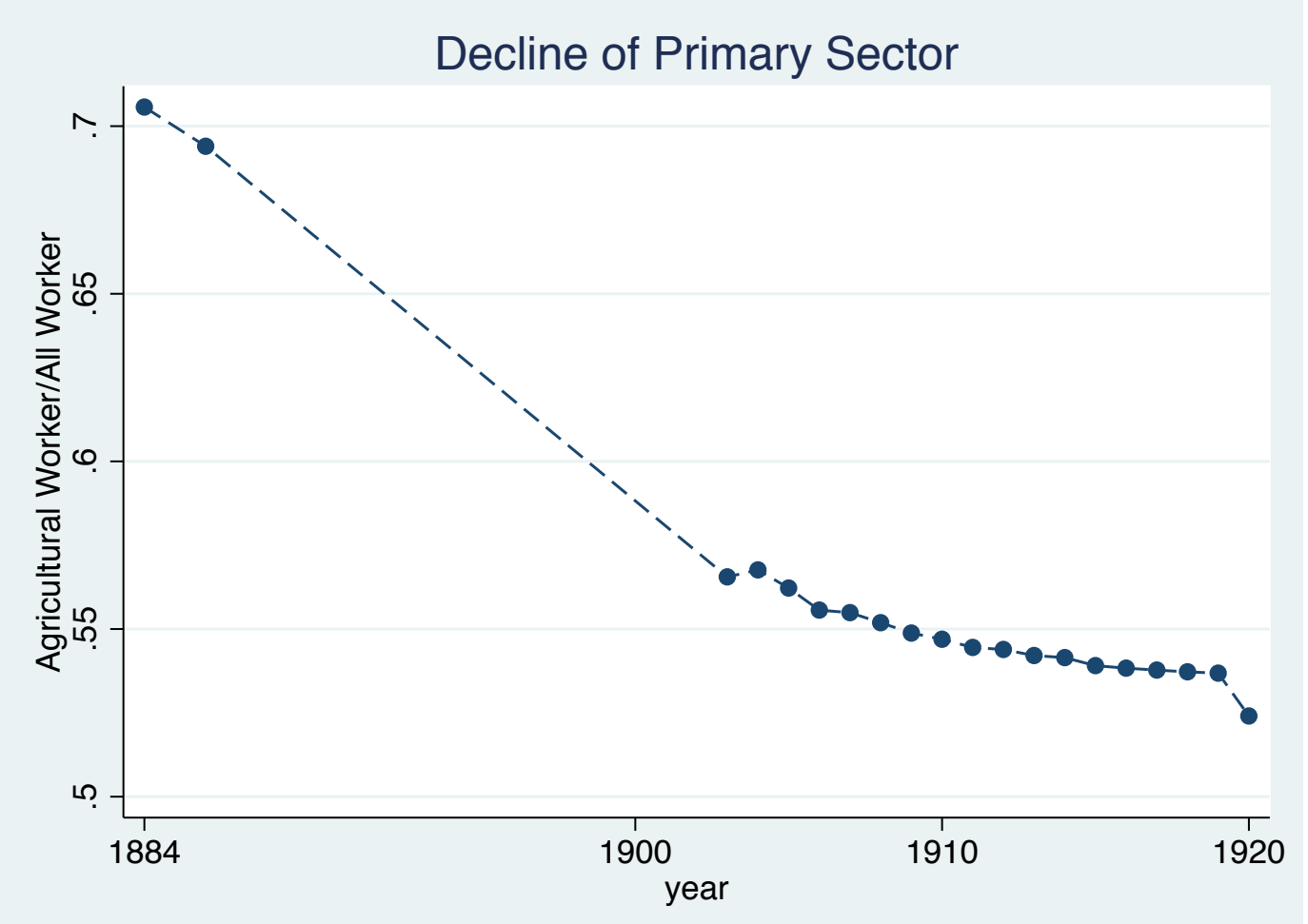

Source: Meiji iko Hompo Shuyou Keizai Tokei (Major Economic Statistics After Meiji Period) published by Bank of Japan in 1999 
Figure 5: Population Density in 1885, 1902, and 1920

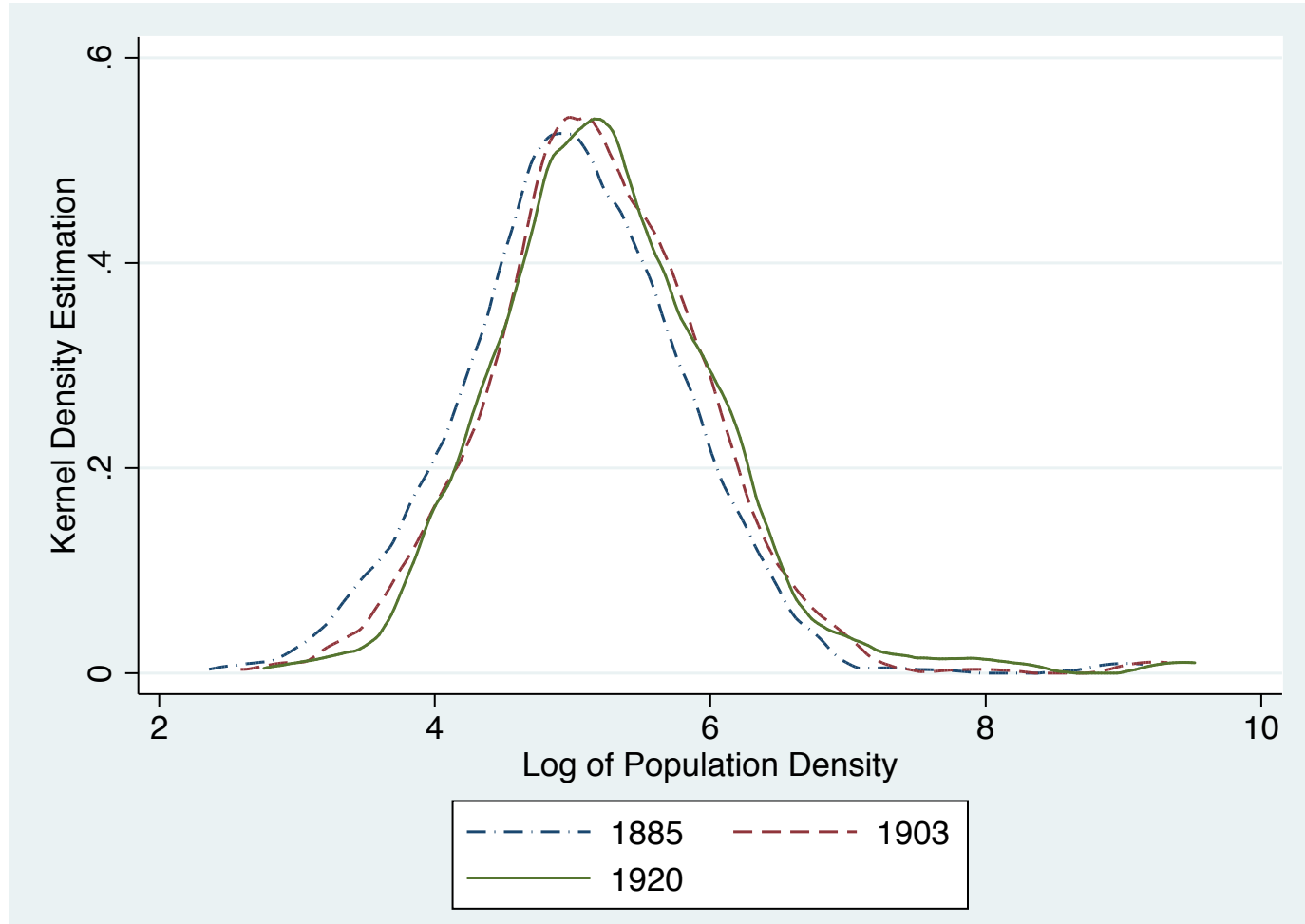

Notes and Source: The data is based on the 1885 and 1902 population statistics and the 1920 census. Section [3.2.2 provides more detailed information about the data source. 
Figure 6: Log of GDP per Capita, 1800-2000

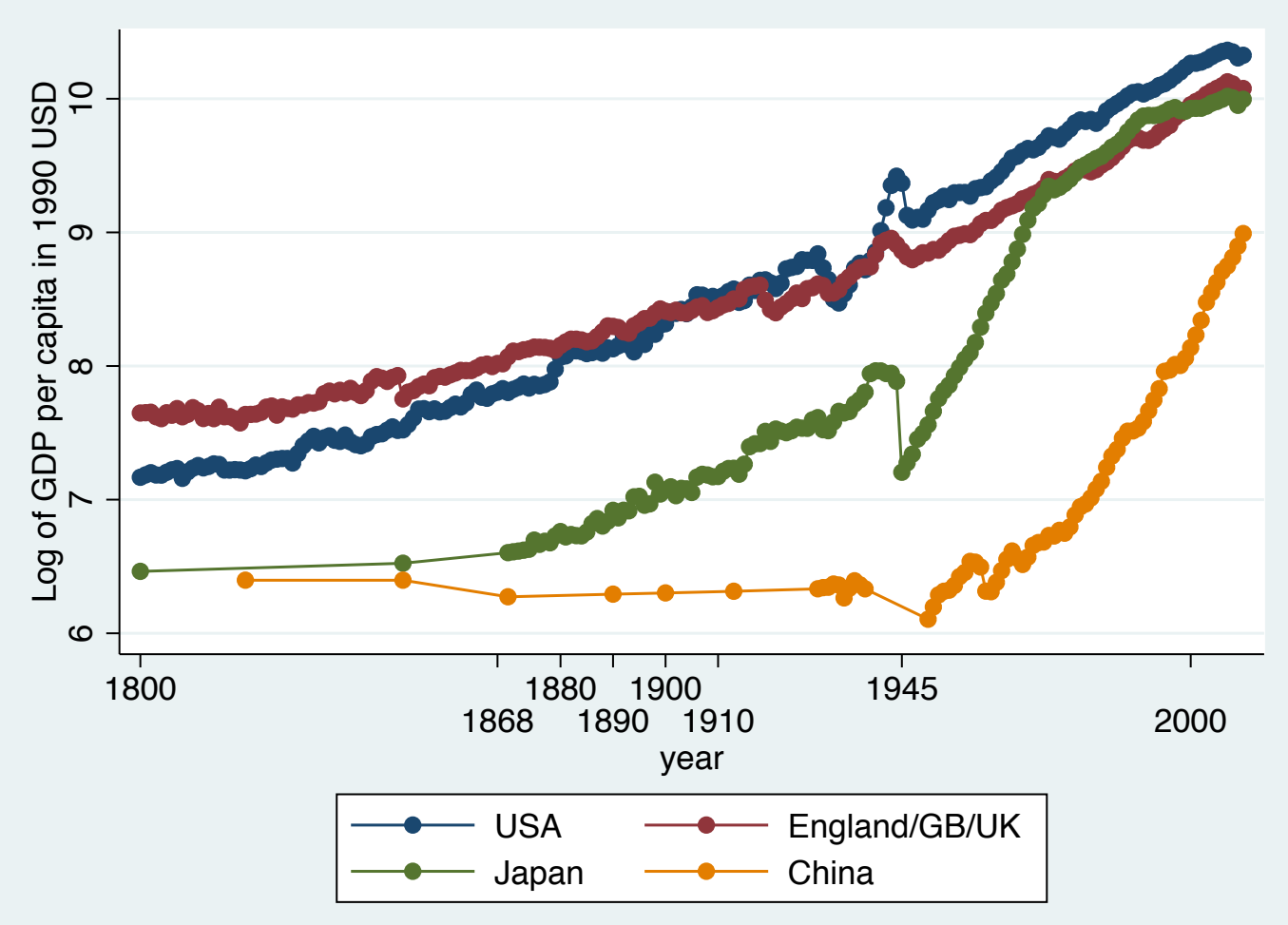

Source: The Maddison-Project, http://www.ggdc.net/maddison/maddison-project/home.htm, 2013 version. 
Figure 7: Freight and Passenger Traffic by Railroad

\section{Growth in Railroad Service from 1890}
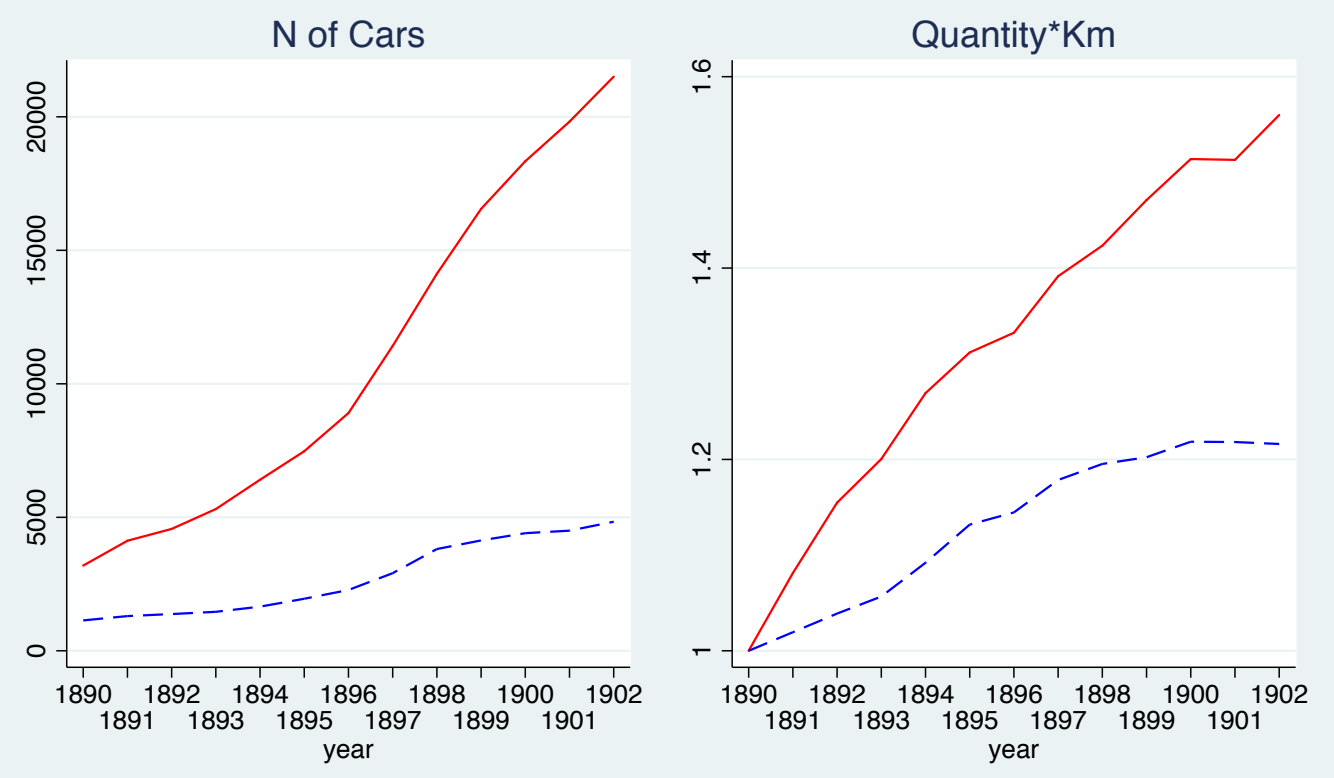

Freight ----- Passenger

Source: Meiji Iko Hompo Shuyo Keizai Tokei(Nihon Ginko Tokeikyoku, 1997). In the left panel, the Y-axis depicts the total number of cars for freight (red and solid line) or passengers (blue and dashed line), divided by their level in 1890. In the right panel, the Y-axis shows million ton * $\mathrm{km}$ for freight and million passenger * $\mathrm{km}$ for passenger, divided by their level in 1890. 
Figure 8: Construction Work in Steeper Areas (The Usui Pass)

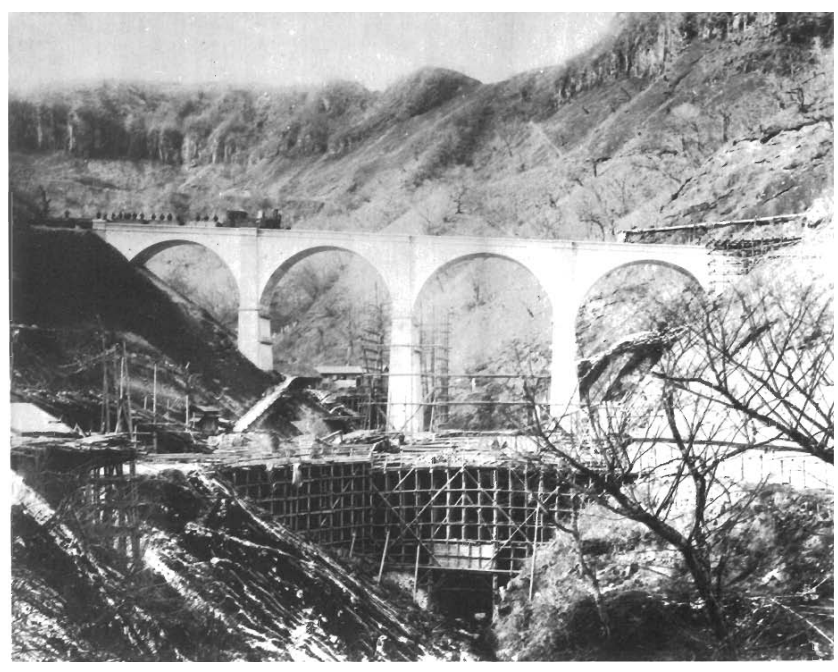

Source: Nihon Kokuyu Tetsudoshi 
Figure 9: Abandoned Line due to Steepness

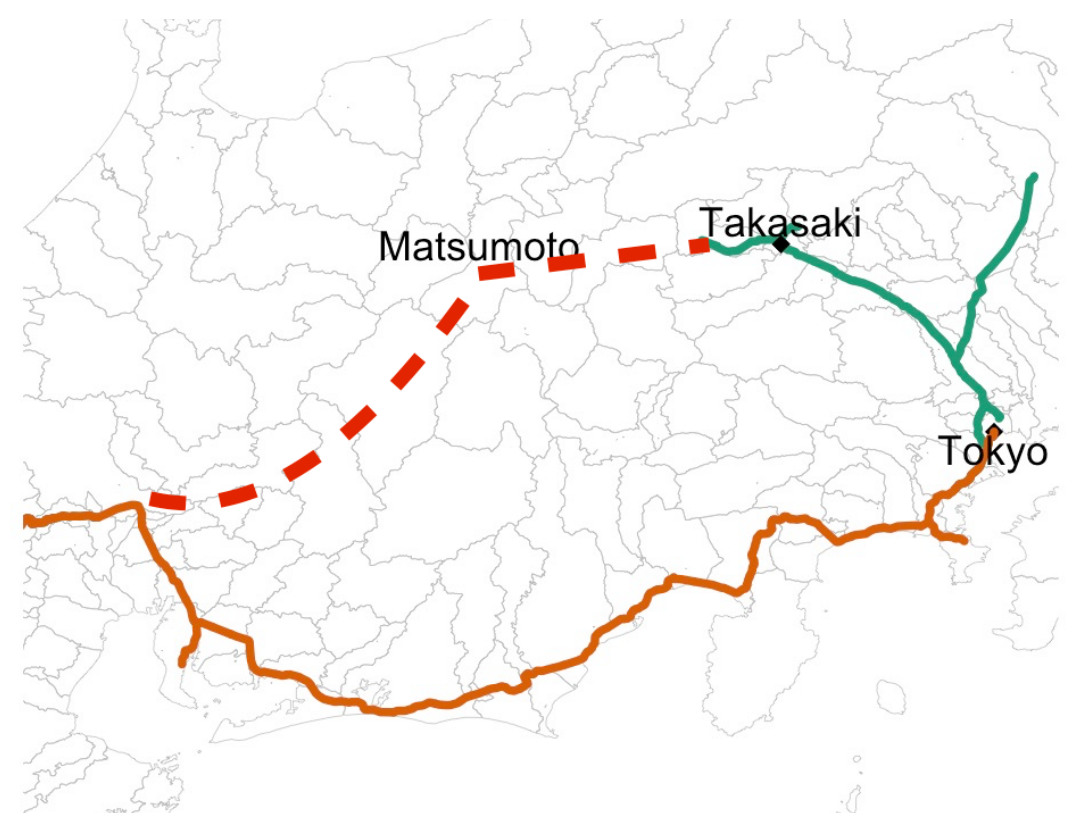

The green lines are those that existed in 1885 . The red dotted lines depict the original plan to connect Tokyo with the West, but was abandoned. The brown line depicts the line that subsequently connected Tokyo with the West. 
Figure 10: IV Conditional on Local Geography

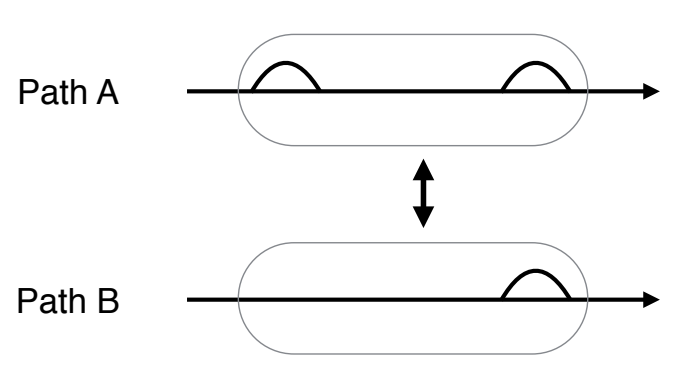

Unconditional IV

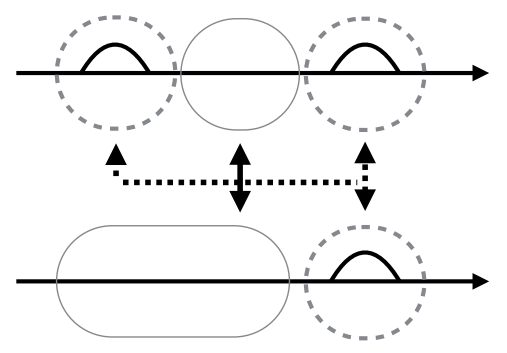

Conditional IV 
Figure 11: Regional Pattern of Steam Power Usage between 1888 and 1902

\section{Steam Power [HP] in 1888}

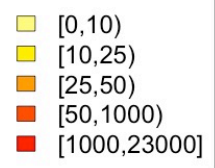

$\square \quad[10,25)$

$\square[25,50)$

- $[50,1000)$

- $[1000,23000]$

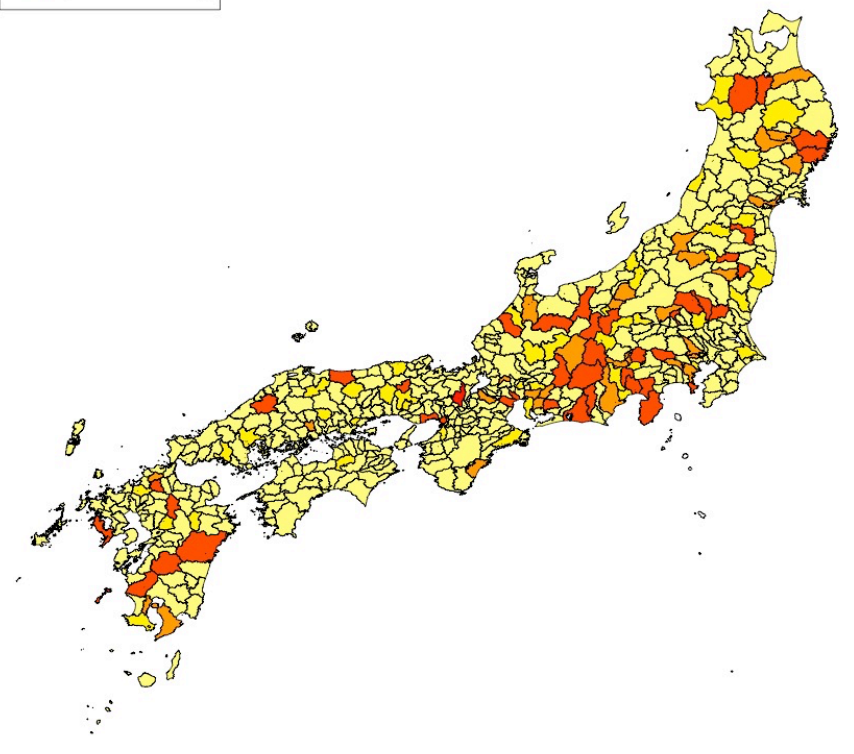

Steam Power [HP] in 1902

$\square \quad[0,10)$

$\square \quad[10,25)$

$\square \quad[25,50)$

$\square[50,1000)$

$\square[1000,23000]$

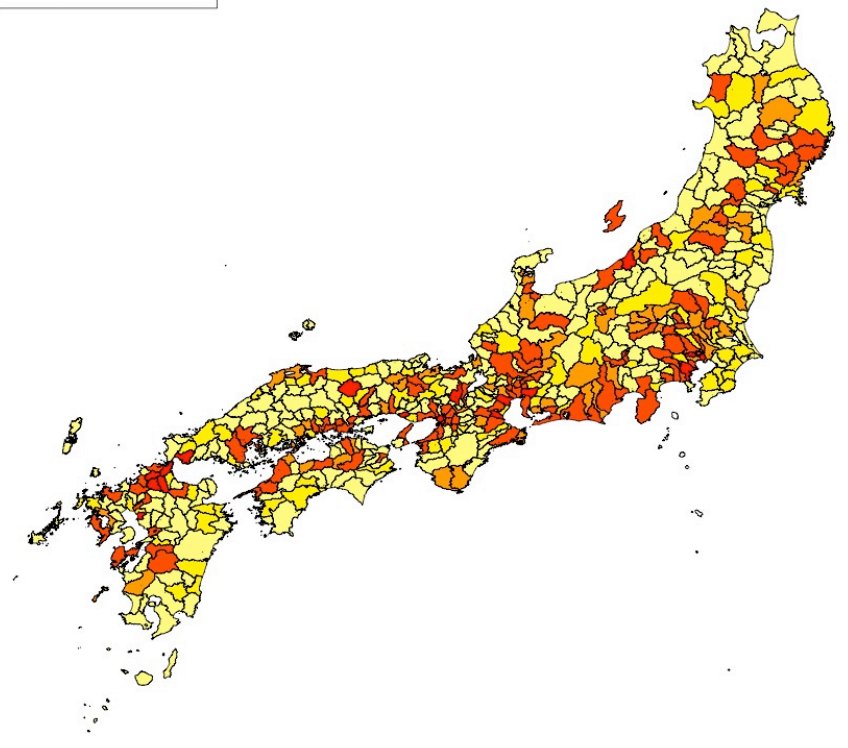


Figure 12: Technology in Factories and Primary Sector Employment Share in 1920

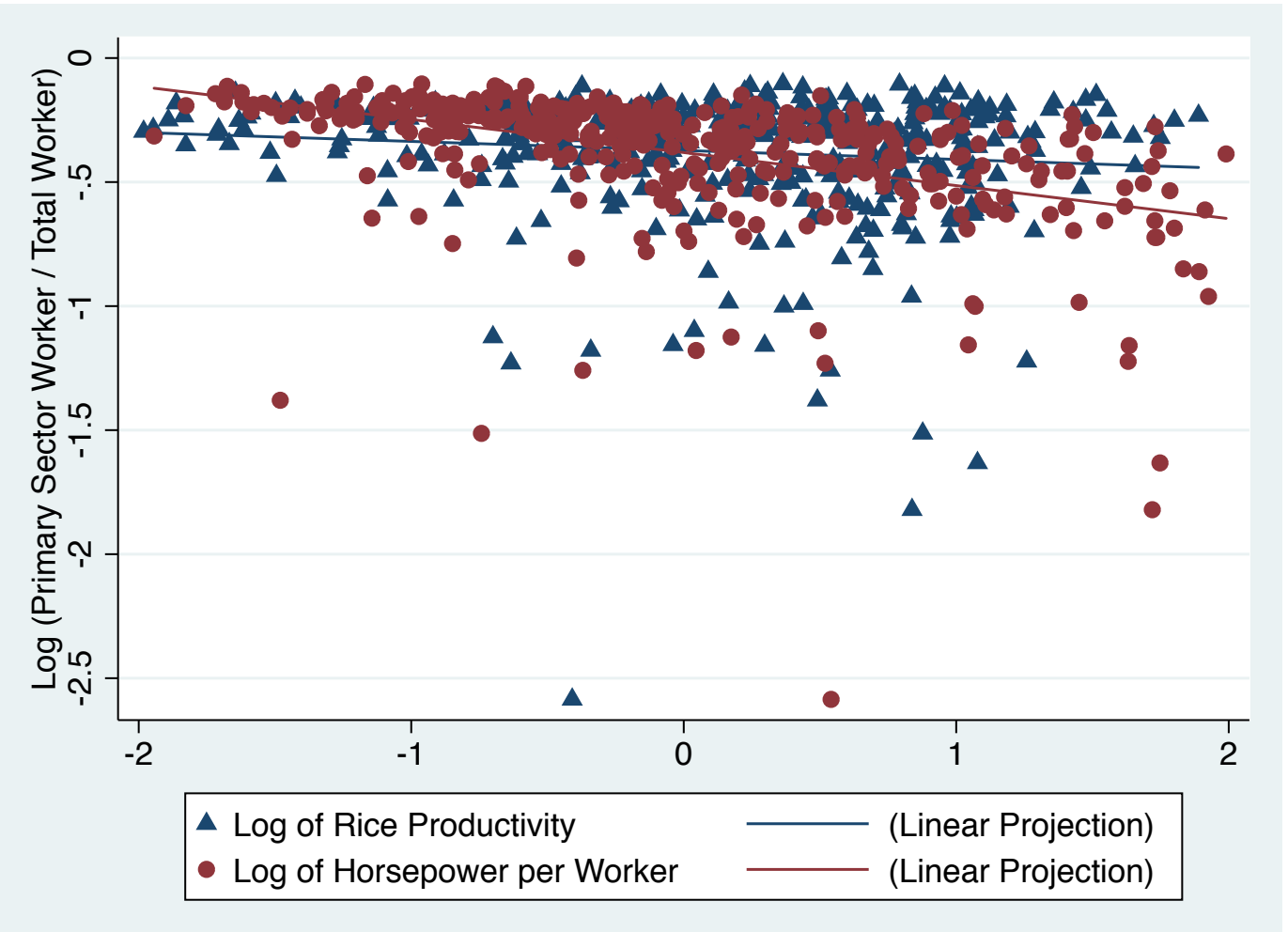

Notes and Source: Steam power data is from the 1919 Factory catalog and primary sector employment share data is from the 1920 census. To calculate the total workers, I add agriculture, fishery, manufacturing, and mining industry workers, to divide the steam power and primary sector workers (agriculture and fisheries). Section $\$ .2 .2$ provides more detailed information about the data source. Rice productivity is the mean of mesh-level crop suitability of rain-fed with low-fertilizer type rice, obtained from the FAO GAEZ data. I used the same sample in the main analysis. For readability, the figure excludes samples with more than two standard deviations from the mean in either of the $\mathrm{x}$ variables. 
Figure 13: Population Density and Primary Sector Employment Share in 1920

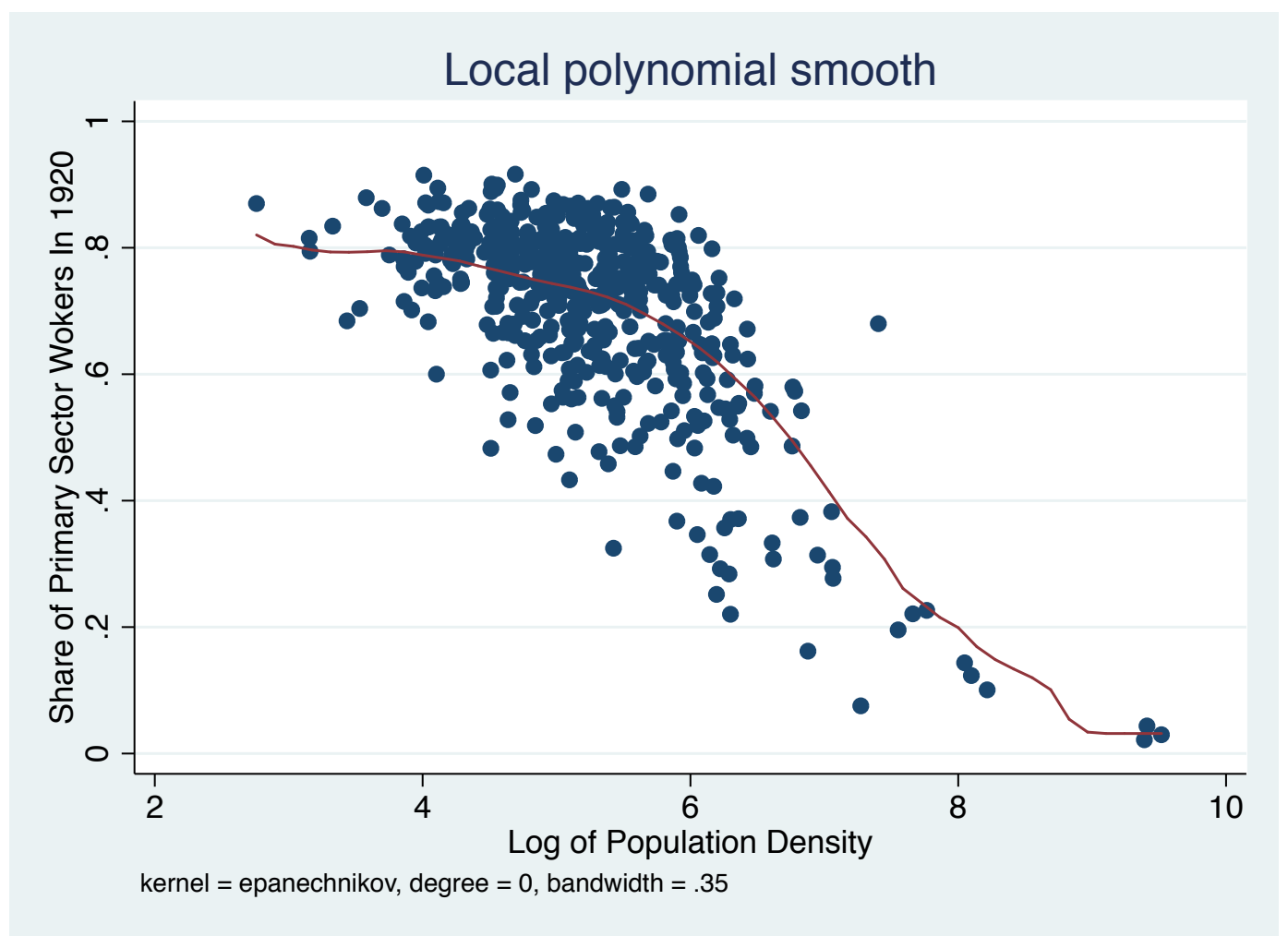

Notes and Source: Primary sector employment share is from the 1920 census. To calculate total workers, I add the agriculture, fishery, manufacturing, and mining industry workers, to divide the horsepower and primary sector workers (agriculture and fisheries). Section $\$ .2 .2$ provides more detailed information about the data source. Log of population density is also based on the Population Census. 
Figure 14: Traditional Roads Built before 1868

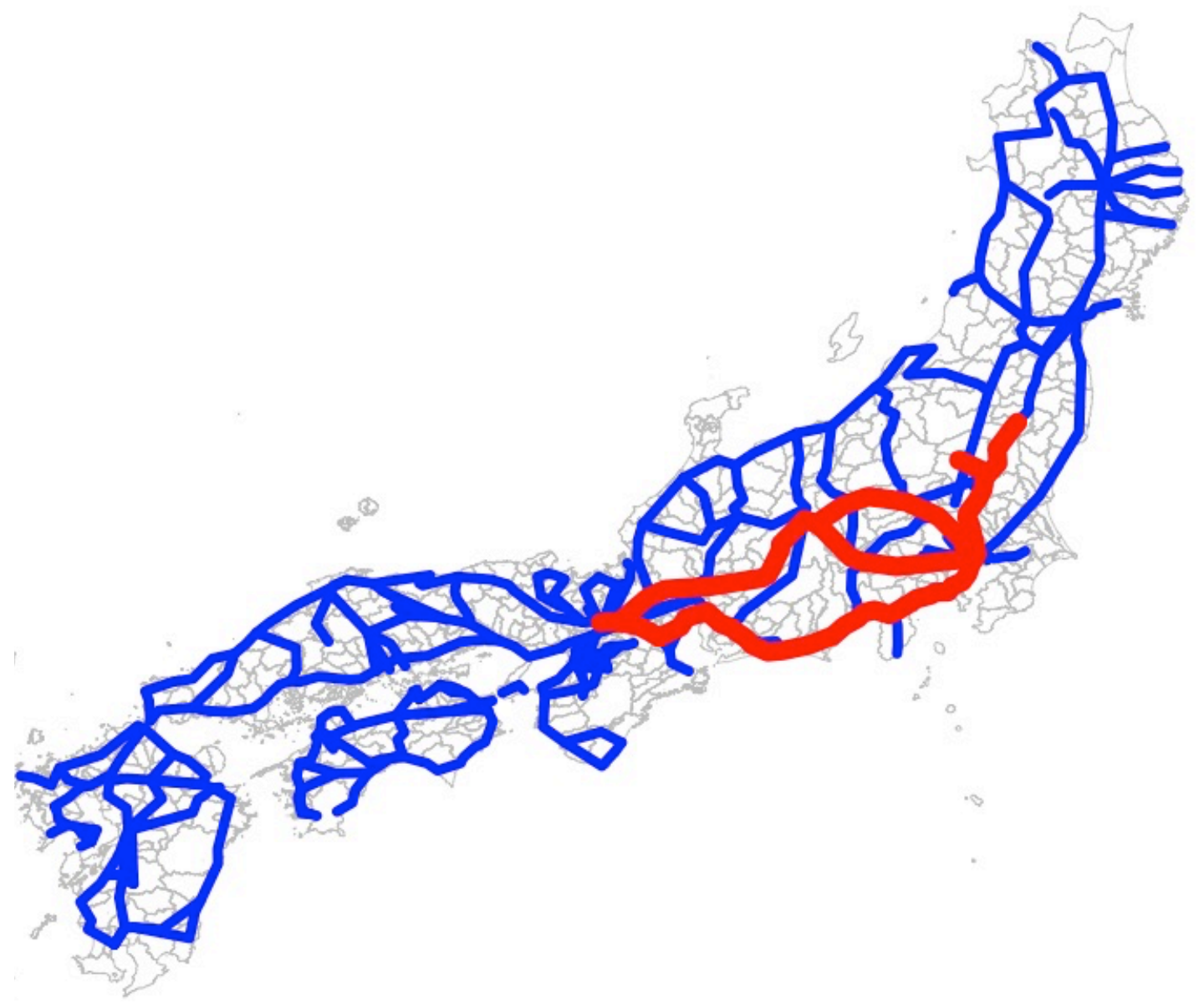

Source: Takeuchi ([2006). Blue lines indicate traditional roads and red lines are the Gokaido, five major roads directly controlled by Tokugawa Shogunate during the Edo period (1615-1868). 
Figure 15: Railroad Network in 1892 and Cost-Minimizing Paths

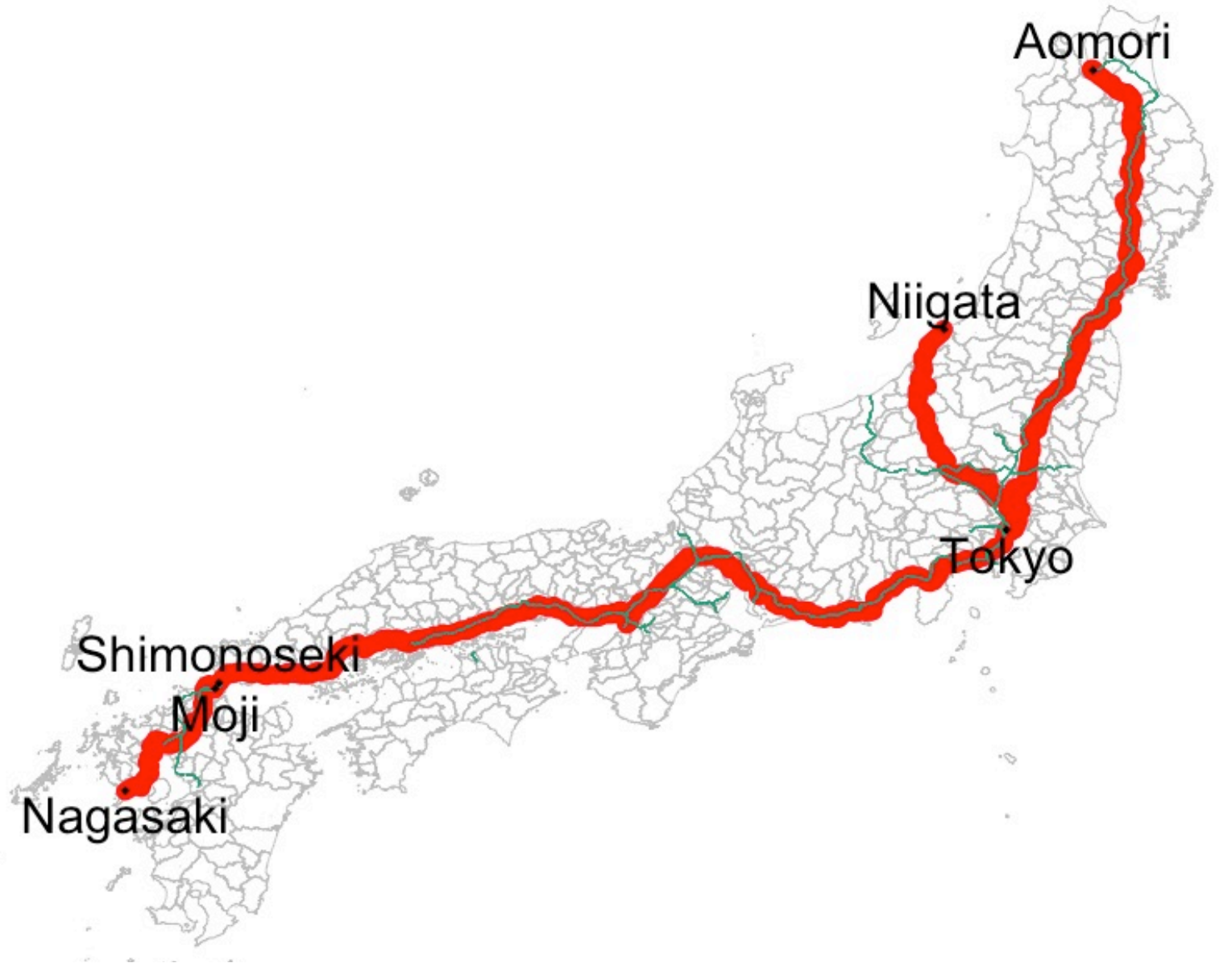

The green lines represent the railroad network in 1892 and the red lines depict the cost-minimizing path. 
Figure 16: Unconditional Relationship Between IV and Railroad Access

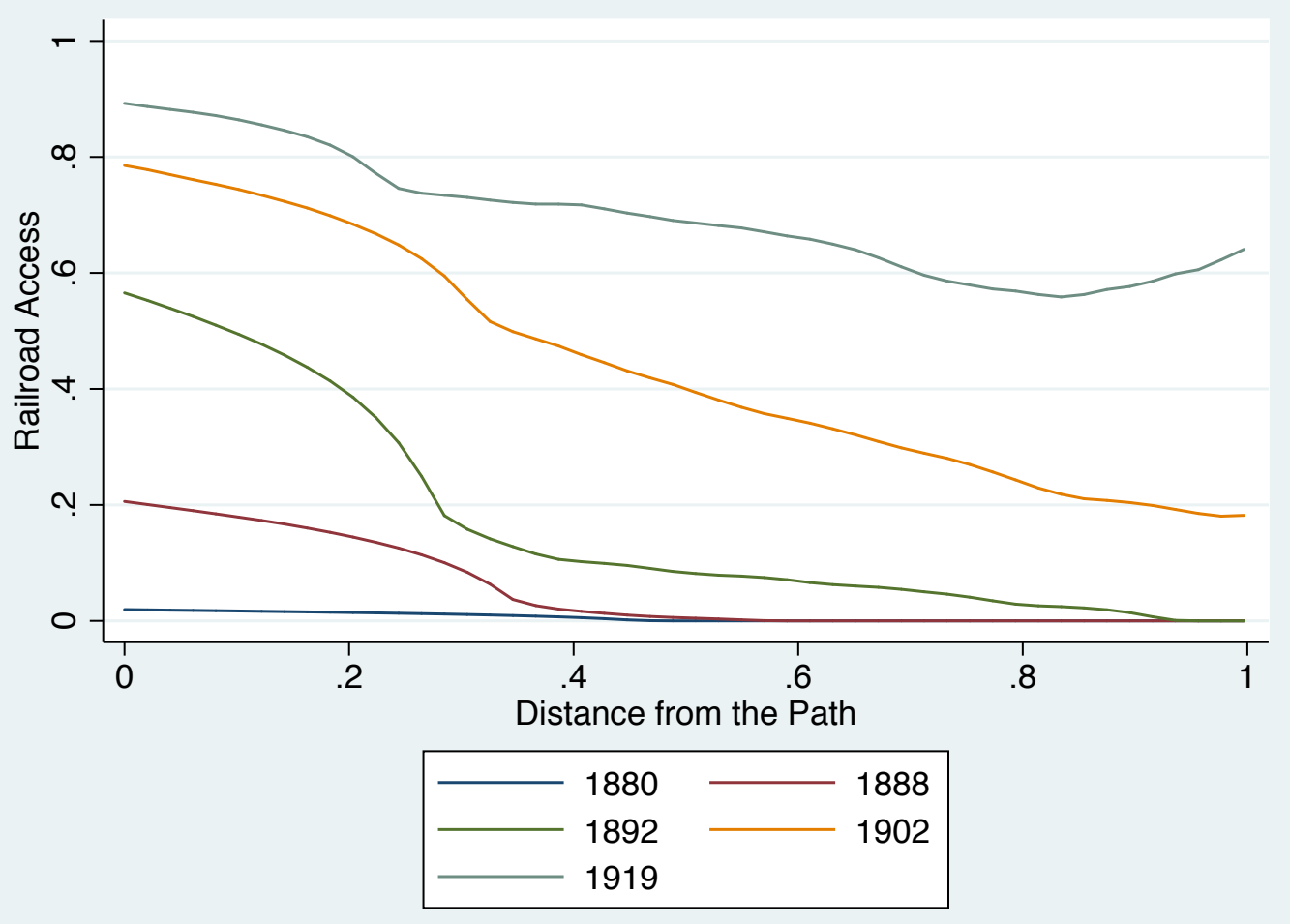


Table 1: Descriptive Statistics: County-level Data

\begin{tabular}{|c|c|c|c|c|}
\hline & mean & sd & $\min$ & $\max$ \\
\hline \multicolumn{5}{|l|}{ A. Initial Stage (1888) } \\
\hline \multicolumn{5}{|l|}{ 1. Factory Data } \\
\hline Steam Power [horsepower] & 12.23819 & 63.26859 & 0 & 878 \\
\hline Water Power [horsepower] & 2.057495 & 8.296014 & 0 & 80 \\
\hline $\mathrm{N}$ of Steam Power Engines & 1.209446 & 7.158499 & 0 & 110 \\
\hline $\mathrm{N}$ of Steam-Powered Factory & .5770021 & 2.47076 & 0 & 36 \\
\hline $\mathrm{N}$ of Workers in Steam-Powered Factory & 70.78029 & 353.955 & 0 & 4917 \\
\hline \multicolumn{5}{|l|}{ 2. Population Data } \\
\hline Population & 68918.87 & 36176.1 & 13246 & 255985 \\
\hline Population Density (/km2) & 243.554 & 665.8755 & 10.60407 & 9307.554 \\
\hline \multicolumn{5}{|l|}{ 3. Other Data } \\
\hline Railroad Access & .0616016 & .2406778 & 0 & 1 \\
\hline Traditional Road & .835729 & .3709023 & 0 & 1 \\
\hline Main Traditional Road & .137577 & .3448097 & 0 & 1 \\
\hline \multicolumn{5}{|l|}{ B. Middle Stage (1902 or 1903) } \\
\hline \multicolumn{5}{|l|}{ 1. Factory Data } \\
\hline Steam Power [horsepower] & 111.2263 & 425.1105 & 0 & 4107 \\
\hline Water Power [horsepower] & 22.26298 & 89.64335 & 0 & 971 \\
\hline $\mathrm{N}$ of Steam Power Engines & 5.924025 & 14.45172 & 0 & 155 \\
\hline $\mathrm{N}$ of Steam-Powered Factory & 3.478439 & 5.926075 & 0 & 57 \\
\hline $\mathrm{N}$ of Workers in Steam-Powered Factory & 336.6858 & 740.0709 & 0 & 7259 \\
\hline \multicolumn{5}{|l|}{ 2. Population Data } \\
\hline Population & 82831.4 & 45262.23 & 16275 & 439531 \\
\hline Population Density (/km2) & 293.3173 & 815.558 & 13.34293 & 11160.75 \\
\hline \multicolumn{5}{|l|}{ 3. Other Data } \\
\hline Railroad Access & .6406571 & .4803012 & 0 & 1 \\
\hline \multicolumn{5}{|l|}{ C. End Stage (1919 or 1920) } \\
\hline \multicolumn{5}{|l|}{ 1. Factory Data } \\
\hline Steam Power [horsepower] & 621.5736 & 2374.43 & 0 & 28129.5 \\
\hline $\mathrm{N}$ of Steam Power Engines & 11.7577 & 19.98597 & 0 & 205 \\
\hline N of Steam-Powered Factory & 8.172485 & 14.89963 & 0 & 186 \\
\hline Elec. or Gas Power [horsepower] & 1207.957 & 8418.538 & 0 & 174151.9 \\
\hline $\mathrm{N}$ of Elec. or Gas Power Engines & 46.79466 & 130.7535 & 0 & 1565 \\
\hline $\mathrm{N}$ of Elec. or Gas-Powered Factory & 20.05133 & 40.79971 & 0 & 396 \\
\hline $\mathrm{N}$ of Workers in Steam-Powered Factory & 1088.12 & 2318.957 & 0 & 26526 \\
\hline \multicolumn{5}{|l|}{ 2. Population Data } \\
\hline Population & 93255.39 & 76286.78 & 16364 & 1156973 \\
\hline Population Density (/km2) & 342.6105 & 1028.052 & 15.79187 & 13599.35 \\
\hline \multicolumn{5}{|l|}{ 3. Other Data } \\
\hline Railroad Access & .7926078 & .4058558 & 0 & 1 \\
\hline Observations & 487 & & & \\
\hline
\end{tabular}

Railroad Access and (Main) Traditional Road are binary variables, which take the value of one if there are railroads or (main) traditional roads, respectively. In Panels B and C, only Population Data uses the data in 1903 and 1920, respectively, and Factory Data and Other Data use data in 1902 and 1919, respectively. 54 
Table 2: Factory-level Data: Steam Power and Log of Workers or Share Capital

\begin{tabular}{|c|c|c|c|c|c|c|}
\hline & \multicolumn{3}{|c|}{ Log Workers } & \multicolumn{3}{|c|}{ Log Share Capital } \\
\hline & $(1)$ & (2) & (3) & (4) & (5) & $(6)$ \\
\hline \multirow[t]{2}{*}{ Steam-Powered Fty. } & $0.586^{* * *}$ & $0.593^{* * *}$ & $0.624^{* * *}$ & $0.787^{* * *}$ & $0.777^{* * *}$ & $0.731^{* * *}$ \\
\hline & $(0.0697)$ & $(0.0651)$ & $(0.0637)$ & $(0.101)$ & $(0.126)$ & $(0.121)$ \\
\hline County*Year FE & Yes & Yes & Yes & Yes & Yes & Yes \\
\hline County*Industry (First Digit) FE & No & Yes & No & No & Yes & No \\
\hline County*Industry (Second Digit) FE & No & No & Yes & No & No & Yes \\
\hline Observations & 7194 & 6299 & 6231 & 7427 & 6526 & 6478 \\
\hline
\end{tabular}

The county-level cluster robust SEs are in parentheses. $+p<0.1, * p<0.05$, ** $p<0.01$, *** $p<0.001$. Steam-Powered Fty. takes one if the factory is using steam power engines. Industries are classified into Chemical, Machines, Tobacco, Gas and Electricity, Spinning and Weaving, Metal, Mining, Food, and Miscellaneous as the first digit. There are 39 subcategories in the second digit. 
Table 3: Factory-level Data: Steam Power and Log of Labor Productivity

\begin{tabular}{|c|c|c|c|c|c|c|}
\hline \multirow{3}{*}{ Panel A: Full Available Prefectures } & \multicolumn{6}{|c|}{ Log (Revenue / Labor) } \\
\hline & (1) & (2) & (3) & (4) & (5) & (6) \\
\hline & & & & & & \\
\hline & $\begin{array}{c}0.847^{* * *} \\
(0.187)\end{array}$ & $\begin{array}{c}1.233^{* * *} \\
(0.218)\end{array}$ & $\begin{array}{c}0.767^{* * *} \\
(0.196)\end{array}$ & $\begin{array}{c}0.221^{* *} \\
(0.0760)\end{array}$ & $\begin{array}{c}0.577^{* * *} \\
(0.108)\end{array}$ & $\begin{array}{l}0.410^{* *} \\
(0.143)\end{array}$ \\
\hline Log Share Capital/Workers & & & & $\begin{array}{l}0.538^{* * *} \\
(0.0620)\end{array}$ & $\begin{array}{l}0.504^{* * *} \\
(0.0771)\end{array}$ & $\begin{array}{l}0.427^{* * *} \\
(0.0843)\end{array}$ \\
\hline Panel B: Prefectures with Multiple Ye & & & & & & \\
\hline Steam-Powered Fty. & $\begin{array}{c}1.118^{* * *} \\
(0.205)\end{array}$ & $\begin{array}{c}1.235^{\text {*** }} \\
(0.248)\end{array}$ & $\begin{array}{c}0.778^{* * *} \\
(0.163)\end{array}$ & $\begin{array}{c}0.417^{* * *} \\
(0.108)\end{array}$ & $\begin{array}{l}0.652^{* * *} \\
(0.0933)\end{array}$ & $\begin{array}{c}0.497^{* * *} \\
(0.112)\end{array}$ \\
\hline Log Share Capital/Workers & & & & $\begin{array}{l}0.490^{* * *} \\
(0.0764)\end{array}$ & $\begin{array}{l}0.491^{* * *} \\
(0.0844)\end{array}$ & $\begin{array}{l}0.414^{* * *} \\
(0.0880)\end{array}$ \\
\hline Observations in Panel A & 960 & 807 & 786 & 934 & 782 & 761 \\
\hline Observations in Panel B & 724 & 724 & 724 & 724 & 724 & 724 \\
\hline County*Year FE & Yes & Yes & Yes & Yes & Yes & Yes \\
\hline County*Industry (First Digit) FE & No & Yes & No & No & Yes & No \\
\hline County*Industry (Second Digit) FE & No & No & Yes & No & No & Yes \\
\hline
\end{tabular}

The county-level cluster robust SEs are in parentheses. $+p<0.1, * p<0.05, * * p<0.01$, *** $p<0.001$. Steam-Powered Fty. takes one if the factory is using steam power engines. Panel A uses all the available sets of data, which uses the data in 1884-1893, while Panel B uses the data on prefectures only, which I can obtain for more than one time period. As a result, Panel B uses Osaka (1886-1888), Yamanashi (1885, 1887, 1888, and 1890), Hiroshima (1892-1893), Aichi (1886-1887), Shiga (18871888), Fukuoka (1887-1888), Nagasaki (1887-1890), and Tottori (1889-1891). See Table 2 for the description of industry groups. 
Table 4: Main Result: Effect of Railroad on Technology Adoption in 1888-1902

\begin{tabular}{lcccc}
\hline \hline & \multicolumn{4}{c}{ DID-IV } \\
\cline { 2 - 5 } Panel A: Steam Power [HP] & $(1)$ & $(2)$ & $(3)$ & $(4)$ \\
\hline Railroad (-1892) & & & & \\
& $299.0^{* *}$ & $304.3^{* *}$ & $256.3^{* *}$ & $255.5^{* *}$ \\
Panel B: Number of Steam Engines & $(102.0)$ & $(110.6)$ & $(89.07)$ & $(93.49)$ \\
\hline Railroad (-1892) & & & & \\
& $21.16^{* * *}$ & $20.59^{* *}$ & $19.11^{* * *}$ & $18.25^{* *}$ \\
County FE and Year FE & $(6.015)$ & $(6.526)$ & $(5.404)$ & $(5.766)$ \\
Sum of Slope * Year FE & Yes & Yes & Yes & Yes \\
Log Flat Area * Year FE & Yes & Yes & Yes & Yes \\
Log Area * Year FE & Yes & Yes & Yes & Yes \\
Distance to Coast* Year FE & Yes & Yes & Yes & Yes \\
Initial Population Density * Year FE & Yes & Yes & Yes & Yes \\
(Main) Traditional Road * Year FE & No & Yes & No & Yes \\
Dist. to Destinations * Year FE & No & No & No & Yes \\
\hline First_F & 41.52 & 38.15 & 40.91 & Yes \\
N & 956 & 956 & 956 & 956 \\
N_g & 487 & 487 & 487 & 487 \\
\hline \hline
\end{tabular}

$N$ shows the sample size and $N_{-} g$ shows the number of counties. The countylevel cluster robust SEs are in parentheses. $+p<0.1, * p<0.05$, $* * p<0.01$, $* * * p<0.001$. First $F$ shows the Kleibergen-Paap statistics to test for the weak instrument. I use the data in 1888 and 1902. 
Table 5: Falsification Test: IV and Population

\begin{tabular}{|c|c|c|c|c|}
\hline & \multicolumn{4}{|c|}{ Log Population } \\
\hline & \multicolumn{2}{|c|}{$1879-1880$} & \multicolumn{2}{|c|}{$1879-1882$} \\
\hline & $(1)$ & $(2)$ & (3) & (4) \\
\hline Distance from the Path $* 1879$ & $\begin{array}{c}0.00179 \\
(0.00169)\end{array}$ & $\begin{array}{c}0.00144 \\
(0.00165)\end{array}$ & $\begin{array}{c}0.0116 \\
(0.0210)\end{array}$ & $\begin{array}{c}0.0144 \\
(0.0205)\end{array}$ \\
\hline County FE and Year FE & Yes & Yes & Yes & Yes \\
\hline Sum of Slope $*$ Year FE & Yes & Yes & Yes & Yes \\
\hline Log Flat Area * Year FE & Yes & Yes & Yes & Yes \\
\hline Log Area $*$ Year FE & Yes & Yes & Yes & Yes \\
\hline Distance to Coast $*$ Year FE & Yes & Yes & Yes & Yes \\
\hline (Main) Traditional Road $*$ Year FE & No & Yes & No & Yes \\
\hline Initial Log Population * Year FE & No & Yes & No & Yes \\
\hline $\mathrm{N}$ & 956 & 956 & 956 & 956 \\
\hline N_g & 478 & 478 & 478 & 478 \\
\hline
\end{tabular}

$N$ shows the sample size and $N_{-} g$ shows the number of counties. The robust SEs in columns (1) and (2), and the county-level cluster robust SEs are in parentheses in columns (3) and (4). $+p<0.1, * p<0.05$, ** $p<0.01$, *** $p<0.001$. The sample size is different from that in other analyses because I adjusted the border change before 1884, and also excluded two outliers ( $\Delta$ Log Population in 1879-1880 was 0.65 and 0.7 while the 99 th percentile is 0.1 ) possibly due to measurement error. 
Table 6: Exclusion Restriction: Does the Path Increase Other Public Goods?

\begin{tabular}{|c|c|c|c|c|}
\hline & \multicolumn{2}{|c|}{ Public Expenditure } & \multicolumn{2}{|c|}{ Log Public Expenditure } \\
\hline & OLS & IV & OLS & IV \\
\hline & (1) & (2) & (3) & (4) \\
\hline Railroad County Prop (-1892) & $\begin{array}{c}-51740.7 \\
(123228.2)\end{array}$ & $\begin{array}{c}80865.5 \\
(208140.6)\end{array}$ & $\begin{array}{l}-0.388 \\
(0.239)\end{array}$ & $\begin{array}{l}-0.216 \\
(0.527)\end{array}$ \\
\hline County FE and Year FE & Yes & Yes & Yes & Yes \\
\hline Sum of Slope * Year FE & Yes & Yes & Yes & Yes \\
\hline Log Flat Area * Year FE & Yes & Yes & Yes & Yes \\
\hline Log Area $*$ Year FE & Yes & Yes & Yes & Yes \\
\hline Initial Population Density * Year FE & Yes & Yes & Yes & Yes \\
\hline Coastal $*$ Year FE & Yes & Yes & Yes & Yes \\
\hline (Main) Old Road * Year FE & Yes & Yes & Yes & Yes \\
\hline First_F & & 14.05 & & 14.09 \\
\hline $\mathrm{N}$ & 504 & 504 & 490 & 490 \\
\hline $\mathrm{N}_{-} \mathrm{g}$ & 36 & 36 & 36 & 36 \\
\hline
\end{tabular}

$N$ shows the sample size and $N_{-} g$ shows the number of prefectures. Prefecture-level cluster robust SEs are in parentheses. $+p<0.1, * p<0.05,{ }^{* *} p<0.01, * * * p<0.001$. First_F shows the Kleibergen-Paap statistics to test for the weak instrument. I use the data from 1889 to 1902. I excluded Tokyo, Osaka, Kyoto, Kanagawa, and Hyogo as outliers, but the qualitative results do not change by excluding them. Public Expenditure is in Yen and the mean of Public Expenditure of the sample in this analysis is 514, 013. 
Table 7: Heterogeneous Impact Analysis on Steam Power of Non-Mining Industry

\begin{tabular}{|c|c|c|c|c|c|c|}
\hline & \multicolumn{3}{|c|}{$1888-1891$} & \multicolumn{3}{|c|}{$1888-1902$} \\
\hline & (1) & (2) & (3) & (4) & $(5)$ & (6) \\
\hline \multirow[t]{2}{*}{ Railroad (-1892) } & 23.41 & $35.72^{+}$ & 20.94 & 83.39 & 83.96 & 62.50 \\
\hline & $(20.51)$ & $(21.63)$ & $(20.44)$ & $(58.56)$ & $(62.46)$ & $(65.61)$ \\
\hline \multirow[t]{2}{*}{ Railroad * Initial Population Density } & $44.77^{*}$ & 36.48 & $56.16^{*}$ & 129.6 & 148.6 & 120.6 \\
\hline & $(22.80)$ & $(22.21)$ & $(26.80)$ & $(84.53)$ & $(97.20)$ & $(79.43)$ \\
\hline \multirow[t]{2}{*}{ Railroad * Distance to Tokyo } & \multirow{2}{*}{\multicolumn{3}{|c|}{$\begin{array}{c}18.76 \\
(20.42)\end{array}$}} & \multirow{2}{*}{\multicolumn{3}{|c|}{$\begin{array}{l}-65.17 \\
(83.43)\end{array}$}} \\
\hline & & & & & & \\
\hline \multirow[t]{2}{*}{ Railroad $*$ Distance to Tokyo or Osaka } & & & 26.20 & & & -16.35 \\
\hline & & & $(19.21)$ & & & $(58.71)$ \\
\hline County FE and Year FE & Yes & Yes & Yes & Yes & Yes & Yes \\
\hline Sum of Slope $*$ Year FE & Yes & Yes & Yes & Yes & Yes & Yes \\
\hline Log Flat Area * Year FE & Yes & Yes & Yes & Yes & Yes & Yes \\
\hline Log Area $*$ Year FE & Yes & Yes & Yes & Yes & Yes & Yes \\
\hline Distance to Coast $*$ Year FE & Yes & Yes & Yes & Yes & Yes & Yes \\
\hline Initial Population Density * Year FE & Yes & Yes & Yes & Yes & Yes & Yes \\
\hline (Main) Traditional Road * Year FE & Yes & Yes & Yes & Yes & Yes & Yes \\
\hline Dist. to Tokyo $*$ Year FE & No & Yes & No & No & Yes & No \\
\hline Dist. to Tokyo or Osaka * Year FE & No & No & Yes & No & No & Yes \\
\hline First_F & 6.835 & 3.521 & 5.726 & 20.42 & 6.718 & 7.124 \\
\hline $\mathrm{N}$ & 1948 & 1948 & 1948 & 974 & 974 & 974 \\
\hline N_g & 487 & 487 & 487 & 487 & 487 & 487 \\
\hline
\end{tabular}

$N$ shows the sample size and $N_{-} g$ shows the number of counties. The county-level cluster robust SEs are in parentheses. $+p<0.1, * p<0.05, * * p<0.01$, *** $p<0.001$. First_F shows the Kleibergen-Paap statistics to test for the weak instrument. I used steam power in the non-mining industry, because the mining industry occupies the largest share in horsepower, but its location is quite sensitive to the natural resource location, which is far from Tokyo or Osaka, so the coefficient of the interaction term for distance will be misleading if we include this industry. Due to the low F-value in the first stage, I estimated the same model with LIML as well, but the results do not change qualitatively. 
Table 8: The Effect on Structural Change in 1920

\begin{tabular}{|c|c|c|c|c|c|c|}
\hline & \multicolumn{3}{|c|}{ Primary/Total (Worker) } & \multicolumn{3}{|c|}{ Industry/Total (Worker) } \\
\hline & (1) & (2) & (3) & (4) & (5) & (6) \\
\hline \multirow[t]{2}{*}{ Railroad Growth 1885-1892 } & $-0.0675^{+}$ & $-0.0632^{+}$ & -0.0640 & $0.0569^{+}$ & $0.0529^{+}$ & 0.0544 \\
\hline & $(0.0409)$ & $(0.0369)$ & $(0.0410)$ & $(0.0324)$ & $(0.0303)$ & $(0.0342)$ \\
\hline Initial Agri. Worker / Population & Yes & Yes & Yes & Yes & Yes & Yes \\
\hline Sum of Slope & Yes & Yes & Yes & Yes & Yes & Yes \\
\hline Log Flat Area & Yes & Yes & Yes & Yes & Yes & Yes \\
\hline Log Area & Yes & Yes & Yes & Yes & Yes & Yes \\
\hline Distance to Coast & Yes & Yes & Yes & Yes & Yes & Yes \\
\hline Initial Population Density & No & Yes & Yes & No & Yes & Yes \\
\hline Traditional Road & No & Yes & Yes & No & Yes & Yes \\
\hline Main Traditional Road & No & No & Yes & No & No & Yes \\
\hline First_F & 62.57 & 62.26 & 55.75 & 62.57 & 62.26 & 55.75 \\
\hline $\mathrm{N}$ & 400 & 400 & 400 & 400 & 400 & 400 \\
\hline
\end{tabular}

Robust SEs are in parentheses. $+p<0.1{ }^{*} p<0.05, * * p<0.01$, *** $p<0.001$. $N$ shows the sample size. Initial Agri Worker/Population is calculated as agricultural workers divided by population in 1885. Agricultural workers' data is obtained from Huken Tokeisho, and I used the earliest available data from 1884 to 1886 for each. Since this information is missing for some prefectures, 87 counties were dropped from the main results. Note that the mining industry is accounted in the industry sector. 
Table 9: The Effect on Urbanization in 1885-1903, 1920

\begin{tabular}{|c|c|c|c|c|}
\hline & \multicolumn{4}{|c|}{$\Delta$ L Log of Population Density } \\
\hline & \multicolumn{2}{|c|}{$1885-1903$} & \multicolumn{2}{|c|}{$1885-1920$} \\
\hline & (1) & (2) & (3) & $(4)$ \\
\hline \multirow[t]{2}{*}{ Railroad Growth 1885-1892 } & $0.0860^{* *}$ & $0.0788^{*}$ & $0.169^{*}$ & $0.141^{+}$ \\
\hline & $(0.0316)$ & $(0.0336)$ & $(0.0772)$ & $(0.0825)$ \\
\hline \multirow[t]{2}{*}{ Railroad Growth $1885-1892 *$ Initial Pop. Density } & $0.0531^{*}$ & $0.0513^{*}$ & $0.282^{* * *}$ & $0.275^{* * *}$ \\
\hline & $(0.0245)$ & $(0.0239)$ & $(0.0653)$ & $(0.0630)$ \\
\hline \multirow[t]{2}{*}{ Log Initial Population Density } & $-0.0720^{* * *}$ & $-0.0734^{* * *}$ & $-0.169^{* * *}$ & $-0.175^{* * *}$ \\
\hline & $(0.0117)$ & $(0.0118)$ & $(0.0304)$ & $(0.0310)$ \\
\hline Sum of Slope & Yes & Yes & Yes & Yes \\
\hline Log Flat Area & Yes & Yes & Yes & Yes \\
\hline Log Area & Yes & Yes & Yes & Yes \\
\hline Distance to Coast & Yes & Yes & Yes & Yes \\
\hline (Main) Traditional Road & No & Yes & No & Yes \\
\hline First_F & 36.21 & 33.93 & 36.21 & 33.93 \\
\hline $\mathrm{N}$ & 480 & 480 & 480 & 480 \\
\hline
\end{tabular}

$N$ shows the sample size. Robust SEs are in parentheses. $+p<0.1, * p<0.05, * * p<0.01$, $* * * p<0.001$. First_F shows the Kleibergen-Paap statistics to test for the weak instrument. The dependent variable is Log of Population Density ${ }_{1903}-$ Log of Population Density 1885 in columns (1) and (2) and Log of Population Density 1920 - Log of Population Density ${ }_{1885}$ in columns (3) and (4). I drop the counties whose log of population is more than 2.5 s.d. from the mean as outliers for this analysis. When I clustered the SEs at prefecture level, SEs for the interaction terms become .036, $.034, .106$, and .101 . 


\section{A Appendix}

\section{A.1 A Formal Model}

\section{A.1.1 Consumers}

Consumers have the following utility function over two types of goods, $x$ and $y$. $x$ is the composite of industrial goods, and $y$ represents agricultural goods. They have CES preference over a continuous variety of $x$.

$$
\begin{aligned}
& u=(1-\beta) \log y+\beta \log (x+\bar{x}) \\
& x=\left[\int_{0}^{N} x_{i}^{\alpha} d i\right]^{1 / \alpha}
\end{aligned}
$$

The elasticity of substitution across varieties is given by

$$
\sigma=\frac{1}{1-\alpha}>1
$$

As in the standard way, we can define $p_{x}$ as the aggregate price for aggregated goods $x$.

$$
p_{x}=\left[\int_{0}^{N} p_{i}^{1-\sigma} d i\right]^{1 / 1-\sigma}
$$

The budget constraint is

$$
p_{x} x+p_{y} y=E
$$

where $E$ is the total expenditure and wage is the numeraire.

Given these, we obtain the following equation from the FOCs with respect to $x$ and $y$,

$$
\frac{1-\beta}{\beta} p_{x}(x+\bar{x})+p_{x} x=E \Longrightarrow x=\frac{E}{p_{x}} \beta-(1-\beta) \bar{x}
$$


and the demand for each variety $i$ is

$$
x_{i}=\left[\frac{E}{p_{x}} \beta-(1-\beta) \bar{x}\right]\left(\frac{p_{i}}{p_{x}}\right)^{-\sigma}
$$

Consumers can decide which sector to engage in by using one unit of time.

\section{A.1.2 Production}

The agricultural sector is competitive and has a production function, $A L_{y}^{\theta}$, where $A$ is its technology level, and I assume $0<\theta<1$. On the other hand, the industrial sector is characterized by monopolistic competition as in Bustos (2011). Firms are ex-ante homogeneous and have to pay a fixed cost $f_{e}$ for entry. They draw their productivity $\phi$ from the Pareto distribution $G(\phi)=1-\phi^{-k}$ during entry. There are two types of technology in this sector, low (old) and high (new). The total cost function of production is given by the following:

$$
\begin{aligned}
& T C_{l}(q, \gamma)=\left(f+\frac{q}{\phi}\right) \\
& T C_{h}(q, \gamma)=\left(f \eta+\frac{q}{\gamma \phi}\right)
\end{aligned}
$$

where $\eta>1$ and $\gamma>1$. Also, they can export to the other symmetric region by paying $f_{x}$ with the iceberg cost $\tau$. Given the demand $q(\omega)=E_{x} P^{\sigma-1} p(\omega)^{-\sigma}$, and pricing rules $p_{l}^{d}=w /(\rho \phi)$, we obtain the following profit equation,

$$
\begin{aligned}
& \pi_{l}^{d}(\phi)=\frac{1}{\sigma} E_{x}\left(p_{x} \rho\right)^{\sigma-1} \phi^{\sigma-1}-f \\
& \pi_{h}^{d}(\phi)=\frac{1}{\sigma} E_{x}\left(p_{x} \rho\right)^{\sigma-1}(\phi \gamma)^{\sigma-1}-f \eta \\
& \pi_{l}^{x}(\phi)=\left(1+\tau^{1-\sigma}\right) \frac{1}{\sigma} E_{x}\left(p_{x} \rho\right)^{\sigma-1} \phi^{\sigma-1}-\left(f+f_{x}\right) \\
& \pi_{h}^{x}(\phi)=\left(1+\tau^{1-\sigma}\right) \frac{1}{\sigma} E_{x}\left(p_{x} \rho\right)^{\sigma-1}(\phi \gamma)^{\sigma-1}-\left(f \eta+f_{x}\right)
\end{aligned}
$$

where $\pi$ 's subscript $l(h)$ denotes the case for choosing low (high) technology, and superscript $d(x)$ denotes the case for not exporting (exporting). 


\section{A.1.3 Equilibrium}

I can show the following by using the results of Bustos (20II).

Proposition 1. 1. (Sorting) Firms with $\phi<\phi^{*}$ will exit, firms with $\phi^{*}<\phi<\phi^{x}$ will neither export nor adopt high technology, those with $\phi^{x}<\phi<\phi^{h}$ will export and will not adopt high technology, and those with $\phi^{h}<\phi$ will export and adopt high technology.

2. (Technology adoption) $\phi^{h}$ is strictly decreasing in $\tau$.

3. (Industrial price index) $p_{x}$ is strictly increasing in $\tau$ if $\sigma$ is sufficiently large.

Proof. (1) and (2) are exactly the same as Bustos (20II), because the endogenous variables $E_{x}$ and $L_{x}$ do not affect these results. Considering (3), since $E_{x}$ is endogenous, it differs from the original result, which simply claims that $p_{x}$ is strictly increasing in $\tau$. Accordingly, following the same step as Bustos (20II), we obtain the following expression,

$$
p_{x} \propto \Delta^{-1 / k}\left(E \beta-(1-\beta) \bar{x} p_{x}\right)^{\frac{1}{1-\sigma}} \Longrightarrow p_{x}\left(E \beta-(1-\beta) \bar{x} p_{x}\right)^{\frac{1}{\sigma-1}} \propto \Delta^{-1 / k}
$$

where

$$
\Delta=1+\tau^{-k}\left(\frac{f_{x}}{f}\right)^{\frac{\sigma-1-k}{\sigma-1}}+\left(1+\tau^{1-\sigma}\right)^{\frac{k}{\sigma-1}}\left(\gamma^{\sigma-1}-1\right)^{\frac{k}{\sigma-1}}(\eta-1)^{\frac{\sigma-1-k}{\sigma-1}}
$$

We can see that the LHS is strictly increasing in $p_{x}$ as in partial equilibrium when $\sigma$ is sufficiently large, and if so this $p_{x}$ is increasing in $\tau$ because $\tau$ only strictly increases the RHS through $\Delta$, as shown in Bustos (20II) ${ }^{\square} \sigma$ is the key variable to predict whether the larger total expenditure on industrial goods is associated with the lower price more (or less) than proportionally. If $\sigma$ is high enough, the income effect generated by the drop in price of industrial goods will not dominate the partial equilibrium effect. I assume this fact throughout the paper. ${ }^{[3]}$

The proposition claims railroad access will increase $\phi_{h}$. Note that $1-G\left(\phi_{h}\right)$ is the probability of technology adoption at the firm level, and the number of high technology firms is given by $M\left(1-G\left(\phi_{h}\right)\right)$, which will be the aggregated-level variable, as will be observed in the data. ${ }^{\mathbb{1 0 4}}$ We can see the following result,

\footnotetext{
${ }^{72}$ I assume that $E \beta-(1-\beta) \bar{x} p_{x}$ is positive to exclude corner solutions and confirm that the LHS is strictly increasing in $p_{x}$.

${ }^{73}$ This also matches with the pattern in the aggregated data.

${ }^{74}$ The aggregated amount of new technology will also behave similarly.
} 
Proposition 2. 1. $M\left(1-G\left(\phi_{h}\right)\right)$ is strictly decreasing in $\tau$ when $\bar{x}$ is sufficiently large.

Proof. To see this, $\left(1-G\left(\phi_{h}\right)\right)$ is strictly decreasing in $\tau$ because $\phi_{h}$ is strictly increasing in $\tau$. Therefore, it suffices to show that $M$ is decreasing in $\tau$ to obtain the result. Note that $M$ is $\frac{E_{x}}{\bar{r}}$ where $\bar{r}$ is the average revenue. By taking the $\log$ of $M$,

$$
\frac{\partial \log M}{\partial \tau}=\frac{\frac{\partial E_{x}}{\partial \tau}}{E_{x}}-\frac{\frac{\partial \bar{r}}{\partial \tau}}{\bar{r}}
$$

Next, I will show that this is decreasing in $\bar{x}$. First, $-\frac{\frac{\partial \bar{r}}{\partial \tau}}{\tau}$ is constant about $\bar{x}$. Therefore, we can focus on $\frac{\frac{\partial E_{x}}{\partial \tau}}{E_{x}}$. If we take the derivative with respect to $\bar{x}$,

$$
\begin{aligned}
& \frac{\partial \log E_{x}}{\partial \bar{x} \partial \tau}=\frac{\partial \frac{-(1-\beta) p_{x}}{E_{x}}}{\partial \tau}=\frac{-(1-\beta)}{E_{x}} \frac{\partial p_{x}}{\partial \tau}+\frac{(1-\beta) p_{x}}{E_{x}^{2}} \frac{\partial E_{x}}{\partial \tau}=\frac{-(1-\beta)}{E_{x}} \frac{\partial p_{x}}{\partial \tau}+\frac{(1-\beta) p_{x}}{E_{x}^{2}}(\beta-1) \bar{x} \frac{\partial p_{x}}{\partial \tau} \\
& =\frac{\partial p_{x}}{\partial \tau} \frac{1}{E_{x}^{2}}\left(-(1-\beta)\left(E \beta-(1-\beta) p_{x} \bar{x}\right)-(1-\beta)^{2} p_{x} \bar{x}\right)=\frac{\partial p_{x}}{\partial \tau} \frac{1}{E_{x}^{2}}(-1+\beta) E \beta
\end{aligned}
$$

This is negative because $\beta<1$ and $\frac{\partial p_{x}}{\partial \tau}>0$. Note that when $\bar{x}=\frac{E \beta}{(1-\beta) p_{x}}-\epsilon \frac{\partial M}{\partial \tau}=-\frac{\frac{E \beta}{p_{x}}+\epsilon(1-\beta)}{\bar{r}} \frac{\partial p_{x}}{\partial \tau}-\frac{\epsilon}{r^{2}} \frac{\partial r}{\partial \tau}$, and when $\epsilon \rightarrow 0$, since $p_{x} \frac{\partial p_{x}}{\partial \tau}$ is now constant about $\epsilon$ and the other terms go to zero, it goes to a negative constant. Therefore, there must be a feasible $\bar{x}^{*}$ ensuring a positive demand for industrial goods such that when $\bar{x}^{*}<\bar{x}$, then $\frac{\partial M}{\partial \tau}<0$.

This result has an intuition; if there is no income effect, $M$ will decrease by railroad because the average revenue will increase. However, if there is an income effect, it also increases labor in the industrial sector and consequently increases the number of firms. Therefore, if this effect is strong enough, $M$ will also increase.

How does railroad access affect structural change? I can show the following using Proposition 1.

Proposition 3. 1. $L_{y}$ is strictly increasing in $\tau$.

2. $p_{x} / p_{y}$ is strictly increasing in $\tau$.

Proof. We only have to solve the price of agricultural goods and labor allocation in the two sectors. Agricultural wage is determined by the labor market condition in the agricultural sector. Like wage income, they can get $p_{y} \theta A L_{y}^{\theta-1}$ per labor. The total profit in the agricultural sector is $p_{y} A L_{y}^{\theta}-p_{y} L_{y} \theta A L_{y}^{\theta-1}$. Therefore, by engaging in the agricultural sector, workers can get $p_{y} A L_{y}^{\theta}$ as their aggregated income. Note that by competitive labor market conditions, workers can obtain the same amount of income if they engage in the industrial 
sector, so $p_{y} A L_{y}^{\theta-1}$ must be one. Given this, $L_{y}$ is pinned down by the following market clearing condition for agricultural goods.

$$
\begin{aligned}
& p_{y} A L_{y}^{\theta}=(1-\beta) L\left(1+\bar{x} p_{x}\right) \\
& \Longrightarrow L_{y}-(1-\beta) L-(1-\beta) \bar{x} p_{x}=0
\end{aligned}
$$

This is strictly increasing in $L_{y}$ ( $p_{x}$ is not a function of $L_{y}$, because $E_{x}=E \beta-p_{x}(1-\beta) \bar{x}$ and $p_{x}$ ), and strictly decreasing in $\tau$ (by increasing $p_{x}$ ). Therefore, $L_{y}$ is increasing in $\tau$.

To see the second part, we can consider the following equation,

$$
\frac{p_{x}}{p_{y}}=\frac{1-\beta}{\beta} \frac{y}{x+\bar{x}}
$$

$\tau$ increases $y$ through the increase in $L_{x}$ and decrease $x$ through an increase in $P_{x}$ because $x=E / P_{x}-(1-\beta) \bar{x}$ ( $E$ do not change by $\tau$ ).

\section{A.2 Data Description}

\section{A.2.1 Railroad-Related Data Sources}

Nihon Kokuyu Tetsudoshi (The History of Japan National Railroad) This is an official record of national railroad services published in 1972 by the Japan National Railway. It covers all national railroad lines constructed before 1945 and the private lines nationalized in 1906, and contains information such as the opening year of each section. Therefore, I can identify the opening year of the sections in the shapefile above using this source.

Nihon Tetsudoshi (History of Japanese Railroad) This is also a publication of Japanese railroad history published by the Ministry of Railroads in 1921. This document covers the lines not included in the Nihon Kokuyu Tetsudoshi and private lines that were not nationalized in 1906 or built after 1906 since this document has less readability than the Nihon Kokuyu Tetsudoshi.

\footnotetext{
${ }^{75}$ A very limited number of lines closed by 1950 , so I used a straight line to locations that the line connected.
} 
Nihon no Kaido Handbook (Handbook of Japanese Traditional Roads) Though there is no official records about traditional roads, this book collects local information and describes the routes of traditional roads with the names of the towns that the traditional roads passed through. I made straight lines to connect these towns to cities to represent the traditional road network. Straight lines will not be the exactly same with traditional roads, but I do not think that this will change the county-level variation or results because towns listed are fairly close to each other. The main roads, Gokaido, is also identified as five roads specified by Tokugawa Shogunate.

\section{A.2.2 Factory-Related Sources}

Noshomu Tokeihyo (Agriculture, Commerce and Manufacturing Statistics) I digitize these official statistics for factory-related variables. The Ministry of Agriculture and Commerce published this data, which covers the entire nation. This is the most comprehensive industrial statistics series covering Japan in the 1880s-1890s. It has a list of factories with addresses and the horsepower of each type of engine (water or steam) and number of workers. Unfortunately, the names in some cases were not recorded properly (there are some cases, such as "silk factory"), so I construct county-level panel data for the total number and horsepower of engines, and total number of factories and workers for each type of power source. The document also has product information, so I construct industry-level outcomes for further analysis. Only the publications in $1885,1888,1889,1890$, and 1891 have the list; for 1885 , many prefectures could not report their results to the central government, so use only data for 1888-1891 for the analysis.

Kojo Tsuran (Factory Catalog) This series is published after 1902 and has the same list of factories as above. I use its publication in 1902 and 1919, which is after the factory list in Noshomu Tokeihyo became unavailable. ${ }^{[7 / 8}$ The format is consistent with Noshomu Tokeihyo, which is enough to construct the same variables related to steam engines at the industry and county levels.

\footnotetext{
${ }^{76}$ They are Tokai-Do and Nakasen-Do from Tokyo to Kyoto, Oshu-Dochu from Tokyo to Shirakawa, Koshu-Kaido from Tokyo to Shimosuwa and Nikko-Kaido from Tokyo to Nikko.

${ }^{77}$ Again, I greatly appreciate Yutaka Arimoto, Kaori Ito, Asuka Imaizumi, Tetsuji Okazaki, Kentaro Nakajima, and Tomohiro Machikita, who digitized these catalog with support from the JSPS KAKENHI Grant-in-Aid for Scientific Research (B) 21330064, for providing me permission to use this data.

${ }^{78}$ This data set covers factories with more than nine workers. Because Noshomu Tokeihyo covers all factories using water or steam power, these series do not have consistent data. However, results do not change when excluding factories with less than 10 workers from the Noshomu Tokeihyo sample because these factories are not the majority and negligible at aggregation.
} 
Huken Tokeisho (Prefectural Statistics) These series of prefecture-level statistics were published by prefecture governments. They contain factory list, as in the publications above, and sometimes have more precise information such as revenue or share capital. This is useful to check the positive relationship between technology and productivity or firm size, which I presume throughout this paper. However, this publication has many missing volumes in addition to inconsistent data formats across time and prefectures, especially after the central government repealed its publication order. Prefecture governments were free to publish at will thereafter. Thus, I do not use this factory data for the main results, and keep it only to examine the relationship between steam power and labor productivity or firm size at the factory level. Again, it was impossible to match factory names to construct panel data.

\section{A.2.3 Population-Related Data Sources}

Nihon Teikoku Minseki Koguchi Hyo (Table of Registered Population) This is county-level population statistics published almost annually from 1879 to 1898 and between 1903 and 1908 under a different title (Nihon Teikoku Seitai Jinko Tokei). ${ }^{\text {I }}$ I use a digitized version for 1879, 1880, 1882 and 1885 from the Historical Regional Statistical Data, ${ }^{\mathbb{1 0}}$ and newly digitized the data in the other years, 1888-1891 and 1903.

Population Census In 1920, the government conducted its first census, which I digitized to obtain population data at the county level. ${ }^{-1}$ Additionally, this document reports the number of workers by sector, so that we can construct the share of workers in each sector in 1920.

Huken Tokeisho (Prefectural Statistics) I use this series again to obtain the number of agricultural workers around 1885. Because some prefecture did not publish in this year, I used 1884 or 1886 if available. Combined with the number of population in Nihon Teikoku Minseki Koguchi Hyo, I calculated the share of population working in the agricultural sector around 1885 to use it as control for regression analysis to see the impact on industrialization.

\footnotetext{
${ }^{79}$ There were two types of registered population, Honseki and Genju, which requires an explanation of Japanese registry system to illustrate the difference. Suppose you are born in a family county X; your name will be registered in your house account (Koseki) in county X. Honseki counts the population based on this information. Now, if you move from county X to county Y, you must submit a document to the county offices, which will then account for this movement to calculate the total population currently living in each county, which is the Genju population. For this reason, I choose Genju as the main variable, though for 1879, 1880, and 1882, there are no available data for Genju and I therefore use Honseki in these years only for the falsification test without connecting them with Genju data after 1885.

${ }^{80}$ http://giswin.geo.tsukuba.ac.jp/teacher/murayama/datalist_e.htm

${ }^{81}$ I regard this census population variable equivalent to the Genju population variable, since both attempt to measure the residential population.
} 


\section{A.3 Excluded Counties}

Some counties are excluded from all the analysis in this paper for various reasons. I have listed such counties in Table A.1. After excluding these, 487 counties remain in the main data set.

\section{A.4 Descriptive Statistics of Factory-Level Data in 1902}

Table A.2 shows the descriptive statistics of factory-level data in 1902 with industry-level breakdowns. Out of 3361 factories, 2097 adopted steam power. This adoption rate is higher for the mining industry, and lower for the domestic industry. The average steam power and number of workers at the steam-powered factory level varies. The mining industry factories are larger than the textile and domestic industries.

\section{A.5 Regression Analysis on the First Stage}

I confirmed the relationship in Figure 16 by a regression analysis, using the following specification:

Railroad Access $_{i t}=$ Distance from the Path $*$ Year FE + Local Geographical Controls $_{i} *$ Year FE

$\left(+\right.$ Local Other Controls $_{i} *$ Year FE) + Year FE + County FE $+e_{i t}$

where Railroad Access $i t$ is a binary variable, which takes one if county $i$ has railroad access in year $t$, Distance from the Path ${ }_{i}$ is the distance between the cost-minimizing path and county $i$, Local Geographical Controls $s_{i}$ are the time-invariant controls at county $i$, such as the sum of slopes, log of area, log of flat area, and distance from the coast. Table $A .3$ shows the results. Column (1) is the basic specification and column (2) has the additional non-pure geographical controls (interacted with Year FE), Local other Controls the population density in $1885^{\mathbb{1 8 2}}$ and the existence of traditional roads. The result shows that the instruments are working as expected such that the Distance from the Path has significantly negative coefficients. The magnitude of coefficients show that until 1898 there is monotonic growth of railroad access in counties close to the path, and in 1902 and 1903, the prioritized counties continued to have advantage in railroad access through a backlash that had already started.

\footnotetext{
${ }^{82} 1885$ is not the year before construction started so there may be concern about bad control, but most construction started after 1885 , and the main results do not change by including this variable.
} 


\section{A.6 Other Factory-related Outcomes and Prefecture-level Control and Clustering}

Table A.5 shows the results for other factory-related variables. See the main text for the interpretation. Tat ble A.6 shows the result with prefecture-level control and clustering corresponding to Table A.5. The point estimates do not change dramatically from Table A.5, and the effect on steam power and the share of people working in steam-powered factories are still significant. The effect on population became insignificant,

suggesting high correlation in the error term of population within prefectures. However, when I analyze the heterogeneous impact analysis using the same specification as in Table 9 with prefecture-level control and clustering, I find a significant heterogeneous effect on the population growth between 1885 and 1920, although I do not discuss it in this paper for brevity. Overall, I think that prefecture-level control and clustering do not affect the implications of the main results.

\section{A.7 Additional Specification for Cost Function}

In the main result, I simply assume the following cost function when passing mesh $i$

$$
\text { Cost }_{i}=\text { Ave. } \text { Slope }_{i}
$$

, but for robustness check I tried additional specifications, which are

$$
\text { Cost }_{i}=1+\text { Ave. Slope }_{i}
$$

and

$$
\text { Cost }_{i}=\text { Ave.Slope }_{i} * \mathbf{1}\left[\text { Ave.Slope }_{i}>25 \text { per mill }\right] \text {. }
$$

Equation (A.5) is very similar to a functional form considered in Faber (2014). By adding a constant term, not only the slope, but also the moving cost in a totally flat area is now considered, and consequently, the slope is considered less important than in the main specification.

Equation (A.6) uses an indicator function to drop the slope information below 25 per mill. The motivation is that the Railroad Ministry set 25 per mill as the maximum slope for mountain areas (Nihon Kokuyu Tetsudo, 1997), mainly by the operative reason given the capacity of their locomotives. By having specifications, the cost-minimizing path could avoid steeper areas more than the main specification. 
Newly calculated paths and paths using the main specification are depicted in Figure A3]. They are quite similar, but there is one line where new specifications consistently diverge from the main specification. In this area, new cost-minimizing paths are along the coastline, which was not chosen as the main line in reality. This is because when they constructed the mainline to the north, there was already a line from Tokyo to Takasaki, which originally was constructed from Tokyo to the West. This route was abolished because the route to the West from Takasaki was too steep as explained in the original text, but they extended the line from Takasaki to reach the northern area, which is why the line in inland areas, and not the coastline, was chosen.

The result using these alternative cost functions is in Table A.7. Overall, the results in Panels B and $\mathrm{C}$ with alternative IVs show that the effect on steam power and engines, and the results do not change qualitatively. I also see the robustness of Table 8 and Table 9 by using these alternative cost specifications, and I find similar results, although I omit the results for brevity.

The effect on steam power, which is the main outcome of this paper, is lower in Panels B and C than in Panel A. To determine the reason, I compare industry-specific effects in Table A.7. The results show that the difference in the effect on steam power between the main result and the result with alternative IVs arises from the effect on the mining industry. The difference in the effect on total steam power is roughly $70-80$, and the difference in the effect on the mining industry's steam power is 60-70. This is because the location of the mining industry is sensitive to the location of natural resources and subtle differences in the specification for IV.

\section{A.8 Omitting Subsample}

For further robustness checks, I drop the subsample, which may bias my main results. I compare the result in column (1) of Table 4 with the results obtained by dropping four different regions, Shikoku island, the western part of Honshu island, Gifu prefecture, and the counties that had already gained railroad access in 1885. The reasons for this selection are the following. First, Shikoku island does not have any destinations as in Figure 15. I dropped the western part of Honshu island, because the original statement by Nihon Tetsudo did not include Shimonoseki as its destination, and only noted Kyoto as a destination. As I explained in the main text, Shimonoseki was a quite natural selection as a final destination since it is the gateway to Kyushu island, but the inclusion may cause some bias in the main results. I excluded all the prefectures on the possible routes from Kyoto to Shimonoseki. Gifu prefecture is by a concern of a consistent unit of 
measurement throughout my sample period, because in this prefecture there were many changes in counties at the village level, thereby rendering it difficult to construct a truly consistent unit of measurement. Finally, for further robustness checks, I excluded counties that had already gained railroad access in 1888 or counties that had no steam power in 1888. Table A.10 shows the results. Each column shows the result omitting the subsamples, but the results are fairly robust. Only the result without the western part of Honshu island shows different estimates, but this may be because the construction of the line to Shimonoseki was not finished by 1892. Also, we observe a significant effect in column (6), which implies that the effect in the main result is partly coming from the adoption in counties without any steam power in 1888 .

\section{A.9 Long-term Effects}

As shown in Figure W, after the 1900s, a less prioritized county far from the cost-minimizing path started to get railroad access, and by 1920, the advantage of prioritized county had almost disappeared. Now, I analyze the following reduced form model to see the time series pattern between distance to the path and outcome;

$$
\begin{aligned}
\text { Outcome }_{i t}= & \text { Distance from the Path } \\
& * \text { Year FE }+ \text { Local Geographical Controls }_{i} * \text { Year FE } \\
& + \text { Year FE }+ \text { County FE }+u_{i t} \quad
\end{aligned}
$$

where Outcome $_{i t}$ is the log of population and steam power for 1902; and steam, electricity, or gas power for 1920 because by 1920 electricity and gas became popular as advanced technologies. The coefficients for Distance from the Path $_{i t} *$ Year FE are of main interest; if there is no persistent effect, then the coefficients of railroad access and outcomes will show a similar pattern. However, if there is persistence, then even after the coefficients of railroad access become zero, the coefficients for outcomes will not become zero or even diverge if the positive feedback effect is strong enough.

To show the whole pattern, I rely on a graphical presentation. Figure A4 shows the results, and each panel shows the coefficients of Distance from the Path ${ }_{i} *$ Year FE for each outcome. First, we can see that catching up in railroad access started around 1898, when the coefficient started to go back to zero. In line with this railroad effect, until 1902, less prioritized counties had lower horsepower and population as we saw in the previous regression results.

However, they fail to catch up in engine power as shown in the graph. Moreover, the gap was widened even though less prioritized counties did catch up in railroad access by 1920 . We can prove this relationship 
using data from the years 1888 and 1919 or 1920 by regression analysis in Table $A .21$. We cannot identify the exact mechanism and it is beyond the scope of this paper. However, this result has an implication for policy makers; the decision of where to build railroads first may create a huge gap in the long term. Redding et al. (2010) and Bleakley and Lin (2012) also found that the initial advantage in transportation makes long-term term through sunk cost or path dependence. For population, early adopters still have an advantage although its standard error has increased and is significant. This could be because of the higher variance in population growth, which we often observe under the process of urbanization. 
Figure A1: Aggregated Data on Foreign Trade

Openness
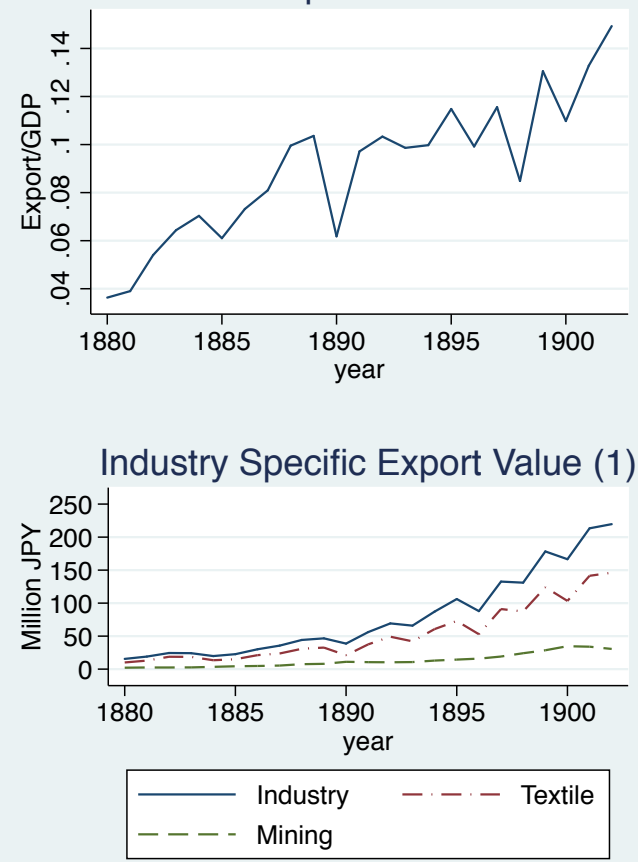

County Specific Export Value

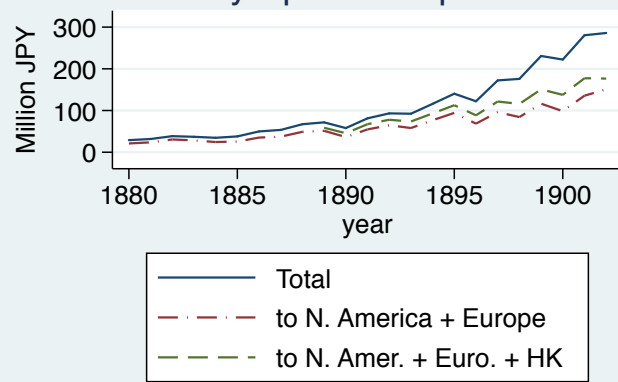

Industry Specific Export Value (2)

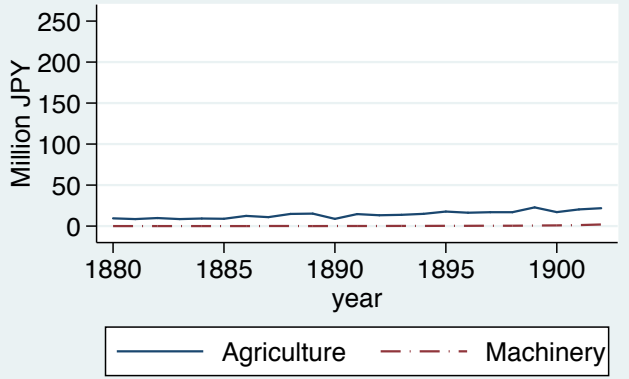

Source: Umemura et al. (1965). The unit for values is million Japanese Yen. 
Figure A2: Relative Price Data at Industry Group Level

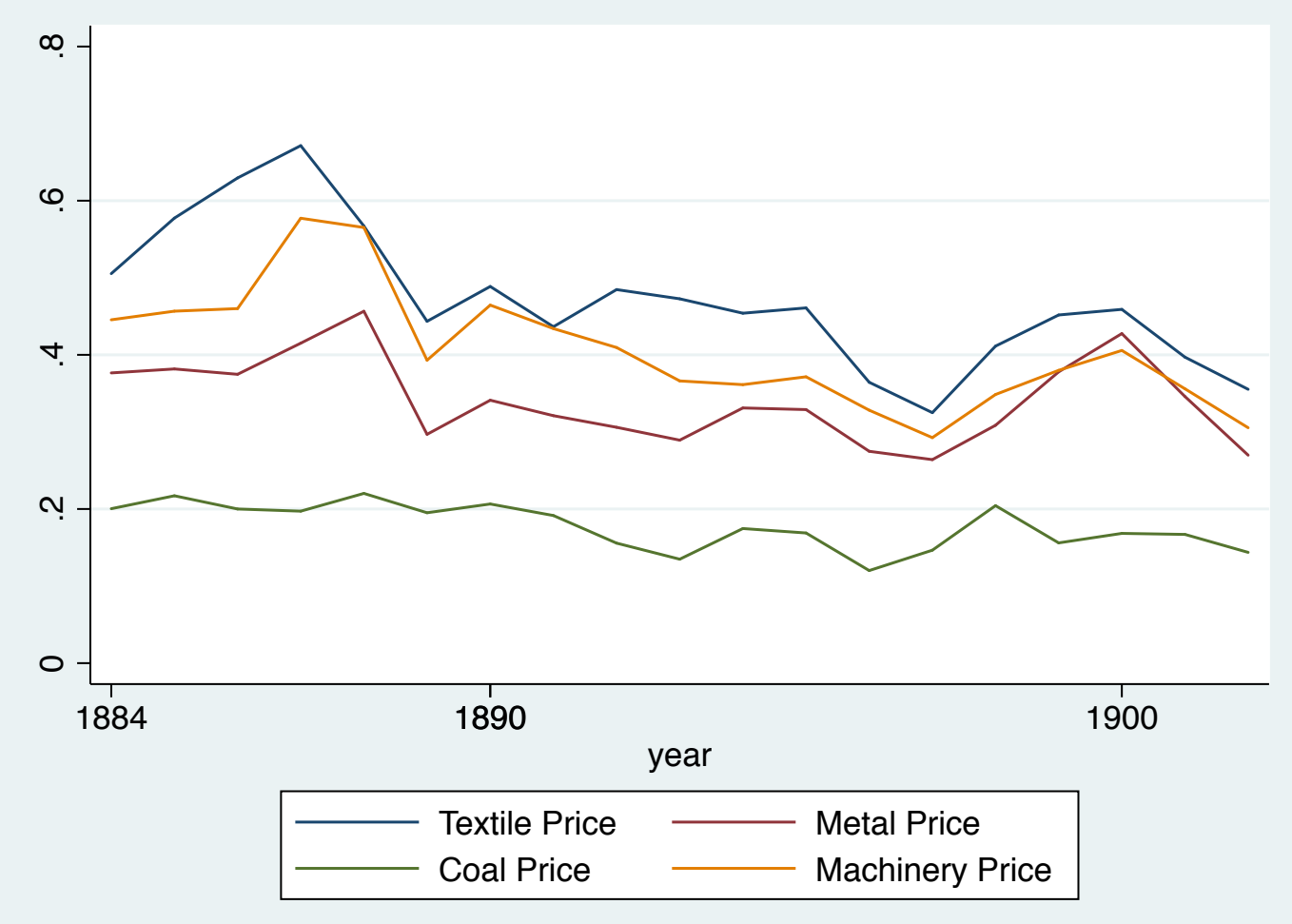

Source: Umemura et al. (1965). I obtained these figures by dividing price index of each industry group by price index of agricultural goods. 
Figure A3: IV with other Specifications

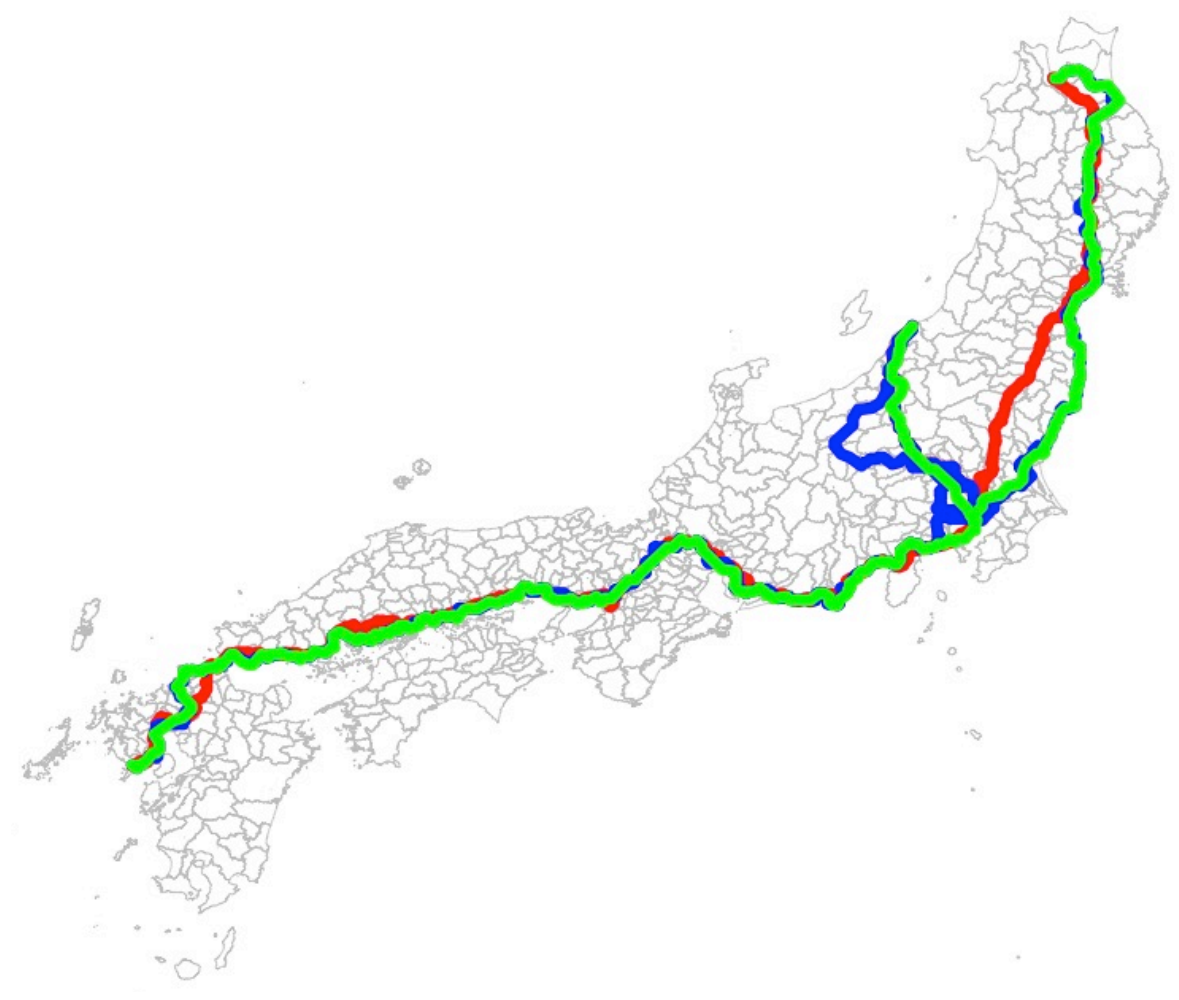


Figure A4: Reduced Form Effects in the Long Term
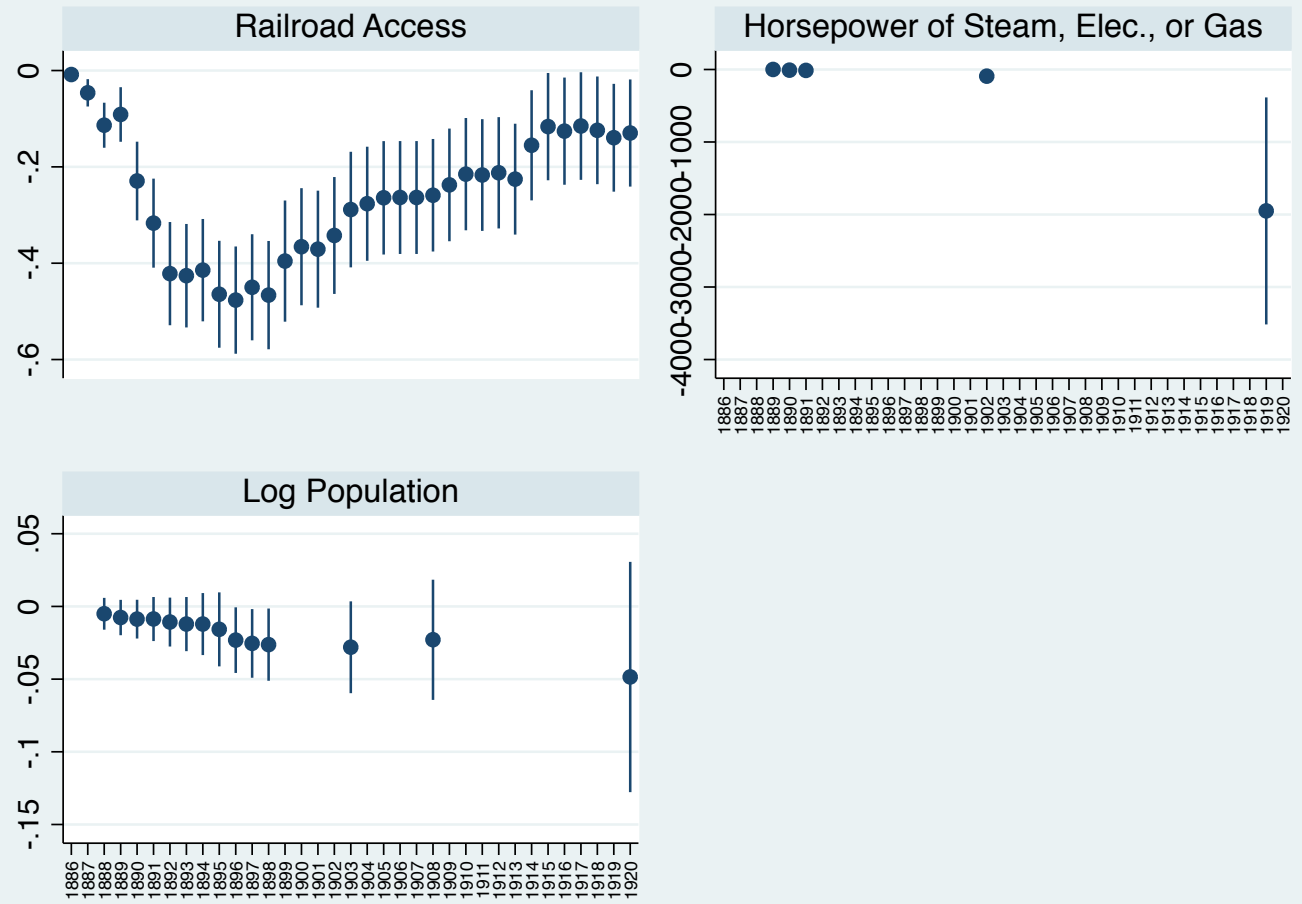
Table A.1: List of Excluded Counties

\begin{tabular}{ll} 
Reason & Counties (By the name in 1885) \\
\hline Domestic Colonies & All counties in Hokkaido and Okinawa \\
\hline Isolated Islands & $\begin{array}{l}\text { All counties in Tsushima-island, Nagasaki, } \\
\text { and Oki-island in Shimane }\end{array}$ \\
\hline Destinations & $\begin{array}{l}\text { All wards in Tokyo city, Toshima and } \\
\text { Higashi-Tama counties in Tokyo, Nakakam- } \\
\text { bara county and Nigata ward in Nigata, Kiku } \\
\text { county in Fukuoka, and Akamagaseki county } \\
\text { in Yamaguchi }\end{array}$ \\
\hline Foreign Ports and Outliers & $\begin{array}{l}\text { All wards in Osaka city in Osaka, Kobe ward } \\
\text { in Hyogo, and Yokohama ward in Kanagawa }\end{array}$
\end{tabular}


Table A.2: Descriptive Statistics: Factory-Level Data in 1902

\begin{tabular}{lcccc}
\hline \hline & Factories & Steam-Powered Factories & - Horsepower & - Workers \\
\hline Mining & & & & \\
mean & & .7254902 & 165.46 & 234.4414 \\
sd & 153 & .4477325 & 278.8256 & 736.0175 \\
sum & 111 & 18035.14 & 26023 \\
\hline Texitle & & & \\
mean & & .6239808 & 17.50445 & 96.80092 \\
sd & & .4845011 & 79.73636 & 213.9992 \\
sum & 2085 & 1301 & 20882.81 & 125938 \\
\hline Brewing and Printing & & & \\
mean & & .3636364 & 18.22857 & 100.1389 \\
sd & .4834938 & 29.10082 & 145.3673 \\
sum & 99 & 36 & 638 & 3605 \\
\hline Other & & & \\
mean & & 60.88207 & 63.72506 \\
sd & & .5991254 & 314.2329 & 124.1667 \\
sum & & .4904333 & 24657.24 & 26191 \\
\hline Total & 411 & & \\
mean & 686 & .614952 & 36.86176 & 97.77138 \\
sd & & 183.136 & 263.2247 \\
sum & & 1856872 & 64213.19 & 181757 \\
\hline \hline
\end{tabular}

The mining industry includes the mining, metal, and explosion materials (such as oil production) industries. The textile industry includes the cotton-spinning, weaving, and yarnmaking industries. 
Table A.3: IV and Railroad Expansion

\begin{tabular}{|c|c|c|}
\hline & $(1)$ & $(2)$ \\
\hline Distance from Path * 1889 & $\begin{array}{c}0.0223 \\
(0.0192)\end{array}$ & $\begin{array}{c}0.0163 \\
(0.0193)\end{array}$ \\
\hline Distance from Path * 1890 & $\begin{array}{l}-0.116^{* * *} \\
(0.0335)\end{array}$ & $\begin{array}{c}-0.0865^{* *} \\
(0.0290)\end{array}$ \\
\hline Distance from Path * 1891 & $\begin{array}{c}-0.203^{* * *} \\
(0.0392)\end{array}$ & $\begin{array}{l}-0.179^{* * *} \\
(0.0366)\end{array}$ \\
\hline Distance from Path * 1892 & $\begin{array}{c}-0.308^{* * *} \\
(0.0477)\end{array}$ & $\begin{array}{l}-0.288^{* * *} \\
(0.0467)\end{array}$ \\
\hline Distance from Path * 1893 & $\begin{array}{c}-0.312^{* * *} \\
(0.0478)\end{array}$ & $\begin{array}{l}-0.293^{* * *} \\
(0.0469)\end{array}$ \\
\hline Distance from Path * 1894 & $\begin{array}{c}-0.301^{* * *} \\
(0.0476)\end{array}$ & $\begin{array}{l}-0.281^{* * *} \\
(0.0471)\end{array}$ \\
\hline Distance from Path $* 1895$ & $\begin{array}{c}-0.351^{* * *} \\
(0.0500)\end{array}$ & $\begin{array}{l}-0.336^{* * *} \\
(0.0503)\end{array}$ \\
\hline Distance from Path * 1896 & $\begin{array}{c}-0.363^{* * *} \\
(0.0504)\end{array}$ & $\begin{array}{c}-0.349^{* * *} \\
(0.0512)\end{array}$ \\
\hline Distance from Path * 1897 & $\begin{array}{l}-0.336^{* * *} \\
(0.0505)\end{array}$ & $\begin{array}{l}-0.324^{* * *} \\
(0.0515)\end{array}$ \\
\hline Distance from Path $* 1898$ & $\begin{array}{c}-0.353^{* * *} \\
(0.0539)\end{array}$ & $\begin{array}{l}-0.352^{* * *} \\
(0.0541)\end{array}$ \\
\hline Distance from Path $* 1899$ & $\begin{array}{c}-0.282^{* * *} \\
(0.0609)\end{array}$ & $\begin{array}{l}-0.287^{* * *} \\
(0.0600)\end{array}$ \\
\hline Distance from Path $* 1900$ & $\begin{array}{c}-0.252^{* * *} \\
(0.0596)\end{array}$ & $\begin{array}{c}-0.261^{* * *} \\
(0.0594)\end{array}$ \\
\hline Distance from Path * 1901 & $\begin{array}{c}-0.257^{\text {*** }} \\
(0.0601)\end{array}$ & $\begin{array}{c}-0.262^{* * *} \\
(0.0599)\end{array}$ \\
\hline Distance from Path * 1902 & $\begin{array}{c}-0.229^{* * *} \\
(0.0608)\end{array}$ & $\begin{array}{l}-0.233^{* * *} \\
(0.0597)\end{array}$ \\
\hline Distance from Path * 1903 & $\begin{array}{l}-0.175^{* *} \\
(0.0614)\end{array}$ & $\begin{array}{l}-0.175^{* *} \\
(0.0602)\end{array}$ \\
\hline County FE and Year FE & Yes & Yes \\
\hline Sum of Slope * Year FE & Yes & Yes \\
\hline Log Flat Area * Year FE & Yes & Yes \\
\hline Log Area * Year FE & Yes & Yes \\
\hline Distance to Coast $*$ Year FE & Yes & Yes \\
\hline Initial Population Density * Year FE & No & Yes \\
\hline (Main) Traditional Road * Year FE & No & Yes \\
\hline $\mathrm{N}$ & 7792 & 7792 \\
\hline N_g & 487 & 487 \\
\hline
\end{tabular}

$N$ represents the sample size and $N_{-} g$ shows the number of counties. The county-level cluster robust SEs are in parentheses. $+p<0.1, * p<0.05, * * p<0.01$, *** $p<0.001$. I use data from 1888 to 1903. Distance from Path $i$ is the Euclidean distance $(100 \mathrm{~km})$ from the path to county $i$. 
Table A.4: Result without IV: Effect of Railroads, 1888-1902

\begin{tabular}{lccccc}
\hline \hline & \multicolumn{4}{c}{ DID } \\
\cline { 2 - 3 } & \multicolumn{2}{c}{ Steam Power [HP] } & & \multicolumn{2}{c}{ Steam Engines } \\
\cline { 2 - 3 } \cline { 5 - 6 } & $(1)$ & $(2)$ & & $(3)$ & $(4)$ \\
\hline Railroad (-1892) & 48.63 & 41.30 & & 1.942 & 1.274 \\
& $(52.42)$ & $(57.28)$ & & $(1.748)$ & $(1.812)$ \\
County FE and Year FE & Yes & Yes & & Yes & Yes \\
Sum of Slope * Year FE & Yes & Yes & & Yes & Yes \\
Log Flat Area * Year FE & Yes & Yes & & Yes & Yes \\
Log Area * Year FE & Yes & Yes & & Yes & Yes \\
Distance to Coast * Year FE & Yes & Yes & & Yes & Yes \\
Initial Population Density * Year FE & No & Yes & & No & Yes \\
(Main) Traditional Road * Year FE & No & Yes & & No & Yes \\
\hline $\mathrm{N}$ & 974 & 974 & & 974 & 974 \\
$\mathrm{~N}$ g & 487 & 487 & & 487 & 487 \\
\hline \hline
\end{tabular}

$N$ represents the sample size and $N_{-} g$ shows the number of counties. The county-level cluster robust SEs are in parentheses. $+p<0.1, * p<0.05$, ** $p<0.01$, *** $p<0.001$. I use data in 1888 and 1902 . 
Table A.5: Other Outcomes: Effect of Railroads, 1888-1902

\begin{tabular}{|c|c|c|c|c|}
\hline & \multicolumn{4}{|c|}{ DID-IV } \\
\hline & (1) & $(2)$ & (3) & $(4)$ \\
\hline \multicolumn{5}{|c|}{ Panel A: Number of Steam-Powered Factories } \\
\hline Railroad (-1892) & $\begin{array}{r}4.557 * \\
(2.220)\end{array}$ & $\begin{array}{c}2.589 \\
(2.134)\end{array}$ & $\begin{array}{c}5.150 * \\
(2.335)\end{array}$ & $\begin{array}{c}3.328 \\
(2.216)\end{array}$ \\
\hline \multicolumn{5}{|c|}{ Panel B: Number of Water-or-Steam-Powered Factories } \\
\hline Railroad (-1892) & $\begin{array}{c}-0.428 \\
(4.830)\end{array}$ & $\begin{array}{l}-3.249 \\
(5.113)\end{array}$ & $\begin{array}{c}-0.0876 \\
(4.841)\end{array}$ & $\begin{array}{l}-2.728 \\
(5.091)\end{array}$ \\
\hline \multicolumn{5}{|c|}{ Panel C: Workers in Steam-Powered Factory / Population } \\
\hline Railroad (-1892) & $\begin{array}{l}0.00767 * * \\
(0.00284)\end{array}$ & $\begin{array}{c}0.00616 * \\
(0.00270)\end{array}$ & $\begin{array}{l}0.00826 * * \\
(0.00297)\end{array}$ & $\begin{array}{r}0.00678 * \\
(0.00281)\end{array}$ \\
\hline \multicolumn{5}{|c|}{ Panel D: Workers in Factory / Population } \\
\hline Railroad (-1892) & $\begin{array}{c}0.00214 \\
(0.00397)\end{array}$ & $\begin{array}{l}0.000623 \\
(0.00424)\end{array}$ & $\begin{array}{c}0.00301 \\
(0.00401)\end{array}$ & $\begin{array}{c}0.00162 \\
(0.00428)\end{array}$ \\
\hline \multicolumn{5}{|l|}{ Panel E: Log Population } \\
\hline Railroad (-1892) & $\begin{array}{c}0.0748+ \\
(0.0385)\end{array}$ & $\begin{array}{c}0.0627 \\
(0.0402)\end{array}$ & $\begin{array}{c}0.0383 \\
(0.0381)\end{array}$ & $\begin{array}{c}0.0213 \\
(0.0397)\end{array}$ \\
\hline County FE and Year FE & Yes & Yes & Yes & Yes \\
\hline Sum of Slope * Year FE & Yes & Yes & Yes & Yes \\
\hline Log Flat Area * Year FE & Yes & Yes & Yes & Yes \\
\hline Log Area * Year FE & Yes & Yes & Yes & Yes \\
\hline Distance to Coast $*$ Year FE & Yes & Yes & Yes & Yes \\
\hline Initial Population Density * Year FE & No & Yes & No & Yes \\
\hline (Main) Traditional Road * Year FE & No & Yes & No & Yes \\
\hline Dist. to Destinations $*$ Year FE & No & No & Yes & Yes \\
\hline First_F & 41.52 & 38.15 & 40.91 & 36.48 \\
\hline $\mathrm{N}$ & 956 & 956 & 956 & 956 \\
\hline $\mathrm{N}_{-} \mathrm{g}$ & 487 & 487 & 487 & 487 \\
\hline
\end{tabular}

$N$ shows the sample size and $N_{-} g$ shows the number of counties. The county-level cluster robust SEs are in parentheses. $+p<0.1, * p<0.05$, ** $p<0.01$, *** $p<$ 0.001. First_F shows the Kleibergen-Paap statistics to test for the weak instrument. I use data in 1888 and 1902. 
Table A.6: Robustness Check with Prefecture-level Control and Clustering: Effect of Railroads, 1888-1902

\begin{tabular}{|c|c|c|c|c|}
\hline \multirow[b]{3}{*}{ Panel A: Steam Power [HP] } & \multicolumn{4}{|c|}{ DID-IV } \\
\hline & (1) & $(2)$ & $(3)$ & (4) \\
\hline & & & & \\
\hline Railroad (-1892) & $\begin{array}{c}288.1 * \\
(145.2)\end{array}$ & $\begin{array}{c}295.2+ \\
(154.8)\end{array}$ & $\begin{array}{c}253.8 * \\
(107.8)\end{array}$ & $\begin{array}{c}255.3 * \\
(110.8)\end{array}$ \\
\hline \multicolumn{5}{|l|}{ Panel B: Number of Steam Engines } \\
\hline Railroad (-1892) & $\begin{array}{c}20.86 * \\
(9.557)\end{array}$ & $\begin{array}{c}20.24 * \\
(9.725)\end{array}$ & $\begin{array}{c}19.06 * \\
(8.582)\end{array}$ & $\begin{array}{c}18.16 * \\
(8.408)\end{array}$ \\
\hline \multicolumn{5}{|c|}{ Panel C: Number of Steam-Powered Factories } \\
\hline Railroad (-1892) & $\begin{array}{c}3.946 \\
(2.676)\end{array}$ & $\begin{array}{c}1.873 \\
(2.550)\end{array}$ & $\begin{array}{c}4.759 \\
(3.058)\end{array}$ & $\begin{array}{c}2.777 \\
(2.763)\end{array}$ \\
\hline \multicolumn{5}{|c|}{ Panel D: Number of Water-or-Steam-Powered Factories } \\
\hline Railroad (-1892) & $\begin{array}{c}-0.957 \\
(7.900)\end{array}$ & $\begin{array}{c}-3.736 \\
(7.765)\end{array}$ & $\begin{array}{l}-0.443 \\
(7.957)\end{array}$ & $\begin{array}{c}-3.183 \\
(7.791)\end{array}$ \\
\hline \multicolumn{5}{|c|}{ Panel E: Workers in Steam-Powered Factory / Population } \\
\hline Railroad (-1892) & $\begin{array}{l}0.00706 * * \\
(0.00257)\end{array}$ & $\begin{array}{c}0.00527 * \\
(0.00240)\end{array}$ & $\begin{array}{c}0.00790 * * \\
(0.00263)\end{array}$ & $\begin{array}{c}0.00618 * * \\
(0.00233)\end{array}$ \\
\hline \multicolumn{5}{|c|}{ Panel F: Workers in Factory / Population } \\
\hline Railroad (-1892) & $\begin{array}{c}0.00175 \\
(0.00502)\end{array}$ & $\begin{array}{l}0.000130 \\
(0.00553)\end{array}$ & $\begin{array}{c}0.00273 \\
(0.00506)\end{array}$ & $\begin{array}{c}0.00120 \\
(0.00554)\end{array}$ \\
\hline \multicolumn{5}{|l|}{ Panel G: Log Population } \\
\hline Railroad (-1892) & $\begin{array}{c}0.0712 \\
(0.0742)\end{array}$ & $\begin{array}{c}0.0531 \\
(0.0736)\end{array}$ & $\begin{array}{c}0.0373 \\
(0.0750)\end{array}$ & $\begin{array}{c}0.0152 \\
(0.0750)\end{array}$ \\
\hline County FE and Year FE & Yes & Yes & Yes & Yes \\
\hline Sum of Slope $*$ Year FE & Yes & Yes & Yes & Yes \\
\hline Log Flat Area * Year FE & Yes & Yes & Yes & Yes \\
\hline Log Area * Year FE & Yes & Yes & Yes & Yes \\
\hline Distance to Coast $*$ Year FE & Yes & Yes & Yes & Yes \\
\hline Initial Population Density * Year FE & No & Yes & No & Yes \\
\hline (Main) Traditional Road * Year FE & No & Yes & No & Yes \\
\hline Dist. to Destinations & No & No & Yes & Yes \\
\hline Prefecture Geography * Year FE & Yes & Yes & Yes & Yes \\
\hline First_F & 12.11 & 12.19 & 12.98 & 12.70 \\
\hline $\mathrm{N}$ & 956 & 956 & 956 & 956 \\
\hline$N_{-} g$ & 487 & 487 & 487 & 487 \\
\hline
\end{tabular}

Prefecture-level cluster robust SEs are in parentheses. $+p<0.1, * p<0.05$, ** $p<0.01, * * * p<0.001$. First $F$ shows the Kleibergen-Paap statistics to test for the weak instrument. I use data in 1888 and 1902. Prefecture Geography includes the prefecture-level average slope and share of the flat area. 
Table A.7: Robustness Checks on the Main Results during 1888-1902: IV with Alternative Cost Function

\begin{tabular}{lcc}
\hline \hline & $\begin{array}{c}\text { Steam Power [HP] } \\
(1)\end{array}$ & $\begin{array}{c}\text { Steam Engines } \\
(2)\end{array}$ \\
Panel A: Main Specification & & \\
\hline Railroad (-1892) & $299.0^{* *}$ & $21.16^{* * *}$ \\
& $(102.0)$ & $(6.015)$ \\
Panel B: Adding Constant Term & & \\
\hline Railroad (-1892) & $228.0^{* *}$ & $15.15^{* * *}$ \\
& $(79.90)$ & $(4.600)$ \\
Panel C: Ignoring <25 per mill & & \\
\hline Railroad (-1892) & $219.3^{* *}$ & $10.87^{* *}$ \\
& $(74.80)$ & $(3.856)$ \\
County FE and Year FE & Yes & Yes \\
Sum of Slope * Year FE & Yes & Yes \\
Log Flat Area * Year FE & Yes & Yes \\
Log Area * Year FE & Yes & Yes \\
Distance to Coast * Year FE & Yes & Yes \\
\hline First_F for Panel A & 41.52 & 41.52 \\
First_F for Panel B & 56.48 & 56.48 \\
First_F for Panel C & 50.29 & 50.29 \\
N & 974 & 974 \\
N_g & 487 & 487 \\
\hline \hline
\end{tabular}

$N$ represents the sample size and $N_{-} g$ shows the number of counties. The county-level cluster robust SEs are in parentheses. + $p<0.1, * p<0.05, * * p<0.01, * * * p<0.001$. First $F$ shows the Kleibergen-Paap statistics to test for the weak instrument. I use data in 1888 and 1902. Panel A uses the main IV specification in equation (A.4), which are just replications of the results. Panels B and $C$ use an alternative specification for IV, equations (A.5) and (A.6). 
Table A.8: Robustness Checks on Industry-specific Effects during 1888-1902: IV with Alternative Cost Function

\begin{tabular}{lcccc}
\hline \hline & \multicolumn{4}{c}{ DID-IV } \\
\cline { 2 - 5 } & \multicolumn{4}{c}{ Steam Power [HP] } \\
\cline { 2 - 5 } & Total & Domestic & Mine & Textile \\
& $(1)$ & $(2)$ & $(3)$ & $(4)$ \\
Panel A: Main Specification & & & & \\
\hline Railroad (-1892) & $299.0^{* *}$ & $5.024^{+}$ & $184.9^{*}$ & 34.15 \\
& $(102.0)$ & $(2.606)$ & $(80.73)$ & $(35.29)$ \\
Panel B: Adding Constant Term & & & & \\
\hline Railroad (-1892) & $228.0^{* *}$ & $4.368^{+}$ & $124.3^{*}$ & 41.84 \\
& $(79.90)$ & $(2.247)$ & $(58.99)$ & $(31.82)$ \\
Panel C: Ignoring <25 per mill & & & & \\
\hline Railroad (-1892) & $219.3^{* *}$ & $4.146^{*}$ & $115.6^{*}$ & $50.09^{+}$ \\
& $(74.80)$ & $(2.081)$ & $(55.50)$ & $(26.37)$ \\
County FE and Year FE & Yes & Yes & Yes & Yes \\
Sum of Slope * Year FE & Yes & Yes & Yes & Yes \\
Log Flat Area * Year FE & Yes & Yes & Yes & Yes \\
Log Area * Year FE & Yes & Yes & Yes & Yes \\
Distance to Coast * Year FE & Yes & Yes & Yes & Yes \\
\hline First_F for Panel A & 41.52 & 41.52 & 41.52 & 41.52 \\
First_F for Panel B & 50.29 & 50.29 & 50.29 & 50.29 \\
First_F for Panel C & 56.48 & 56.48 & 56.48 & 56.48 \\
N & 974 & 974 & 974 & 974 \\
N_g & 487 & 487 & 487 & 487 \\
\hline \hline
\end{tabular}

$N$ shows the sample size and $N_{-} g$ shows the number of counties. The county-level cluster robust SEs are in parentheses. $+p<0.1, * p<$ $0.05, * * p<0.01, * * * p<0.001$. First_F shows the KleibergenPaap statistics to test for the weak instrument. I use data in 1888 and 1902. Panel A uses the main IV specification in equation (A.4), which are just replications of the results. Panels $B$ and $C$ use an alternative specification for IV, equations (A.5) and (A.6). 
Table A.9: Robustness Checks on the Main Results during 1888-1902: Main Result without Neighbor Counties of Destinations

\begin{tabular}{|c|c|c|c|c|}
\hline \multirow[b]{3}{*}{ Excluded Neighbors of Destinations } & \multicolumn{4}{|c|}{ DID-IV } \\
\hline & \multicolumn{2}{|c|}{ Steam Power [HP] } & \multicolumn{2}{|c|}{ Steam Engines } \\
\hline & $\begin{array}{c}15 \mathrm{~km} \\
\text { (1) }\end{array}$ & $\begin{array}{c}30 \mathrm{~km} \\
(2)\end{array}$ & $\begin{array}{c}15 \mathrm{~km} \\
\text { (3) }\end{array}$ & $\begin{array}{c}30 \mathrm{~km} \\
\text { (4) }\end{array}$ \\
\hline \multirow[t]{2}{*}{ Railroad (-1892) } & $258.8^{* *}$ & $226.0^{* *}$ & $17.99^{* *}$ & $16.98^{* *}$ \\
\hline & $(90.39)$ & $(84.56)$ & $(5.777)$ & $(5.704)$ \\
\hline County FE and Year FE & Yes & Yes & Yes & Yes \\
\hline Sum of Slope $*$ Year FE & Yes & Yes & Yes & Yes \\
\hline Log Flat Area * Year FE & Yes & Yes & Yes & Yes \\
\hline Log Area $*$ Year FE & Yes & Yes & Yes & Yes \\
\hline Distance to Coast $*$ Year FE & Yes & Yes & Yes & Yes \\
\hline Initial Population Density * Year FE & Yes & Yes & Yes & Yes \\
\hline (Main) Traditional Road * Year FE & Yes & Yes & Yes & Yes \\
\hline Distance to Destinations * Year FE & Yes & Yes & Yes & Yes \\
\hline First_F & 36.09 & 35.98 & 36.09 & 35.98 \\
\hline $\mathrm{N}$ & 964 & 934 & 964 & 934 \\
\hline N_g & 482 & 467 & 482 & 467 \\
\hline
\end{tabular}

$N$ shows the sample size and $N_{-} g$ shows the number of counties. The countylevel cluster robust SEs are in parentheses. $+p<0.1$, * $p<0.05$, ** $p<$ 0.01 , *** $p<0.001$. First $F$ shows the Kleibergen-Paap statistics to test for the weak instrument. I use data in 1888 and 1902. In column (1) and (3), I excluded the counties within $15 \mathrm{~km}$ from the destination counties. In column (2) and (4), I excluded the counties within $30 \mathrm{~km}$ from the destination counties. 
Table A.10: Omitting Subsample

\begin{tabular}{lcccccc}
\hline \hline & \multicolumn{7}{c}{ DID-IV } \\
\cline { 2 - 7 } & \multicolumn{7}{c}{ Steam Power [HP] } \\
\cline { 2 - 7 } & No Omit & Shikoku & West & Gifu & Rail in 1888 & Steam in 1888 \\
& $(1)$ & $(2)$ & $(3)$ & $(4)$ & $(5)$ & $(6)$ \\
\hline Railroad (-1892) & $304.3^{* *}$ & $300.7^{* *}$ & $436.8^{*}$ & $306.0^{* *}$ & $267.5^{* *}$ & $168.6^{+}$ \\
& $(110.6)$ & $(115.1)$ & $(170.9)$ & $(109.4)$ & $(99.14)$ & $(98.38)$ \\
County FE and Year FE & Yes & Yes & Yes & Yes & Yes & Yes \\
Sum of Slope * Year FE & Yes & Yes & Yes & Yes & Yes & Yes \\
Log Flat Area * Year FE & Yes & Yes & Yes & Yes & Yes & Yes \\
Log Area * Year FE & Yes & Yes & Yes & Yes & Yes & Yes \\
Distance to Coast* Year FE & Yes & Yes & Yes & Yes & Yes & Yes \\
Initial Population Density * Year FE & Yes & Yes & Yes & Yes & Yes & Yes \\
(Main) Traditional Road * Year FE & Yes & Yes & Yes & Yes & Yes & Yes \\
\hline First_F & 37.65 & 33.98 & 27.87 & 38.31 & 42.26 & 30.31 \\
$\mathrm{~N}$ & 974 & 906 & 770 & 948 & 856 & 786 \\
N_g & 487 & 453 & 385 & 474 & 428 & 393 \\
\hline \hline
\end{tabular}

$N$ shows the sample size and $N_{-} g$ shows the number of counties. The county-level cluster robust SEs are in parentheses. $+p<0.1, * p<0.05, * * p<0.01,{ }^{* * *} p<0.001$. First $F$ shows the Kleibergen-Paap statistics to test for the weak instrument. I use data in 1888 and 1902. Column (2), (3) and (4) omit Shikoku island, prefectures between Kyoto and Shimonoseki, and Gifu prefecture respectively. Column (5) omits the counties that had railroad access in 1888, and column (6) omits the counties that had steam power in 1888. 
Table A.11: Displacement Effect? Analysis by Different Treatment Variables

\begin{tabular}{|c|c|c|c|c|c|c|}
\hline & \multicolumn{3}{|c|}{ Steam Power [HP] } & \multicolumn{3}{|c|}{ Steam Engines } \\
\hline & (1) & (2) & (3) & $(4)$ & $(5)$ & $(6)$ \\
\hline Railroad (-1892) & $\begin{array}{l}299.0^{* *} \\
(102.0)\end{array}$ & & & $\begin{array}{c}21.16^{* * *} \\
(6.015)\end{array}$ & & \\
\hline Railroad (-1892) within $50 \mathrm{~km}$ & & $\begin{array}{l}275.3^{* *} \\
(96.73)\end{array}$ & & & $\begin{array}{l}19.48^{* *} \\
(6.016)\end{array}$ & \\
\hline Neighbor's Railroad within 50 km & & & $\begin{array}{c}57.10 \\
(198.6)\end{array}$ & & & $\begin{array}{l}-6.043 \\
(5.840)\end{array}$ \\
\hline County FE and Year FE & Yes & Yes & Yes & Yes & Yes & Yes \\
\hline Sum of Slope * Year FE & Yes & Yes & Yes & Yes & Yes & Yes \\
\hline Log Flat Area $*$ Year FE & Yes & Yes & Yes & Yes & Yes & Yes \\
\hline Log Area $*$ Year FE & Yes & Yes & Yes & Yes & Yes & Yes \\
\hline Distance to Coast $*$ Year FE & Yes & Yes & Yes & Yes & Yes & Yes \\
\hline $\mathrm{N}$ & 974 & 974 & 974 & 974 & 974 & 974 \\
\hline$N_{-} g$ & 487 & 487 & 487 & 487 & 487 & 487 \\
\hline First_F & 41.52 & 37.44 & 12.21 & 41.52 & 37.44 & 12.21 \\
\hline
\end{tabular}

$N$ shows the sample size and $N_{-} g$ shows the number of counties. The county-level cluster robust SEs are in parentheses. $+p<0.1, * p<0.05, * * p<0.01, * * * p<0.001$. I use data in 1892 and 1902. First_F shows the Kleibergen-Paap statistics to test for the weak instrument. Railroad

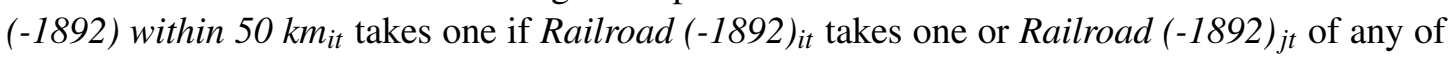
neighbor counties within $50 \mathrm{~km}$ takes one. This is instrumented by Distance to the Path ${ }_{i} *$ Year $F E_{t}$ as in the main specification. Out of counties which switch on Railroad (-1892) within 50 $\mathrm{km}_{i t}$ between 1888 and 1902, 29 per cent counties switch on due to their neighbor's access. Neighbor's Railroad within $50 \mathrm{~km}_{i t}$ takes one if Railroad (-1892) it takes zero but Railroad (1892) within $50 \mathrm{~km}_{i t}$ takes one. This is instrumented by Adjacent to the Path ${ }_{i} * Y_{i} a r F_{t}$ where Adjacent to the Path Pakes one if Distance to the Path $_{i}$ takes from $20 \mathrm{~km}$ to $50 \mathrm{~km}$. 
Table A.12: Displacement Effect? Analysis by using Shikoku Island

\begin{tabular}{|c|c|c|c|c|}
\hline \multirow[t]{3}{*}{ Compared with counties \# km from the Path: } & \multicolumn{2}{|c|}{$20 \mathrm{~km}-50 \mathrm{~km}$} & \multicolumn{2}{|c|}{$>50 \mathrm{~km}$} \\
\hline & Power & Engines & Power & Engines \\
\hline & (1) & (2) & (3) & (4) \\
\hline Shikoku Island * 1902 & $\begin{array}{l}-28.97 \\
(50.53)\end{array}$ & $\begin{array}{l}-1.587 \\
(1.076)\end{array}$ & $\begin{array}{c}45.88 \\
(31.28)\end{array}$ & $\begin{array}{c}-0.817 \\
(1.001)\end{array}$ \\
\hline County FE and Year FE & Yes & Yes & Yes & Yes \\
\hline Sum of Slope $*$ Year FE & Yes & Yes & Yes & Yes \\
\hline Log Flat Area * Year FE & Yes & Yes & Yes & Yes \\
\hline Log Area $*$ Year FE & Yes & Yes & Yes & Yes \\
\hline Distance to Coast * Year FE & Yes & Yes & Yes & Yes \\
\hline $\mathrm{N}$ & 274 & 274 & 242 & 242 \\
\hline N_g & 137 & 137 & 121 & 121 \\
\hline
\end{tabular}

$N$ shows the sample size and $N_{-} g$ shows the number of counties. The county-level cluster robust SEs are in parentheses. $+p<0.1, * p<0.05$, ** $p<0.01$, **** $p<0.001$. I use data in 1892 and 1902. First_F shows the Kleibergen-Paap statistics to test for the weak instrument. In column (1) and (2), I compared counties in Shikoku island with counties in other islands $20 \mathrm{~km}-50 \mathrm{~km}$ far from the path. In column (3) and (4), I compared counties in Shikoku island with counties in other islands more than $50 \mathrm{~km}$ far from the path. 
Table A.13: Short-Term Effects of Railroads, 1888-1891

\begin{tabular}{lccccc}
\hline \hline & DID & \multicolumn{4}{c}{ DID-IV } \\
\cline { 4 - 6 } & $(1)$ & $(2)$ & $(3)$ & $(4)$ & $(5)$ \\
Panel A: Steam Power [HP] & & & & & \\
\hline Railroad (-1892) & 8.062 & $63.07 *$ & $55.55+$ & $53.86 *$ & $43.18+$ \\
& $(6.809)$ & $(26.40)$ & $(29.76)$ & $(23.66)$ & $(25.80)$ \\
Panel B: Log Population & & & & & \\
\hline Railroad (-1892) & $0.00458+$ & 0.0112 & 0.00646 & 0.00467 & -0.00109 \\
& $(0.00235)$ & $(0.0118)$ & $(0.0129)$ & $(0.0116)$ & $(0.0126)$ \\
\hline County FE and Year FE & Yes & Yes & Yes & Yes & Yes \\
Sum of Slope * Year FE & Yes & Yes & Yes & Yes & Yes \\
Log Flat Area * Year FE & Yes & Yes & Yes & Yes & Yes \\
Log Area * Year FE & Yes & Yes & Yes & Yes & Yes \\
Distance to Coast* Year FE & Yes & Yes & Yes & Yes & Yes \\
Initial Population Density * Year FE & No & No & Yes & No & Yes \\
(Main) Traditional Road * Year FE & No & No & Yes & No & Yes \\
Dist. to Destinations & No & No & No & Yes & Yes \\
\hline First_F & & 13.34 & 12.69 & 13.84 & 12.69 \\
$N$ & 1948 & 1948 & 1948 & 1948 & 1948 \\
N_g & 487 & 487 & 487 & 487 & 487 \\
\hline \hline
\end{tabular}

$N$ shows the sample size and $N_{-} g$ shows the number of counties. The county-level cluster robust SEs are in parentheses. $+p<0.1,{ }^{*} p<0.05,{ }^{*} p<0.01,{ }^{* * *} p<0.001$. First_F shows the Kleibergen-Paap statistics to test for the weak instrument. I use data in 1888, 1889, 1890, and 1891. Because of the low F-values in the first stage, I estimated the same model with LIML or used the liner trend to be interacted with the distance to the path as an alternative instrument to increase the F-values as well, but the results do not change qualitatively. 
Table A.14: Heterogeneous Effect of Railroads on Log of Population, 1888-1891

\begin{tabular}{|c|c|c|c|c|}
\hline & \multicolumn{4}{|c|}{ Log Population } \\
\hline & \multirow{2}{*}{$\frac{\text { DID }}{(1)}$} & \multicolumn{3}{|c|}{ DID-IV } \\
\hline & & (2) & (3) & (4) \\
\hline \multirow[t]{2}{*}{ Railroad Access } & 0.00588 & 0.00181 & 0.000848 & -0.00400 \\
\hline & $(0.0115)$ & $(0.0131)$ & $(0.0113)$ & $(0.0129)$ \\
\hline \multirow[t]{2}{*}{ Railroad * Initial Log Pop Density } & -0.000447 & -0.000947 & 0.00361 & 0.00282 \\
\hline & $(0.0138)$ & $(0.0139)$ & $(0.0137)$ & $(0.0139)$ \\
\hline County FE and Year FE & Yes & Yes & Yes & Yes \\
\hline Sum of Slope $*$ Year FE & Yes & Yes & Yes & Yes \\
\hline Log Flat Area $*$ Year FE & Yes & Yes & Yes & Yes \\
\hline Log Area $*$ Year FE & Yes & Yes & Yes & Yes \\
\hline Distance to Coast $*$ Year FE & Yes & Yes & Yes & Yes \\
\hline Initial Population Density * Year FE & Yes & Yes & Yes & Yes \\
\hline (Main) Traditional Road * Year FE & No & Yes & No & Yes \\
\hline Dist. to Destinations & No & No & Yes & Yes \\
\hline First_F & 6.022 & 7.525 & 7.707 & 7.423 \\
\hline $\mathrm{N}$ & 1948 & 1948 & 1948 & 1948 \\
\hline$N_{-} g$ & 487 & 487 & 487 & 487 \\
\hline
\end{tabular}

$N$ shows the sample size and $N_{-} g$ shows the number of counties. The county-level cluster robust SEs are in parentheses. $+p<0.1, * p<0.05, * * p<0.01, * * * p<$ 0.001. First $F$ shows the Kleibergen-Paap statistics to test for the weak instrument. I use data in 1888, 1889, 1890, and 1891. Because of the low F-value in the first stage, I estimated the same model with LIML or used the liner trend to be interacted with the distance to the path as an alternative instrument to increase the F-values as well, but the results do not change qualitatively. 
Table A.15: Coal Price Channel?

\begin{tabular}{|c|c|c|c|c|}
\hline & \multicolumn{4}{|c|}{ Steam Power (Non-Mining) [HP] } \\
\hline & \multicolumn{2}{|c|}{$1888-1891$} & \multicolumn{2}{|c|}{ 1888-1902 } \\
\hline & (1) & $(2)$ & $(3)$ & $(4)$ \\
\hline \multirow[t]{2}{*}{ Railroad (-1892) } & $47.97^{+}$ & 27.76 & 92.83 & 70.14 \\
\hline & $(24.93)$ & $(27.23)$ & $(59.05)$ & (60.07) \\
\hline \multirow[t]{2}{*}{ Railroad $*$ Distance to Coal } & -2.623 & 15.38 & 33.61 & 116.9 \\
\hline & $(14.55)$ & $(24.15)$ & $(38.89)$ & $(90.06)$ \\
\hline \multirow[t]{2}{*}{ Railroad * Initial Population Density } & & 43.55 & & 213.5 \\
\hline & & $(35.93)$ & & $(165.6)$ \\
\hline County FE and Year FE & Yes & Yes & Yes & Yes \\
\hline Sum of Slope $*$ Year FE & Yes & Yes & Yes & Yes \\
\hline Log Flat Area * Year FE & Yes & Yes & Yes & Yes \\
\hline Log Area $*$ Year FE & Yes & Yes & Yes & Yes \\
\hline Distance to Coast $*$ Year FE & Yes & Yes & Yes & Yes \\
\hline Initial Population Density * Year FE & Yes & Yes & Yes & Yes \\
\hline (Main) Traditional Road * Year FE & Yes & Yes & Yes & Yes \\
\hline Dist. to coal $*$ Year FE & Yes & Yes & Yes & Yes \\
\hline First_F & 5.165 & 3.130 & 17.90 & 5.276 \\
\hline $\mathrm{N}$ & 1948 & 1948 & 974 & 974 \\
\hline$N_{-} g$ & 487 & 487 & 487 & 487 \\
\hline
\end{tabular}

$N$ shows the sample size and $N_{-} g$ shows the number of counties. The countylevel cluster robust SEs are in parentheses. $+p<0.1{ }^{*} p<0.05$, *** $p<0.01,{ }^{* * *} p<0.001$. First $F$ shows the Kleibergen-Paap statistics to test for the weak instrument. The dependent variable is steam power, excluding the mining industry. 
Table A.16: Information Channel? The Effect of Railroad on Expositions

\begin{tabular}{|c|c|c|c|c|}
\hline & \multicolumn{2}{|c|}{$\mathrm{N}$ of Expo } & \multicolumn{2}{|c|}{ Total Days of Expo } \\
\hline & OLS & IV & OLS & IV \\
\hline & $(1)$ & $(2)$ & $(3)$ & $(4)$ \\
\hline Railroad County Prop (-1892) & $\begin{array}{c}2.671 \\
(5.483)\end{array}$ & $\begin{array}{c}6.261 \\
(11.97)\end{array}$ & $\begin{array}{c}57.80 \\
(51.74)\end{array}$ & $\begin{array}{c}69.46 \\
(89.99)\end{array}$ \\
\hline County FE and Year FE & Yes & Yes & Yes & Yes \\
\hline Sum of Slope * Year FE & Yes & Yes & Yes & Yes \\
\hline Log Flat Area * Year FE & Yes & Yes & Yes & Yes \\
\hline Log Area * Year FE & Yes & Yes & Yes & Yes \\
\hline Initial Population Density * Year FE & Yes & Yes & Yes & Yes \\
\hline Coastal * Year FE & Yes & Yes & Yes & Yes \\
\hline (Main) Old Road * Year FE & Yes & Yes & Yes & Yes \\
\hline First_F & & 17.77 & & 17.77 \\
\hline $\mathrm{N}$ & 504 & 504 & 504 & 504 \\
\hline$N_{-} g$ & 36 & 36 & 36 & 36 \\
\hline
\end{tabular}

$N$ shows the sample size and $N_{-} g$ shows the number of prefectures. Prefecturelevel cluster robust SEs are in parentheses. $+p<0.1, * p<0.05$, ** $p<0.01$, $* * * p<0.001$. First $F$ shows the Kleibergen-Paap statistics to test for the weak instrument. I use the data from 1889 to 1902. I excluded Tokyo, Osaka, Kyoto, Kanagawa, and Hyogo as outliers, but the qualitative results do not change by excluding them. $N$ of Expos is the number of expositions and Total Days of Expos is the total days the expositions were open. 
Table A.17: Industry-specific Effects: The Effect of Railroads on Steam Power, 1888-1902

\begin{tabular}{lccc}
\hline \hline & $\begin{array}{c}\text { Domestic } \\
(1)\end{array}$ & $\begin{array}{c}\text { Mining } \\
(2)\end{array}$ & $\begin{array}{c}\text { Textile } \\
(3)\end{array}$ \\
\hline Railroad (-1892) & $5.148^{+}$ & $215.9^{*}$ & 17.20 \\
& $(2.822)$ & $(91.59)$ & $(36.84)$ \\
(Normalized coefficient) & $0.771^{+}$ & $1.011^{*}$ & 0.190 \\
County FE and Year FE & Yes & Yes & Yes \\
Sum of Slope * Year FE & Yes & Yes & Yes \\
Log Flat Area * Year FE & Yes & Yes & Yes \\
Log Area * Year FE & Yes & Yes & Yes \\
Distance to Coast * Year FE & Yes & Yes & Yes \\
(Main) Traditional Road * Year FE & Yes & Yes & Yes \\
Initial Population Density * Year FE & Yes & Yes & Yes \\
\hline First_F & 38.15 & 38.15 & 38.15 \\
$\mathrm{~N}$ & 974 & 974 & 974 \\
$\mathrm{~N}$ g & 487 & 487 & 487 \\
\hline \hline
\end{tabular}

$N$ shows the sample size and $N_{-} g$ shows the number of counties. The county-level cluster robust SEs are in parentheses. $+p<0.1,{ }^{*} p<$ $0.05, * * p<0.01$, *** $p<0.001$. First $F$ shows the KleibergenPaap statistics to test for the weak instrument. I use data in 1888 and 1902. 
Table A.18: Robustness Check: Main Result without Telephone-connected Counties

\begin{tabular}{lccccc}
\hline \hline & \multicolumn{4}{c}{ DID-IV } \\
\cline { 2 - 3 } & \multicolumn{2}{c}{ Steam Power [HP] } & & \multicolumn{2}{c}{ Steam Engines } \\
\cline { 2 - 3 } \cline { 6 - 6 } & $(1)$ & $(2)$ & & $(3)$ & $(4)$ \\
\hline Railroad (-1892) & $255.7^{* *}$ & $267.8^{*}$ & & $21.34^{* * *}$ & $20.95^{* *}$ \\
& $(97.01)$ & $(106.8)$ & & $(6.134)$ & $(6.677)$ \\
County FE and Year FE & Yes & Yes & & Yes & Yes \\
Sum of Slope * Year FE & Yes & Yes & & Yes & Yes \\
Log Flat Area * Year FE & Yes & Yes & & Yes & Yes \\
Log Area * Year FE & Yes & Yes & & Yes & Yes \\
Distance to Coast * Year FE & Yes & Yes & & Yes & Yes \\
Initial Population Density * Year FE & No & Yes & & No & Yes \\
(Main) Traditional Road * Year FE & No & Yes & & No & Yes \\
\hline First_F & 41.25 & 36.91 & & 41.25 & 36.91 \\
N & 960 & 960 & & 960 & 960 \\
N_g & 480 & 480 & & 480 & 480 \\
\hline \hline
\end{tabular}

$N$ shows the sample size and $N_{-} g$ shows the number of counties. The countylevel cluster robust SEs are in parentheses. $+p<0.1$, $^{*} p<0.05$, ** $p<0.01$, *** $p<0.001$. First_F shows the Kleibergen-Paap statistics to test for the weak instrument. I use data in 1888 and 1902. I excluded telephone-connected counties as of 1902 from the sample, counties where Nagoya, Fukuoka, Kuwana, Sendai, Kumamoto, Hiroshima, and Kanazawa cities are located. 
Table A.19: Robustness Check: Main Result without Counties where State-owned Factories were Located

\begin{tabular}{|c|c|c|c|c|}
\hline & \multicolumn{4}{|c|}{ DID-IV } \\
\hline & \multicolumn{2}{|c|}{ Steam Power $[\mathrm{HP}]$} & \multicolumn{2}{|c|}{ Steam Engines } \\
\hline & $(1)$ & $(2)$ & (3) & $(4)$ \\
\hline \multirow[t]{2}{*}{ Railroad (-1892) } & $295.0^{* *}$ & $278.6^{* *}$ & $20.53^{* * *}$ & $19.46^{* *}$ \\
\hline & $(102.9)$ & $(106.0)$ & $(6.090)$ & $(6.541)$ \\
\hline County FE and Year FE & Yes & Yes & Yes & Yes \\
\hline Sum of Slope * Year FE & Yes & Yes & Yes & Yes \\
\hline Log Flat Area * Year FE & Yes & Yes & Yes & Yes \\
\hline Log Area $*$ Year FE & Yes & Yes & Yes & Yes \\
\hline Distance to Coast $*$ Year FE & Yes & Yes & Yes & Yes \\
\hline Initial Population Density $*$ Year FE & No & Yes & No & Yes \\
\hline (Main) Traditional Road * Year FE & No & Yes & No & Yes \\
\hline First_F & 39.36 & 35.37 & 39.36 & 35.37 \\
\hline $\mathrm{N}$ & 956 & 956 & 956 & 956 \\
\hline$N_{-} g$ & 478 & 478 & 478 & 478 \\
\hline
\end{tabular}

$N$ shows the sample size and $N_{-} g$ shows the number of counties. The countylevel cluster robust SEs are in parentheses. $+p<0.1, * p<0.05,{ }^{* *} p<0.01$, *** $p<0.001$. First_F shows the Kleibergen-Paap statistics to test for the weak instrument. I use data in 1888 and 1902. I excluded counties with stateowned factories. 
Table A.20: Robustness Check: Interest Rate and Instrument

\begin{tabular}{lccccc}
\hline \hline & \multicolumn{2}{c}{1888} & & \multicolumn{2}{c}{$1888-1902$} \\
\cline { 2 - 3 } \cline { 6 - 7 } & Low & High & & Low & High \\
& $(1)$ & $(2)$ & & $(3)$ & $(4)$ \\
\hline Distance to the Path & -0.0720 & -0.249 & & \\
& $(0.472)$ & $(0.947)$ & & \\
Railroad County Prop (-1892) & & & & -1.699 & -2.113 \\
& & & & $(1.212)$ & $(2.680)$ \\
County FE and Year FE & No & No & & Yes & Yes \\
Sum of Slope (* Year FE) & Yes & Yes & & Yes & Yes \\
Log Flat Area (* Year FE) & Yes & Yes & & Yes & Yes \\
Log Area (* Year FE) & Yes & Yes & & Yes & Yes \\
Initial Population Density $(*$ Year FE) & Yes & Yes & & Yes & Yes \\
Coastal (* Year FE) & Yes & Yes & & Yes & Yes \\
(Main) Old Road $(*$ Year FE) & Yes & Yes & & Yes & Yes \\
\hline First_F & & & & 13.52 & 13.52 \\
$\mathrm{~N}$ & 36 & 36 & & 539 & 539 \\
$\mathrm{~N}$ _g & & & & 36 & 36 \\
\hline \hline
\end{tabular}

Source: Institute for Monetary and Economics Studies, Bank of Japan. Low and High will mean the lowest and highest. The original data is monthly, so I take average for each year. $N$ shows the sample size and $N_{-} g$ shows the number of counties. The robust SEs are in parentheses in column (1) and (2) and county-level cluster robust SEs are in parentheses in column (3) and (4). $+p<0.1, * p<0.05, * * p<0.01$, *** $p<0.001$. First_F shows the Kleibergen-Paap statistics to test for the weak instrument. I use data in 1888 in column (1) and (2) and 1888 - 1902 in column (3) and (4). I excluded counties with state-owned factories. 
Table A.21: Long-Term Effect of Railroads during 1888-1919 or 1888-1920

\begin{tabular}{lccccc}
\hline \hline & DID & \multicolumn{4}{c}{ DID-IV } \\
\cline { 4 - 6 } & $(1)$ & $(2)$ & $(3)$ & $(4)$ & $(5)$ \\
Panel A: Steam Power [HP] & & & & & \\
\hline Railroad (-1892) & -56.54 & $6329.9 *$ & $5252.1 * *$ & $5417.6 * *$ & $4305.2 *$ \\
& $(1100.3)$ & $(2582.7)$ & $(1881.5)$ & $(2077.3)$ & $(2016.3)$ \\
Panel B: Log Population & & & & & \\
\hline Railroad (-1892) & $0.0689 *$ & 0.141 & 0.102 & 0.0621 & 0.0138 \\
& $(0.0333)$ & $(0.114)$ & $(0.122)$ & $(0.113)$ & $(0.120)$ \\
County FE and Year FE & Yes & Yes & Yes & Yes & Yes \\
Sum of Slope * Year FE & Yes & Yes & Yes & Yes & Yes \\
Log Flat Area * Year FE & Yes & Yes & Yes & Yes & Yes \\
Log Area * Year FE & Yes & Yes & Yes & Yes & Yes \\
Distance to Coast * Year FE & Yes & Yes & Yes & Yes & Yes \\
Initial Population Density * Year FE & No & No & Yes & No & Yes \\
(Main) Traditional Road * Year FE & No & No & Yes & No & Yes \\
Dist. to Destinations * Year FE & No & No & No & Yes & Yes \\
\hline First_F & & 41.52 & 38.15 & 40.91 & 36.48 \\
N & 974 & 974 & 974 & 974 & 974 \\
N_g & 487 & 487 & 487 & 487 & 487 \\
\hline \hline
\end{tabular}

$N$ shows the sample size and $N_{-} g$ shows the number of counties. The county-level cluster robust SEs are in parentheses. $+p<0.1, * p<0.05,{ }^{* *} p<0.01,{ }^{* * *} p<0.001$. First_F shows the Kleibergen-Paap statistics to test for the weak instrument. I use data in 1888 and 1920 for steam power, and 1888 and 1919 for population. 